\title{
Concise Synthesis of 1-Thioalkyl Glycoside Donors by Reaction of Per- $O$-acetylated Sugars with Sodium alkanethiolates under Solvent-free Conditions
}

\author{
Guang-Jing Feng, ${ }^{\dagger}$ Tao Luo, ${ }^{\dagger}$ Yang-Fan Guo, ${ }^{\dagger}$ Chun-Yang Liu ${ }^{\dagger}$ and Hai Dong $*,+$,
}

$\dagger$ Key laboratory of Material Chemistry for Energy Conversion and Storage, Ministry of Education, School of Chemistry and Chemical Engineering, Huazhong University of Science and Technology, Luoyu Road 1037, 430074, Wuhan, P. R. China. E-mail: hdong@mail.hust.edu.cn

¥ Hubei Key Laboratory of Bioinorganic Chemistry \& Materia Medica, Huazhong University of Science and Technology, Wuhan, P. R. China

\section{Table of Contents}

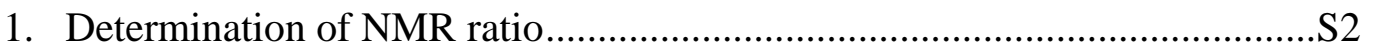

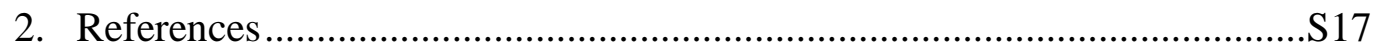

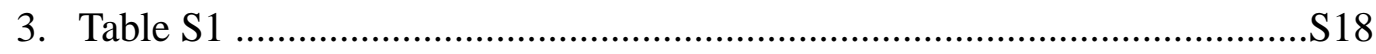

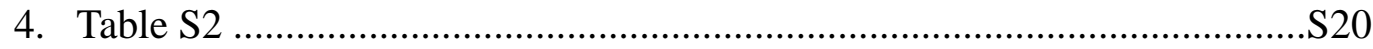

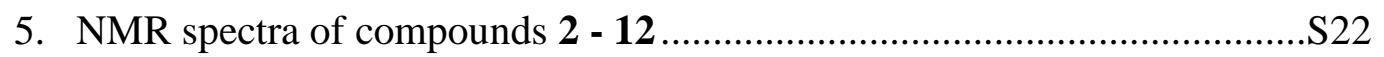




\section{Determination of NMR ratio}

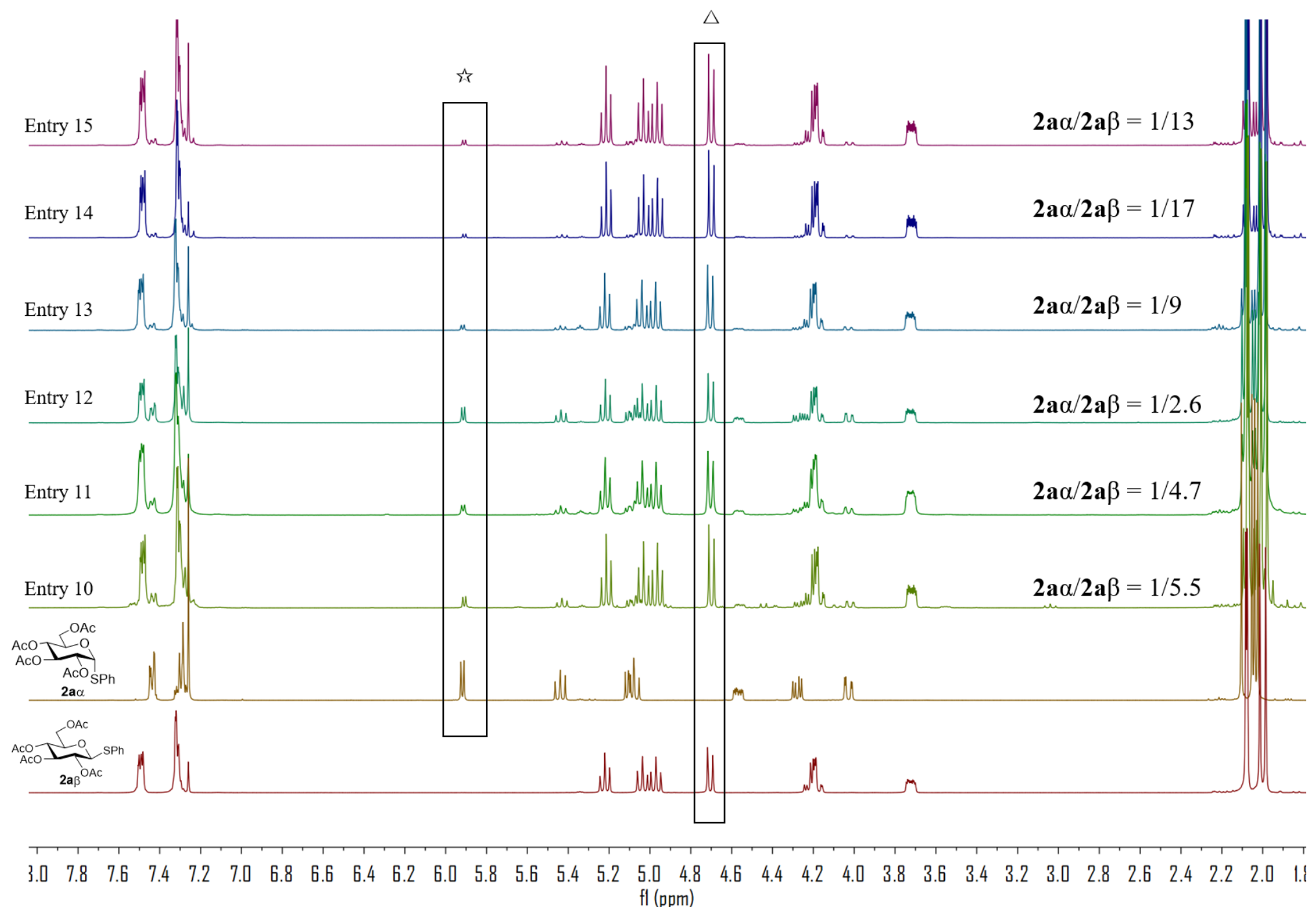

Figure S1a. Determination of the $\alpha / \beta$ ratios by ${ }^{1} \mathrm{H}-\mathrm{NMR}$ spectra of $2 \mathrm{a}$ for Table 1. 


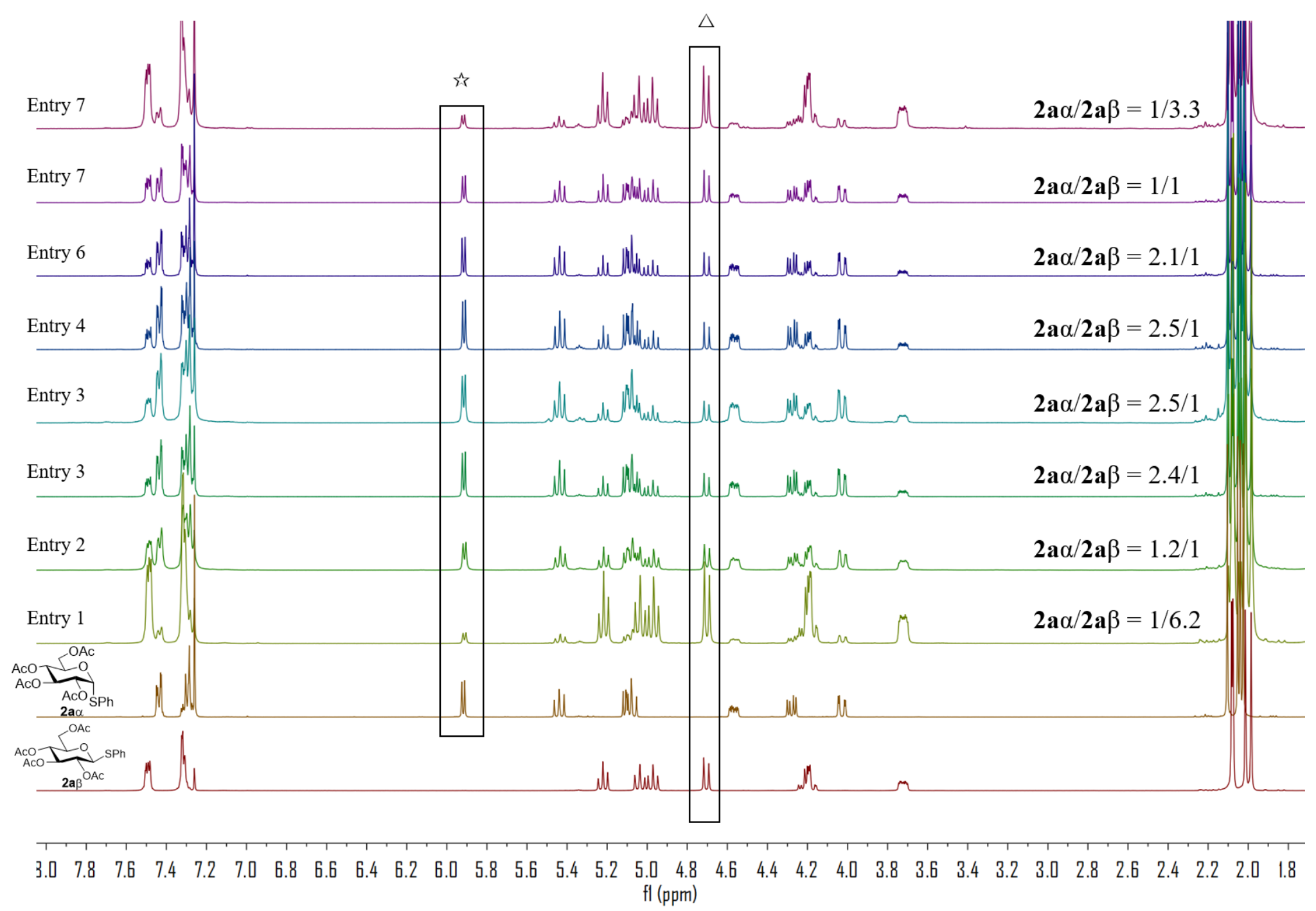

Figure S1b. Determination of the $\alpha / \beta$ ratios by ${ }^{1} \mathrm{H}-\mathrm{NMR}$ spectra of $\mathbf{2 a}$ for Table $\mathbf{S 2}$. 


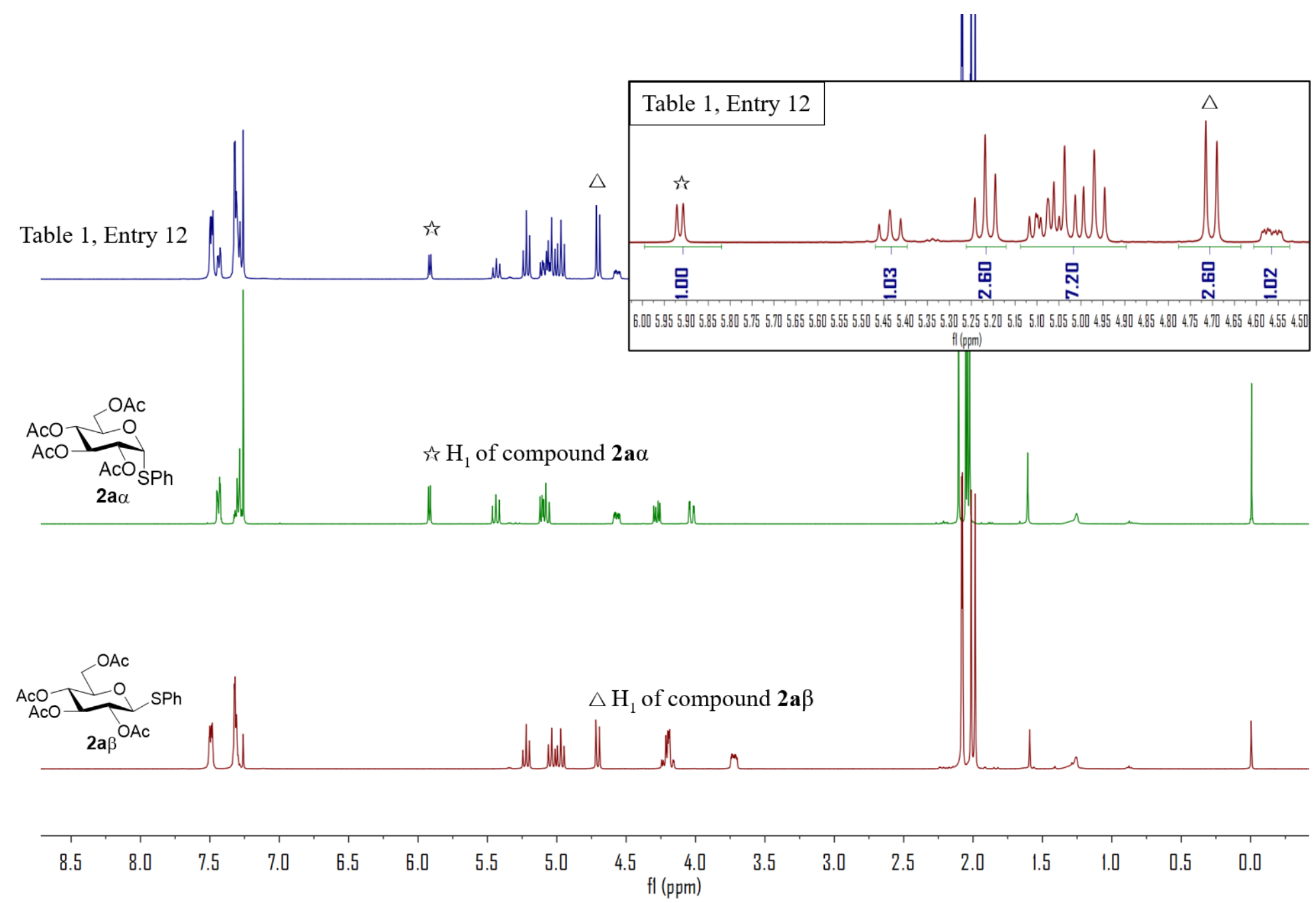

Figure S1c. Example of calculation the NMR ratio for Table 1 and Table S2. NMR ratio was calculated in light of the ratio of the integral peak area: for example for entry 12 of table $1, \mathrm{H}_{1}$ of compound $\mathbf{2} \mathbf{a} \alpha / \mathrm{H}_{1}$ of compound $\mathbf{2 a} \beta=1 / 2.6$, indicating that the NMR ratio: $\mathbf{2 a} \alpha / 2 \mathbf{a} \beta=1 / 2.6$. 


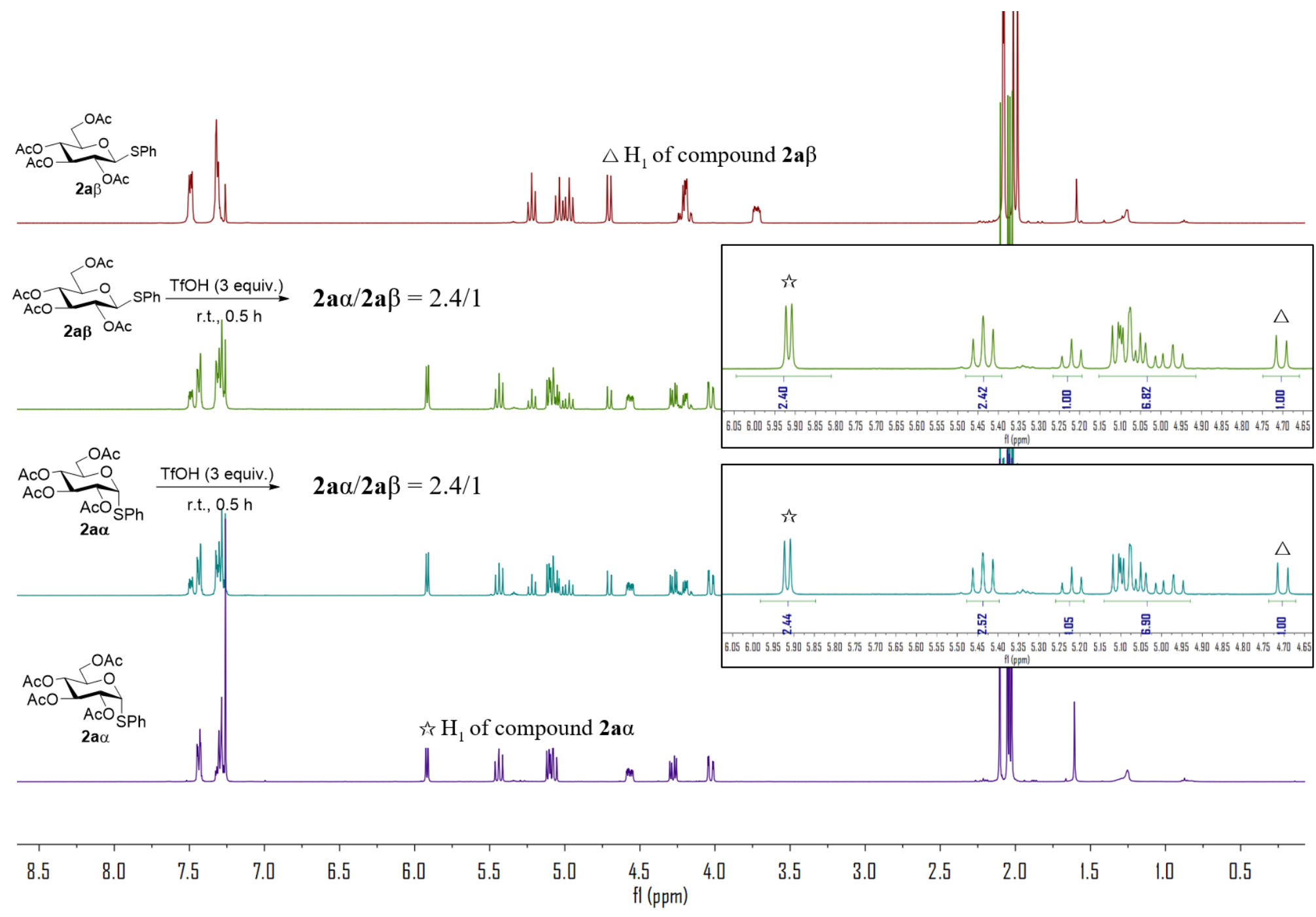

Figure S1d. Comparison of epimerization products when subjecting pure $\mathbf{2 a} \alpha$ or $\mathbf{2 a} \beta$ to the same isomerization conditions. NMR ratio was calculated in light of the ratio of the integral peak area: $\mathrm{H}_{1}$ of compound $\mathbf{2} \mathbf{a} \alpha / \mathrm{H}_{1}$ of compound $\mathbf{2 a} \beta=2.4 / 1$, indicating that the NMR ratio: $\mathbf{2 a} \alpha / \mathbf{2 a} \beta=2.4 / 1$. 


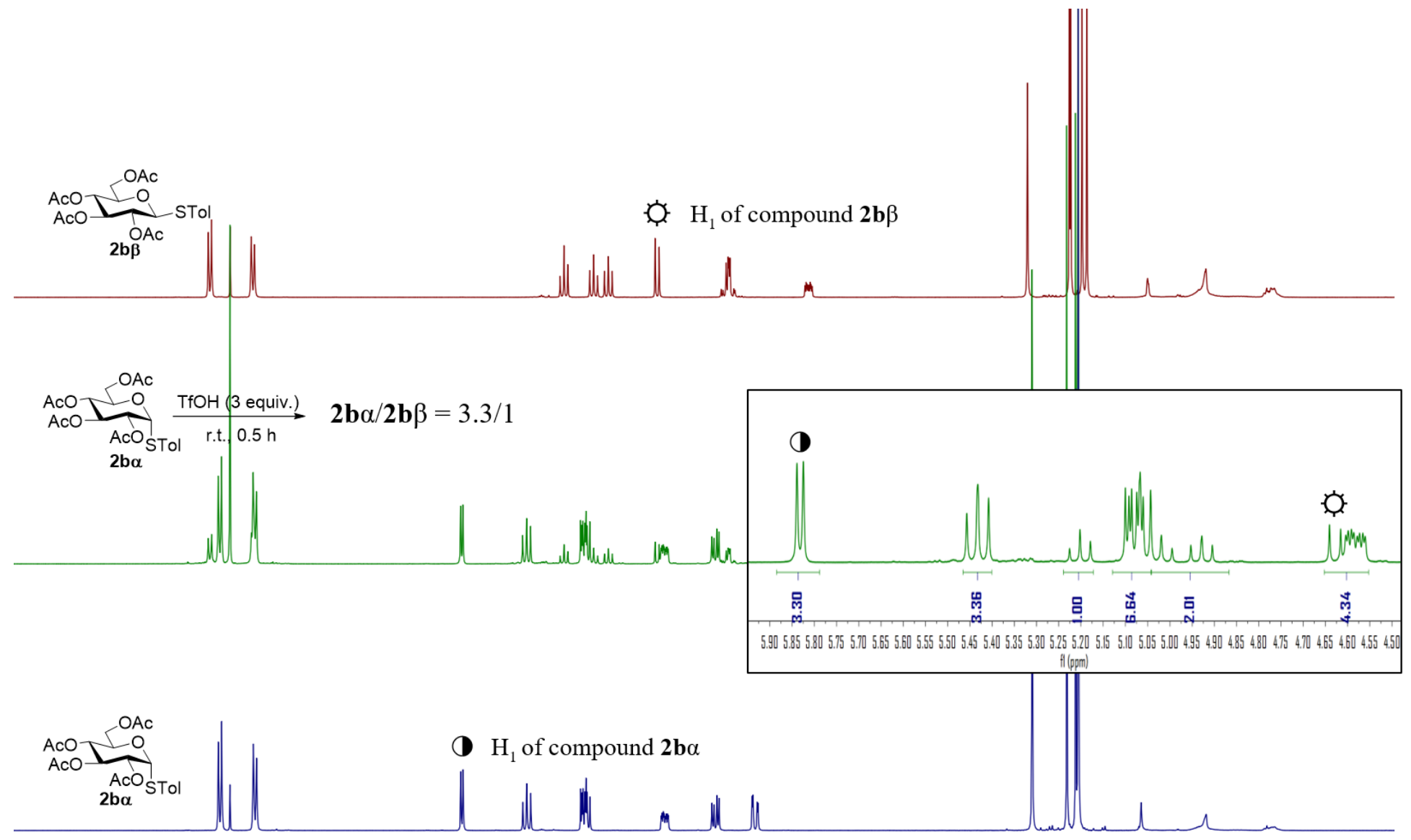

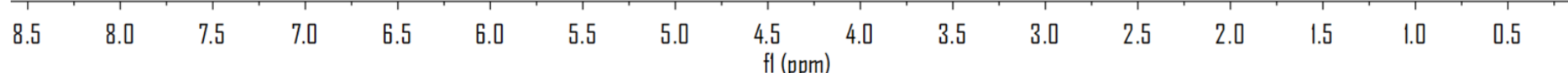

Figure S1e. Subjecting pure $\mathbf{2} \mathbf{b} \alpha$ to the isomerization conditions. NMR ratio was calculated in light of the ratio of the integral peak area: $\mathrm{H}_{1}$ of compound $\mathbf{2} \mathbf{b} \alpha / \mathrm{H}_{1}$ of compound $\mathbf{2} \mathbf{b} \beta=3.3 / 1$, indicating that the NMR ratio: $\mathbf{2} \mathbf{b} \alpha / \mathbf{2} \mathbf{b} \beta=3.3 / 1$. 


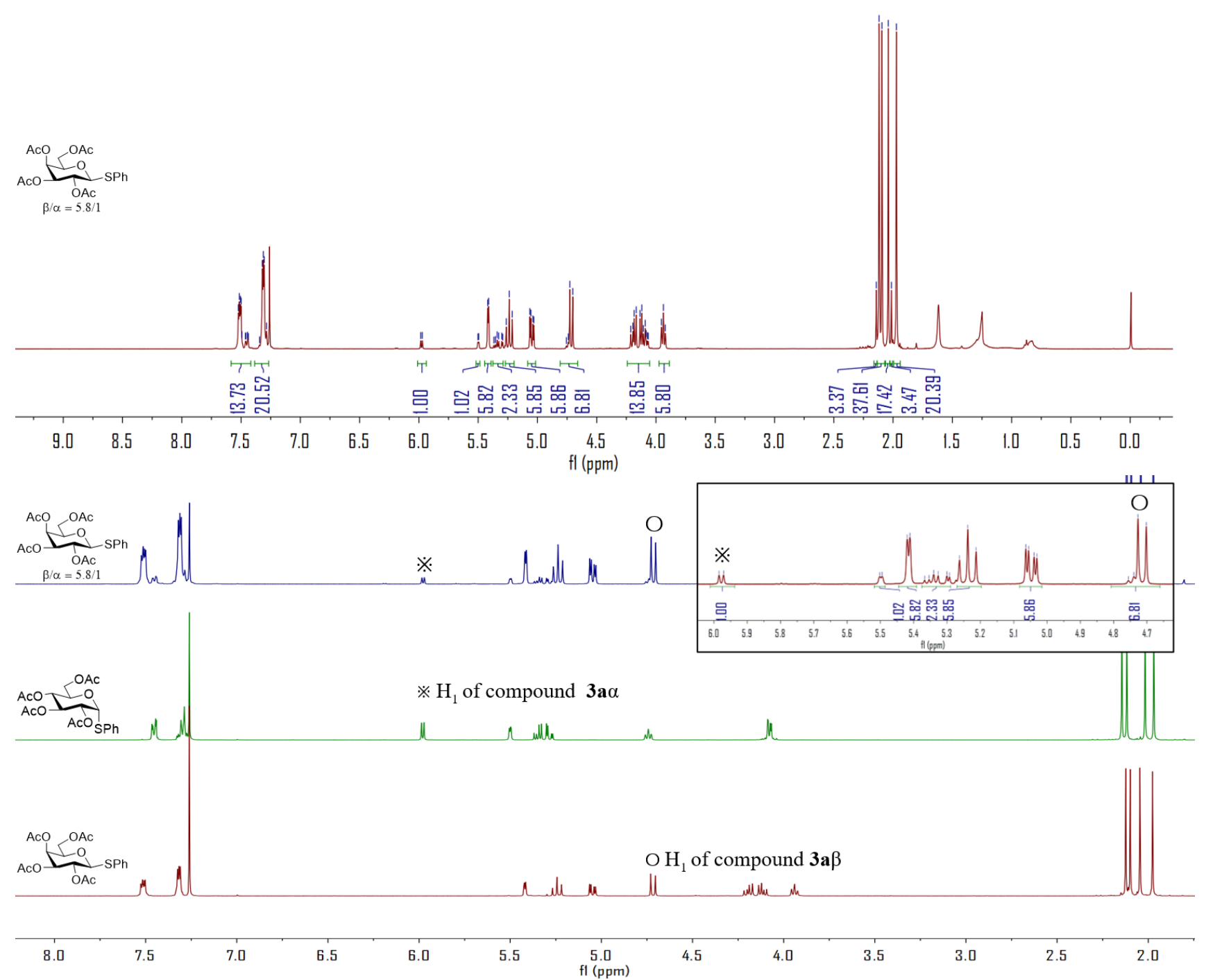

Figure S2. ${ }^{1} \mathrm{H}$ NMR spectrum (400 MHz) of 3a in $\mathrm{CDCl}_{3}$, NMR ratio was calculated in light of the ratio of the integral peak area: $\mathrm{H}_{1}$ of compound 3a $\alpha / \mathrm{H}_{1}$ of compound $\mathbf{3 a} \beta=1 /(6.8-1)=1 / 5.8$, indicating that the NMR ratio: $\mathbf{3 a} \alpha / \mathbf{3 a} \beta=1 / 5.8$. 


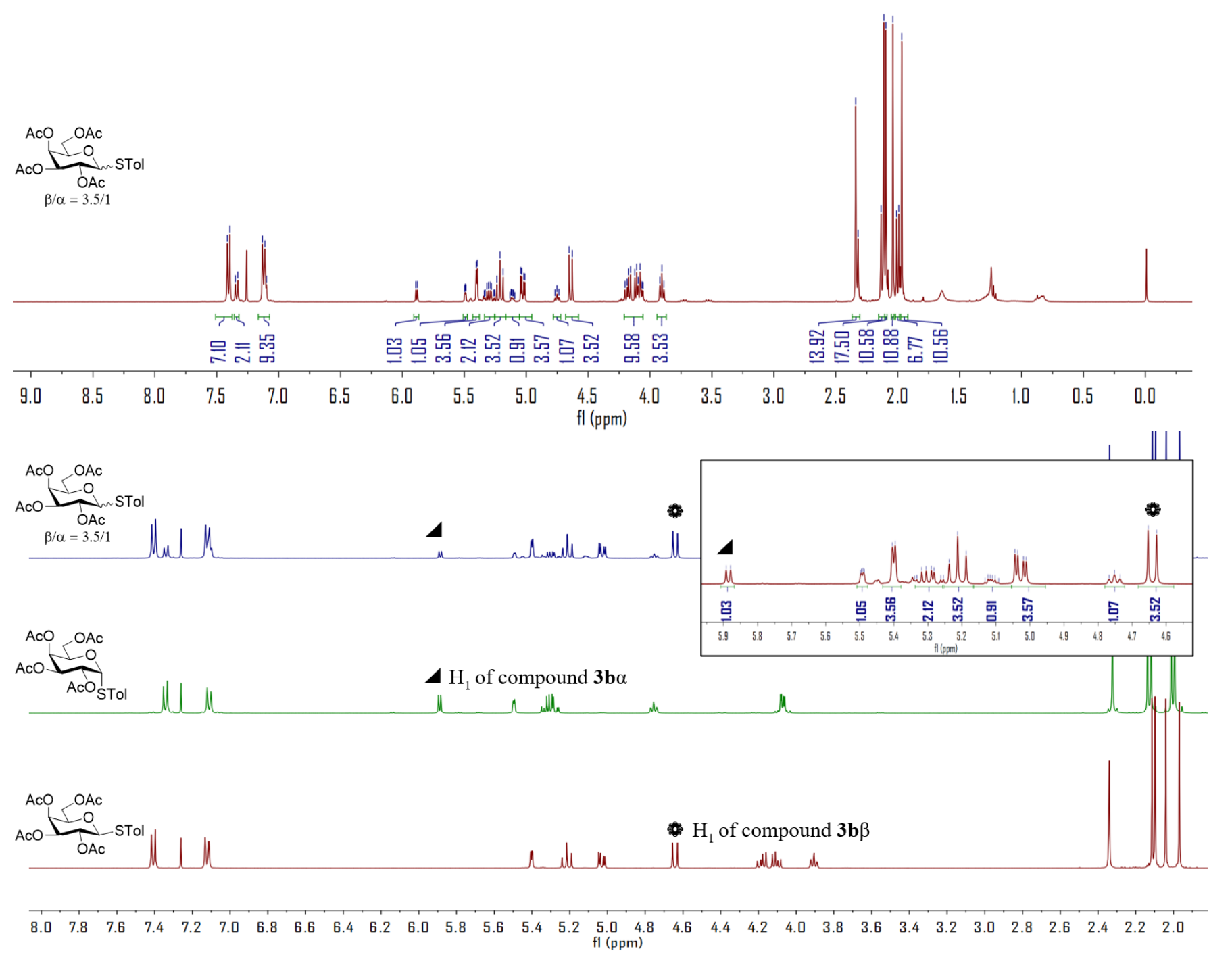

Figure S3. ${ }^{1} \mathrm{H}$ NMR spectrum (400 MHz) of $\mathbf{3 b}$ in $\mathrm{CDCl}_{3}$, NMR ratio was calculated in light of the ratio of the integral peak area: $\mathrm{H}_{1}$ of compound $\mathbf{3 b} \mathbf{b} / \mathrm{H}_{1}$ of compound $3 \mathbf{b} \beta=1 / 3.5$, indicating that the NMR ratio: $3 \mathbf{b} \alpha / 3 \mathbf{b} \beta=1 / 3.5$. 


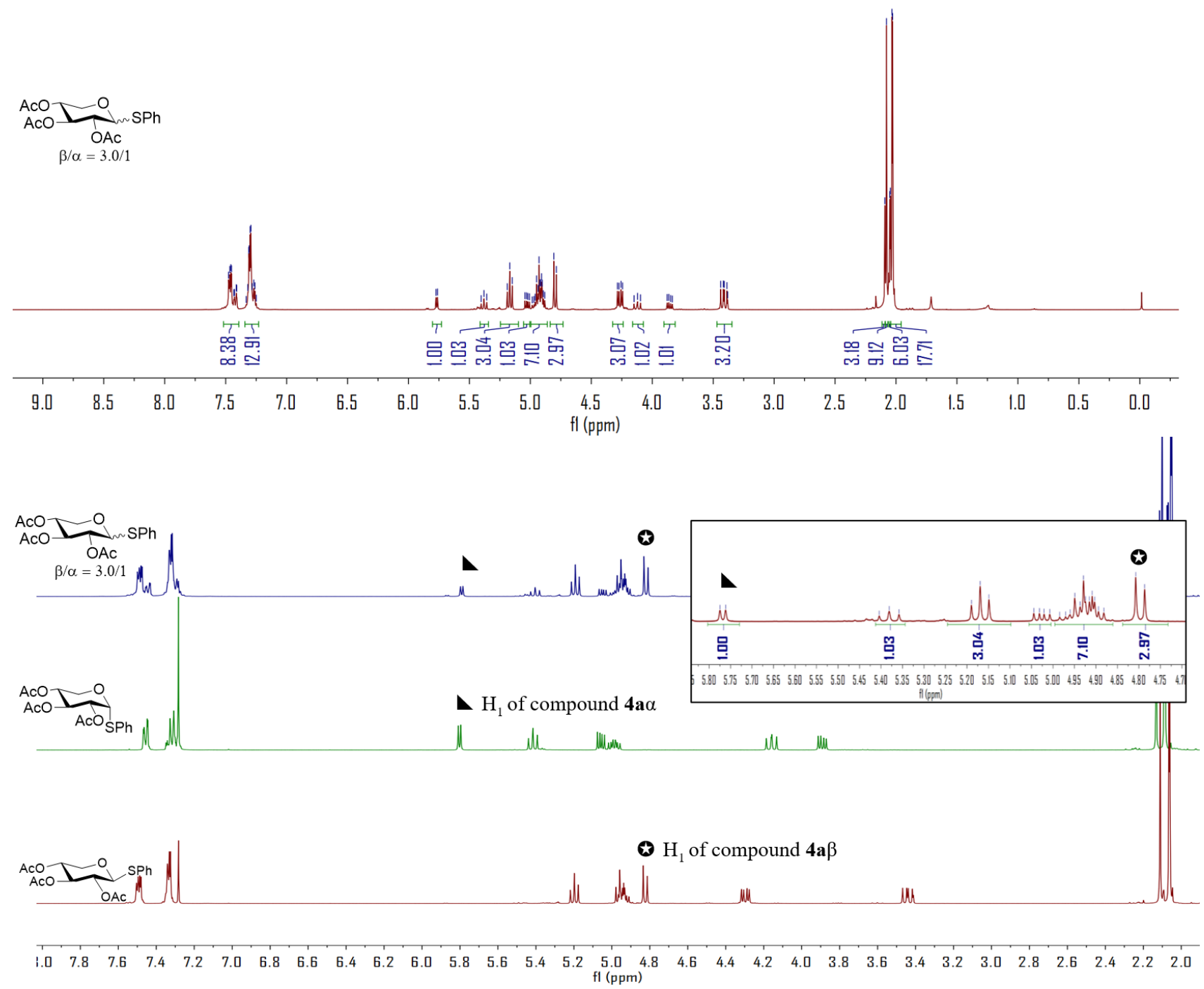

Figure S4. ${ }^{1} \mathrm{H}$ NMR spectrum (400 MHz) of $\mathbf{4 a}$ in $\mathrm{CDCl}_{3}$, NMR ratio was calculated in light of the ratio of the integral peak area: $\mathrm{H}_{1}$ of compound $4 \mathbf{a} \alpha / \mathrm{H}_{1}$ of compound $\mathbf{4 a} \beta=1 / 3.0$, indicating that the NMR ratio: $\mathbf{4 a} \alpha / \mathbf{4 a} \beta=1 / 3.0$. 


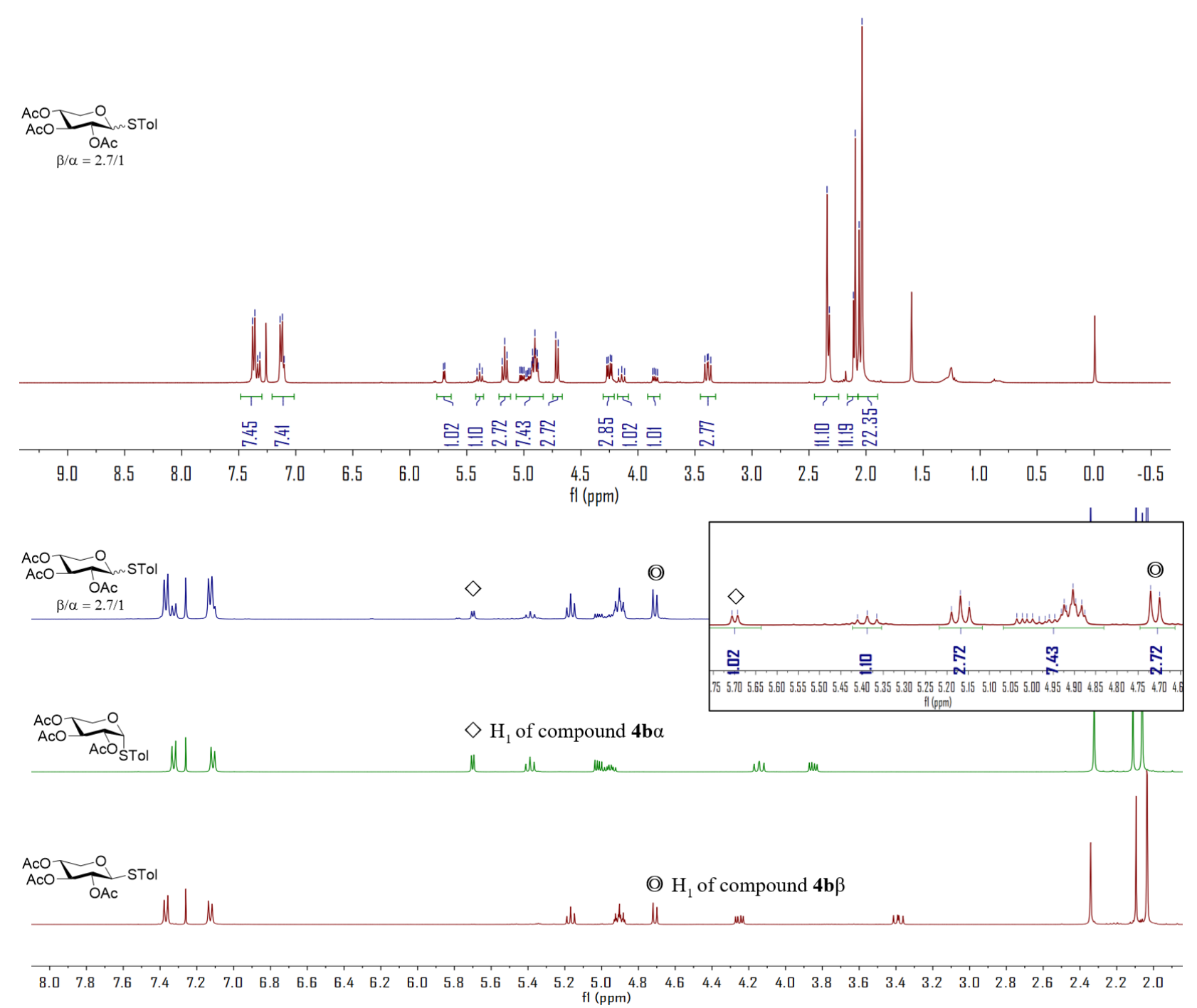

Figure S5. ${ }^{1} \mathrm{H}$ NMR spectrum (400 MHz) of $\mathbf{4 b}$ in $\mathrm{CDCl}_{3}$, NMR ratio was calculated in light of the ratio of the integral peak area: $\mathrm{H}_{1}$ of compound $\mathbf{4 b} \mathbf{b} / \mathrm{H}_{1}$ of compound $4 b \beta=1 / 2.7$, indicating that the NMR ratio: $4 b \alpha / 4 b \beta=1 / 2.7$. 


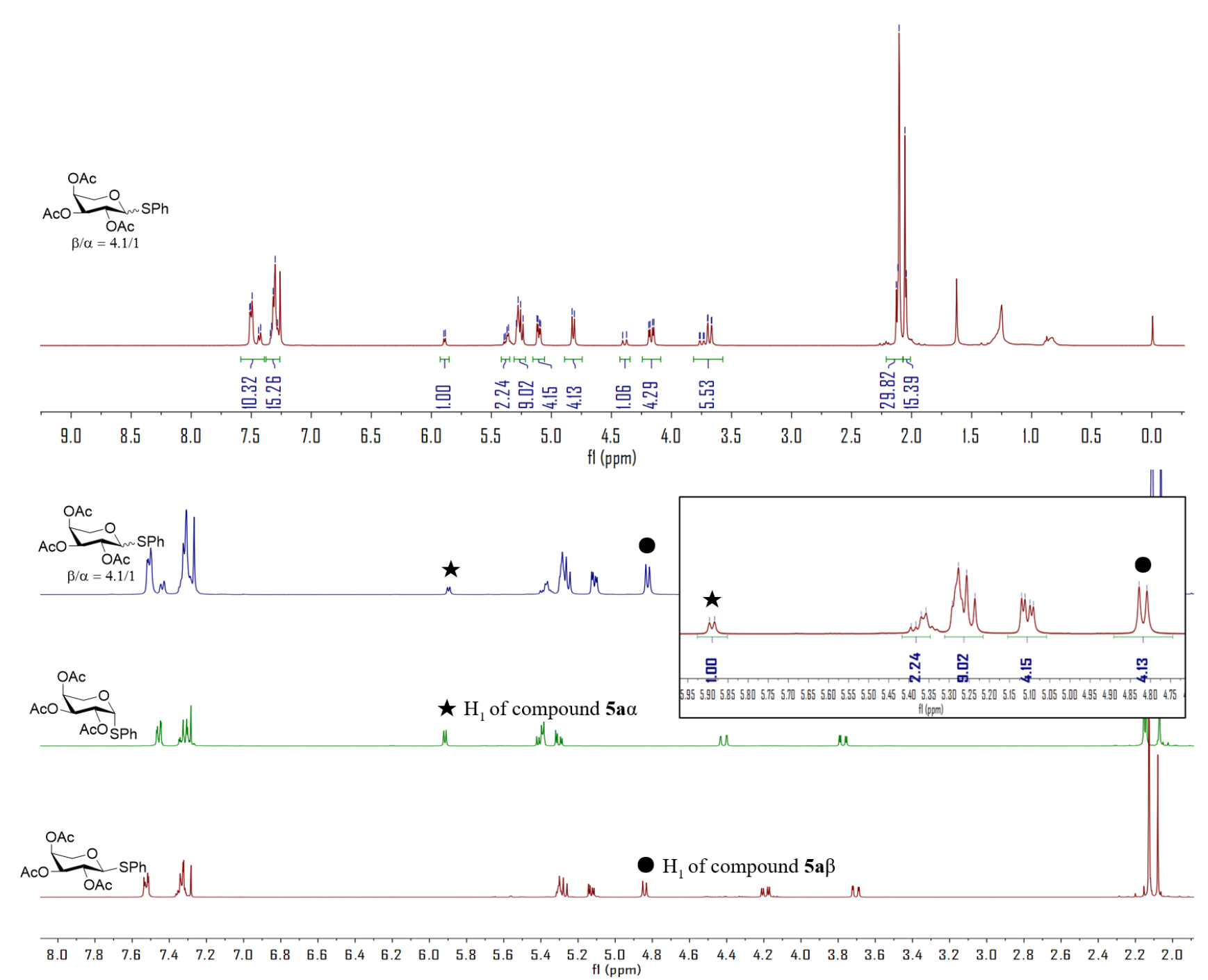

Figure S6. ${ }^{1} \mathrm{H}$ NMR spectrum (400 MHz) of $\mathbf{5 a}$ in $\mathrm{CDCl}_{3}$, $\mathrm{NMR}$ ratio was calculated in light of the ratio of the integral peak area: $\mathrm{H}_{1}$ of compound $\mathbf{5 a} \alpha / \mathrm{H}_{1}$ of compound $\mathbf{5 a} \beta=1 / 4.1$, indicating that the NMR ratio: $\mathbf{5 a} \alpha / \mathbf{5 a} \beta=1 / 4.1$. 


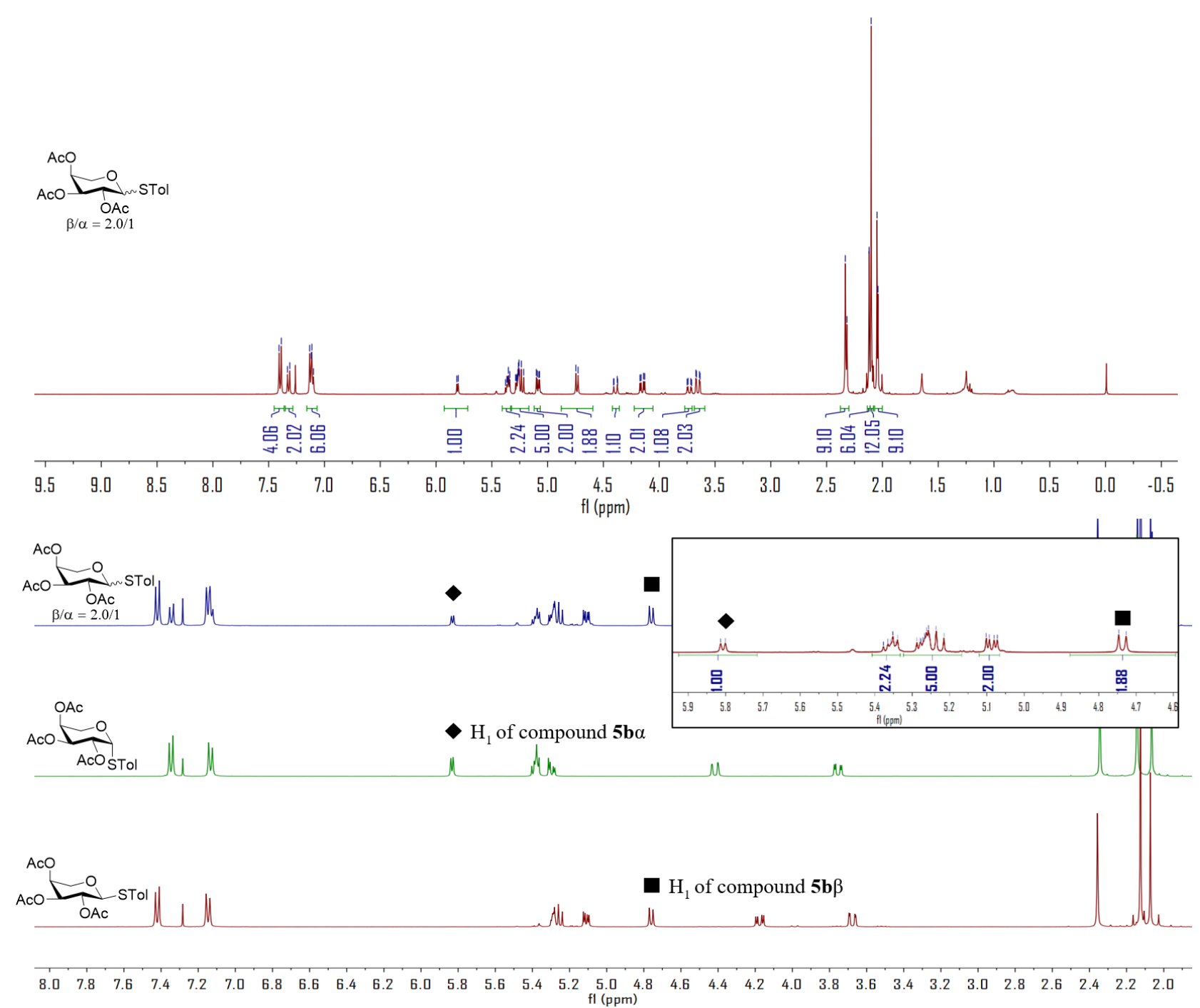

Figure S7. ${ }^{1} \mathrm{H}$ NMR spectrum $\left(400 \mathrm{MHz}\right.$ ) of $\mathbf{5 b}$ in $\mathrm{CDCl}_{3}$, $\mathrm{NMR}$ ratio was calculated in light of the ratio of the integral peak area: $\mathrm{H}_{1}$ of compound $\mathbf{5 b} \alpha / \mathrm{H}_{1}$ of compound $\mathbf{5 b} \beta=1 / 2.0$, indicating that the NMR ratio: $\mathbf{5 b} \alpha / \mathbf{5 b} \beta=1 / 2.0$. 

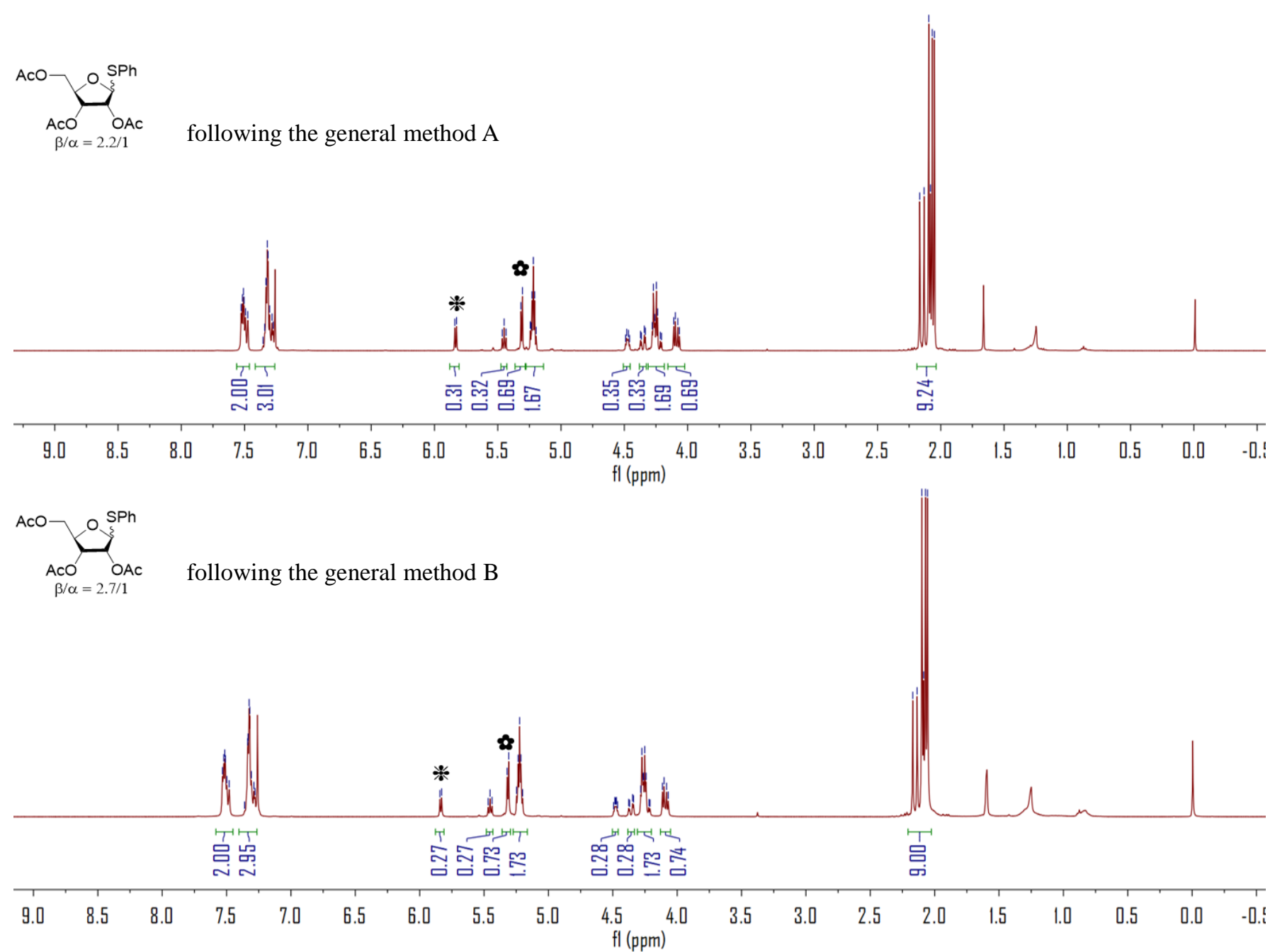

Figure S8. ${ }^{1} \mathrm{H}$ NMR spectrum (400 MHz) of $8 \mathbf{a}$ in $\mathrm{CDCl}_{3}$, NMR ratio was calculated in light of the ratio of the integral peak area: $\mathrm{H}_{1}$ of compound 8a $\alpha / \mathrm{H}_{1}$ of compound $\mathbf{8 a} \beta=0.31 / 0.69$ or $0.27 / 0.73$, indicating that the NMR ratio: $\mathbf{8 a} \alpha / \mathbf{8} \mathbf{a} \beta=1 / 2.2$ or $1 / 2.7$. 


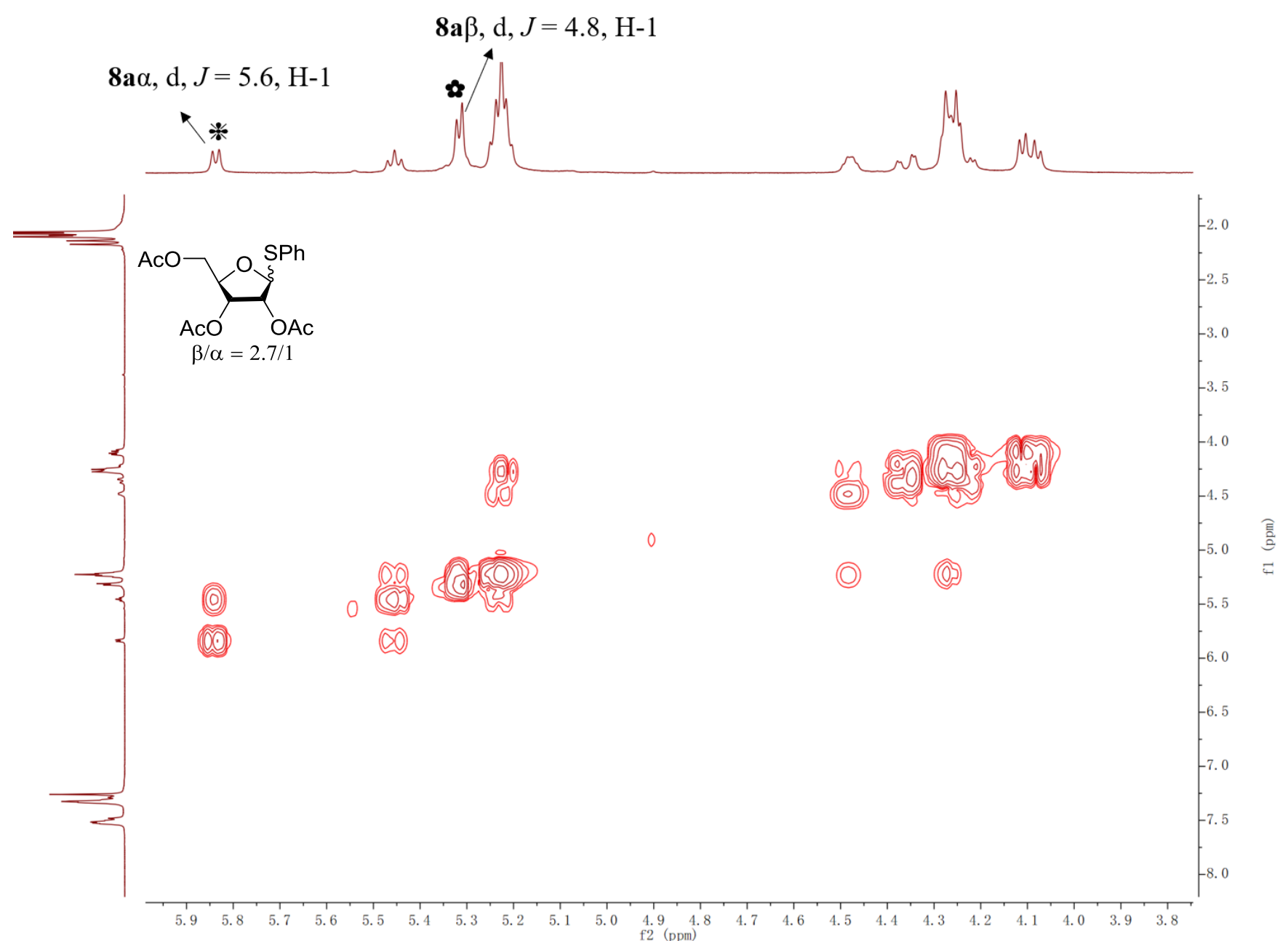

Figure S9. COSY spectrum (400 MHz) of $\mathbf{8 a}$ in $\mathrm{CDCl}_{3}$. The $\mathrm{H}_{1}$ of $\mathbf{8 a} \beta$ was determined in light of a reference. ${ }^{1}$ The $\mathrm{H}_{1}$ of $\mathbf{8 a} \alpha$ was determined in light of this cosy spectrum. 


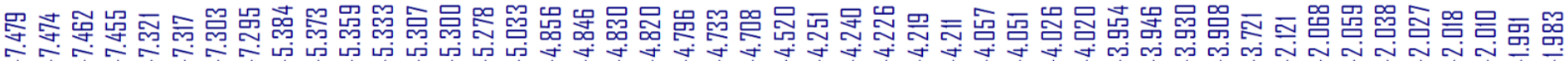
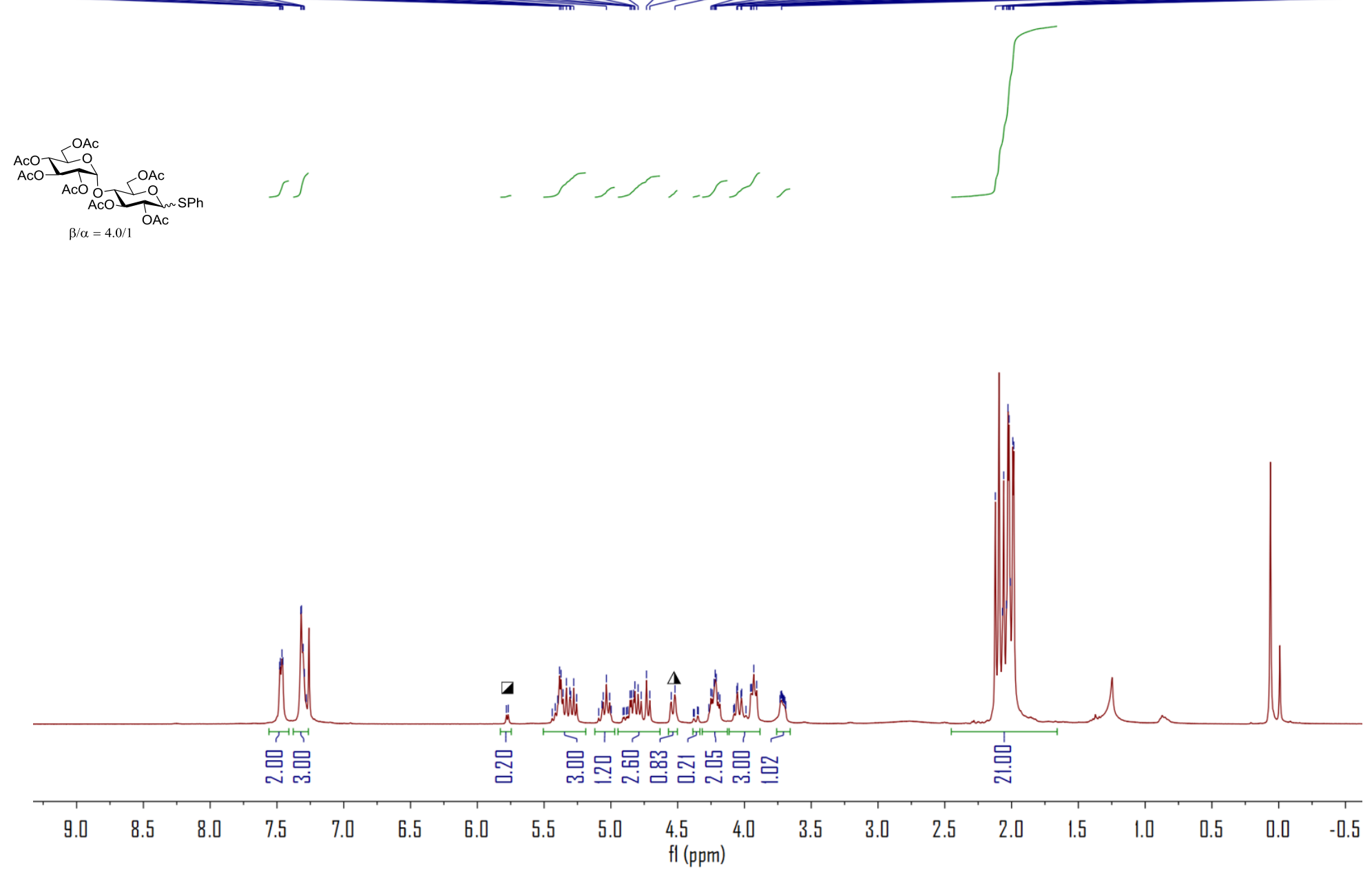

Figure S10. ${ }^{1} \mathrm{H}$ NMR spectrum $(400 \mathrm{MHz})$ of $\mathbf{1 3 a}$ in $\mathrm{CDCl}_{3}, \mathrm{NMR}$ ratio was calculated in light of the ratio of the integral peak area: $\mathrm{H}_{1}$ of compound

13a $\alpha / \mathrm{H}_{1}$ of compound $\mathbf{1 3 a} \beta=0.2 / 0.8$, indicating that the NMR ratio: $13 \mathbf{a} \alpha / \mathbf{1 3 a} \beta=1 / 4.0$. 


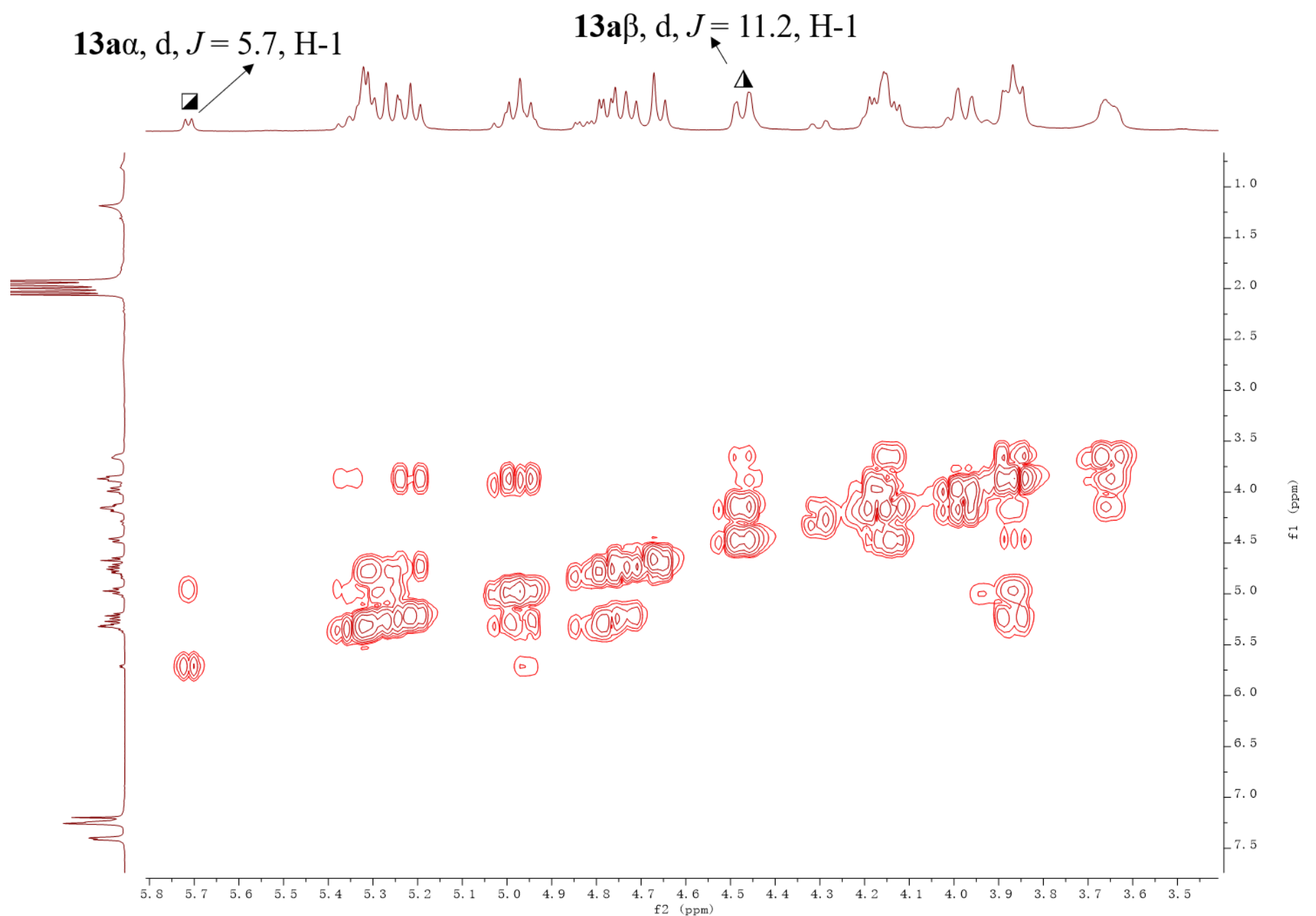

Figure S11. COSY spectrum (400 MHz) of $\mathbf{1 3 a}$ in $\mathrm{CDCl}_{3}$. The $\mathrm{H}_{1}$ of $\mathbf{1 3 a} \beta$ was determined in light of a reference. ${ }^{2}$ The $\mathrm{H}_{1}$ of $\mathbf{1 3 a} \alpha$ was determined in light of this cosy spectrum. 
The dermination of $\mathbf{6 a} \alpha / \mathbf{6 a} \beta$ (Figure S35), ${ }^{2,3} \mathbf{7} \mathbf{a} \alpha / \mathbf{7 a} \beta$ (Figure S36), ${ }^{4} \mathbf{1 0 a} \alpha / \mathbf{1 0 a} \beta$ (Figure S40), ${ }^{5} \mathbf{1 0 b} \alpha / \mathbf{1 0 b} \beta$ (Figure S41), ${ }^{5}$ and 10c $\alpha / \mathbf{1 0 c} \beta$ (Figure $\mathrm{S} 42)^{5}$ in light of references.

\section{References}

(1) Weng, S.-S.; Lin, Y.-D.; Chen, C.-T. Highly Diastereoselective Thioglycosylation of Functionalized Peracetylated Glycosides Catalyzed by $\mathrm{MoO}_{2} \mathrm{Cl}_{2}$. Org. Lett. 2006, 8, 5633-5636.

(2) Kumar, V.; Taxak, N.; Jangir, R.; Bharatam, P. V.; Kartha, K. P. R. In(III) Triflate-Mediated Solvent-Free Synthesis and Activation of Thioglycosides by Ball Milling and Structural Analysis of Long Chain Alkyl Thioglycosides by TEM and Quantum Chemical Methods. J. Org. Chem. 2014, 79, 3427-3439.

(3) Crich, D.; Picione, J. Direct Synthesis of the $\beta$-1-Rhamnopyranosides. Org. Lett. 2003, 5, 781-784.

(4) Paquette, L. A.; Barriault, L.; Pissarnitski, D.; Johnston, J. N. Stereocontrolled Elaboration of Natural (-)-Polycavernoside A, a Powerfully Toxic Metabolite of the Red Alga Polycavernosa tsudai. J. Am. Chem. Soc. 2000, 122, 619-631.

(5) Escopy, S.; Singh, Y.; Demchenko, A. V. Triflic acid-mediated synthesis of thioglycosides. Org. Biomol. Chem. 2019, 17, 8379-8383. 


\section{Table S1. Synthesis of per-O-acetylated 1-thioglycosides by using $\mathrm{RSNa}^{\mathrm{a}}$}

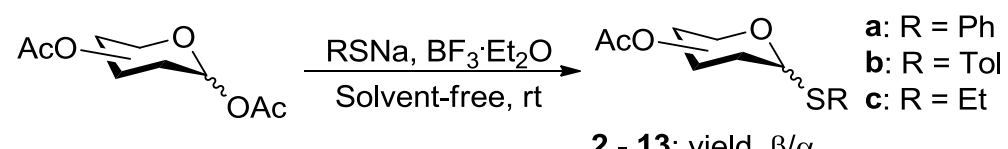

2 - 13: yield, $\beta / \alpha$

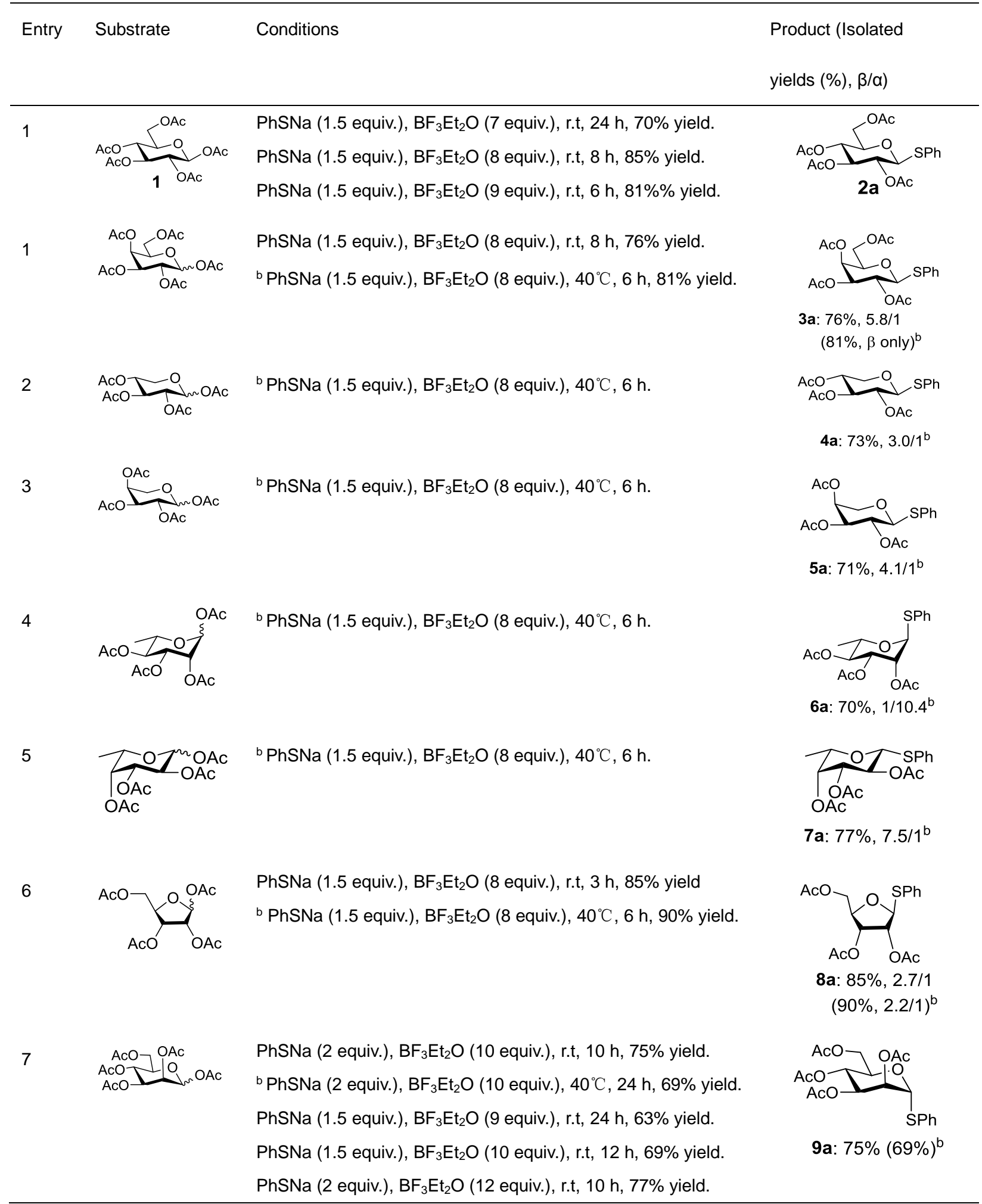


8

$$
\text { OAc }
$$

PhSNa (2 equiv.), $\mathrm{BF}_{3} \mathrm{Et}_{2} \mathrm{O}$ (10 equiv.), r.t, 12 h, $69 \%$

$\mathrm{PhSNa}$ (1.5 equiv.), $\mathrm{BF}_{3} \mathrm{Et}_{2} \mathrm{O}$ (8 equiv.), r.t, 24 h, $50 \%$

PhSNa (2 equiv.), $\mathrm{BF}_{3} \mathrm{Et}_{2} \mathrm{O}$ (12 equiv.), r.t, 12 h, $70 \%$

9

$\underbrace{O A C O}_{O A C} \underbrace{O A C}_{O A C}$

${ }^{b} \mathrm{PhSNa}$ (2 equiv.), $\mathrm{BF}_{3} \mathrm{Et}_{2} \mathrm{O}$ (10 equiv.), $40^{\circ} \mathrm{C}, 24 \mathrm{~h}$

10

${ }_{A C O}^{A C O} \underbrace{S_{O A C O}^{O A C}}_{O A C} \underbrace{O A C}_{O A C}$

${ }^{\text {b }}$ PhSNa (2 equiv.), $\mathrm{BF}_{3} \mathrm{Et}_{2} \mathrm{O}(10$ equiv. $), 40^{\circ} \mathrm{C}, 24 \mathrm{~h}$

10

11

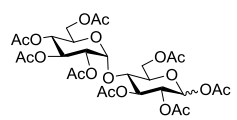

12

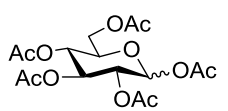

13

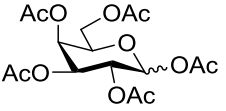

14

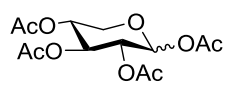

b TolSNa ( 1.5 equiv.), $\mathrm{BF}_{3} \mathrm{Et}_{2} \mathrm{O}$ (8 equiv.), $40^{\circ} \mathrm{C}, 6 \mathrm{~h}$

15

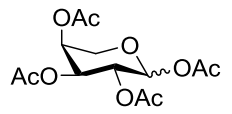

16

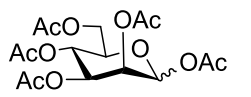

TolSNa (2 equiv.), $\mathrm{BF}_{3} \mathrm{Et}_{2} \mathrm{O}$ (10 equiv.), r.t, $10 \mathrm{~h}$

17

$$
\text { OAc }
$$

TolSNa (2 equiv.), $\mathrm{BF}_{3} \mathrm{Et}_{2} \mathrm{O}$ (10 equiv.), r.t, $12 \mathrm{~h}$

${ }^{b}$ TolSNa (1.5 equiv.), $\mathrm{BF}_{3} \mathrm{Et}_{2} \mathrm{O}$ (8 equiv.), $40^{\circ} \mathrm{C}, 6 \mathrm{~h}$

TolSNa (1.5 equiv.), $\mathrm{BF}_{3} \mathrm{Et}_{2} \mathrm{O}$ (8 equiv.), r.t, $8 \mathrm{~h}$

TolSNa (1.5 equiv.), $\mathrm{BF}_{3} \mathrm{Et}_{2} \mathrm{O}$ (8 equiv.), r.t, $8 \mathrm{~h}$

$\underbrace{A C O}_{O A C} \underbrace{O A C}_{O A C}$

TolSNa (2 equiv.), $\mathrm{BF}_{3} \mathrm{Et}_{2} \mathrm{O}$ (10 equiv.), r.t, $24 \mathrm{~h}, 70 \%$ yield

TolSNa (1.5 equiv.), $\mathrm{BF}_{3} \mathrm{Et}_{2} \mathrm{O}$ ( 8 equiv.), r.t, 24 h, $43 \%$ yield

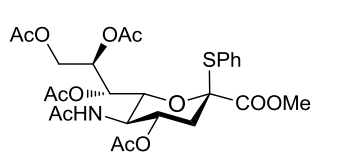

10a: $69 \%, 4.0 / 1$

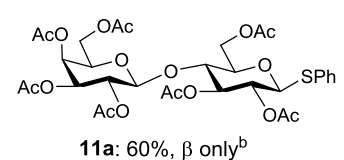

11a: $60 \%, \beta$ only $^{\mathrm{b}}$

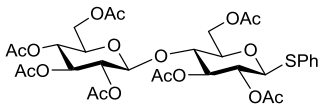

12a: $62 \%, \beta$ only $^{\mathrm{b}}$
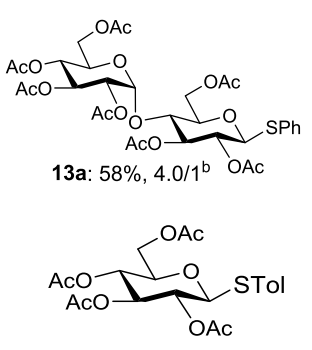

2b: $85 \%, \beta$ only

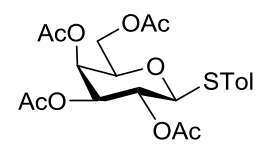

3b: $83 \%, 3.5 / 1$

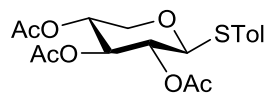

4b: $80 \%, 2.7 / 1^{b}$

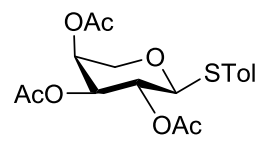

5b: $81 \%, 2.0 / 1^{b}$

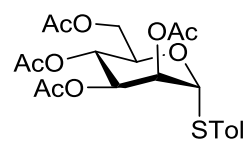

9b: $85 \%$, $\alpha$ only

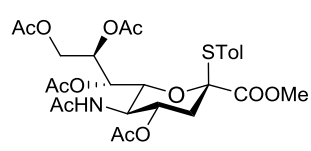

10b: $78 \%, 4.7 / 1$

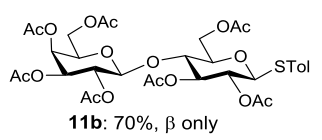




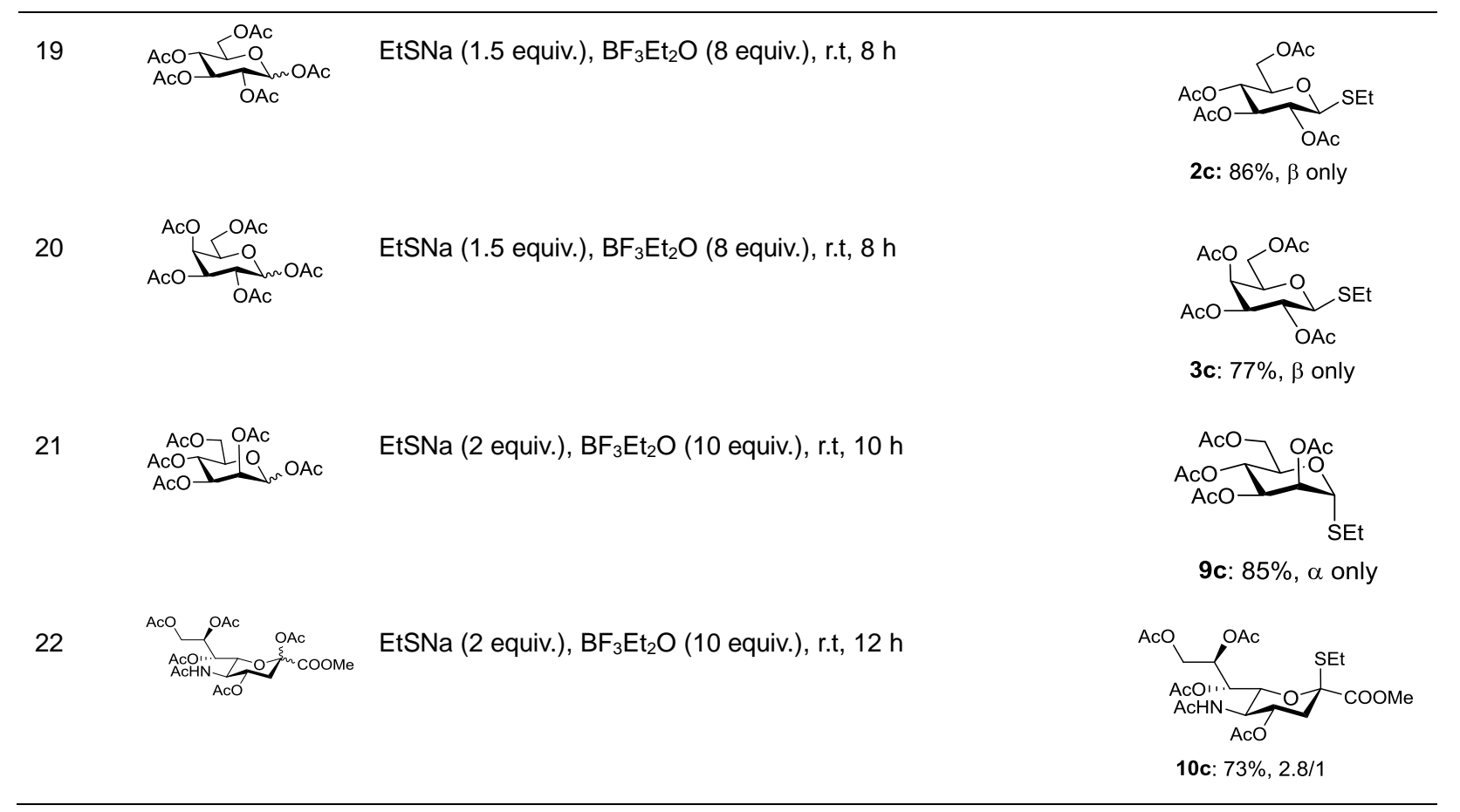

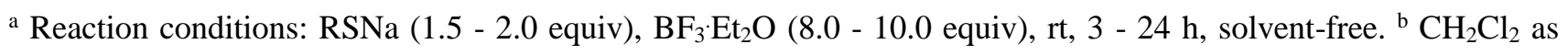
solvent, $4 \AA$.

\section{Table S2. Epimerization between $2 \mathrm{a} \beta$ and $2 \mathrm{a} \alpha .^{\mathrm{a}}$}

\begin{tabular}{|c|c|c|c|c|}
\hline Entry & Solvent & TfOH (equiv) & Additives & $\operatorname{NMR}_{\operatorname{ratios}^{\mathrm{a}}(\boldsymbol{\alpha} / \boldsymbol{\beta})}$ \\
\hline 1 & DCM & 1 & & $1 / 6.2$ \\
\hline 2 & DCM & 2 & & $1.2 / 1$ \\
\hline 3 & DCM & 3 & & $\begin{array}{l}2.4 / 1 \\
2.5 / 1^{\mathrm{b}}\end{array}$ \\
\hline 4 & DCM & 4 & & $2.5 / 1^{\mathrm{b}}$ \\
\hline 5 & DMF/ACN & 3 & & $0 / 100$ \\
\hline 6 & Tol & 3 & & $2.1 / 1$ \\
\hline 7 & DCM & 3 & ACN/DMF ( 0.2 equiv.) & $\begin{array}{l}1 / 1 \\
\mathbf{1} / \mathbf{3 . 3}\end{array}$ \\
\hline 8 & DCM & 3 & ACN/DMF (5 equiv.) & $0 / 100$ \\
\hline 9 & DCM & 0 & TMSOTf (3 equiv.) & $0 / 100$ \\
\hline 10 & DCM & 0 & $\mathrm{BF}_{3} \mathrm{Et}_{2} \mathrm{O}$ (3 equiv.) & $0 / 100$ \\
\hline 11 & DCM & 0 & $\mathrm{FeCl}_{3} / \mathrm{SnCl}_{4}$ (3 equiv.) & $0 / 100$ \\
\hline
\end{tabular}

${ }^{a}$ Reagents and conditions: substrate $\mathbf{2 a} \beta$ (100 mg), TfOH (1.0 - 4.0 equiv.), MS $4 \AA$, solvents $(1 \mathrm{~mL}), 30 \mathrm{~min}$; ${ }^{\mathrm{b}}$ The 
reaction time was extended to $1 \mathrm{~h}$.

When $2 \mathrm{a} \beta$ was treated with $\mathrm{TfOH}$ in $\mathrm{CH}_{2} \mathrm{Cl}_{2}$ at room temperature for 30 mins, it can be seen (Entries $1-4$ in Table S2), the $\alpha / \beta$ ratio of 1 -SPh glucoside caused by 1 equiv of TfOH was $1 / 6.2$ (Entry 1 ), the $\alpha / \beta$ ratio of 1 -SPh glucoside caused by 2 equiv of TfOH was 1.2/1 (Entry 2 ), the $\alpha / \beta$ ratio of 1 -SPh glucoside caused by 3 equiv of TfOH was 2.4/1 (Entry 3), and the $\alpha / \beta$ ratio of 1-SPh glucoside caused by 4 equiv of TfOH was $2.5 / 1$ (Entry 4 ). In the case of using 3 equiv of $\mathrm{TfOH}$, when the reaction time was prolonged from $30 \mathrm{mins}$ to $1 \mathrm{~h}$, the $\alpha / \beta$ ratio of 1 -SPh glucoside only increased from $2.4 / 1$ to $2.5 / 1$ (Entry 3), indicating that the epimerization has reached equilibrium. This epimerization did not occur in the polar solvents DMF and acetonitrile (Entry 5), but still occurred in the non-polar solvent toluene (Entry 6). The reason should be the competitive complexation of polar solvent molecules with TfOH. Therefore, the addition of 0.2 equiv of ACN/DMF had greatly reduced the rate of the epimerization (Entry 7), and the addition of 5 equiv of ACN/DMF had completely inhibited the epimerization (Entry 8). We also tried to use TMSOTf, $\mathrm{BF}_{3} \mathrm{Et}_{2} \mathrm{O}, \mathrm{FeCl}_{3}$ and $\mathrm{SnCl}_{4}$ instead of $\mathrm{TfOH}$ to activate the epimerization, but all failed (Entries 9 - 11). 
5. NMR spectra of compounds 2 - 12

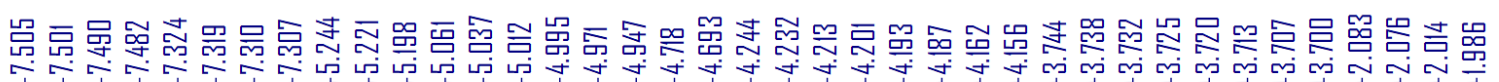
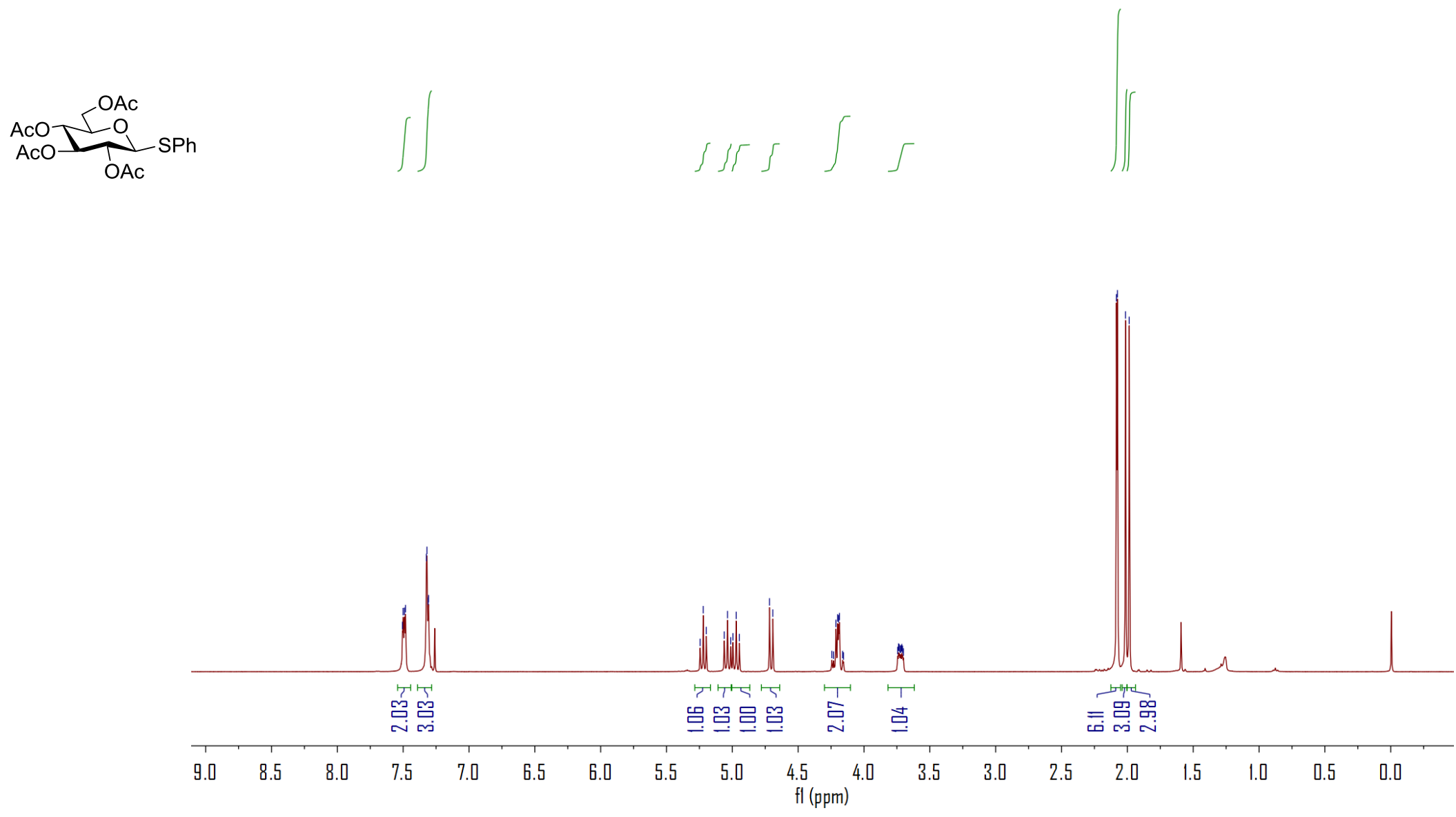

Figure S12. ${ }^{1} \mathrm{H}$ NMR spectrum $(400 \mathrm{MHz})$ of $\mathbf{2 a} \beta$ in $\mathrm{CDCl}_{3}$ 


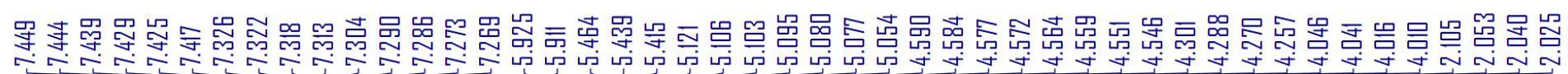
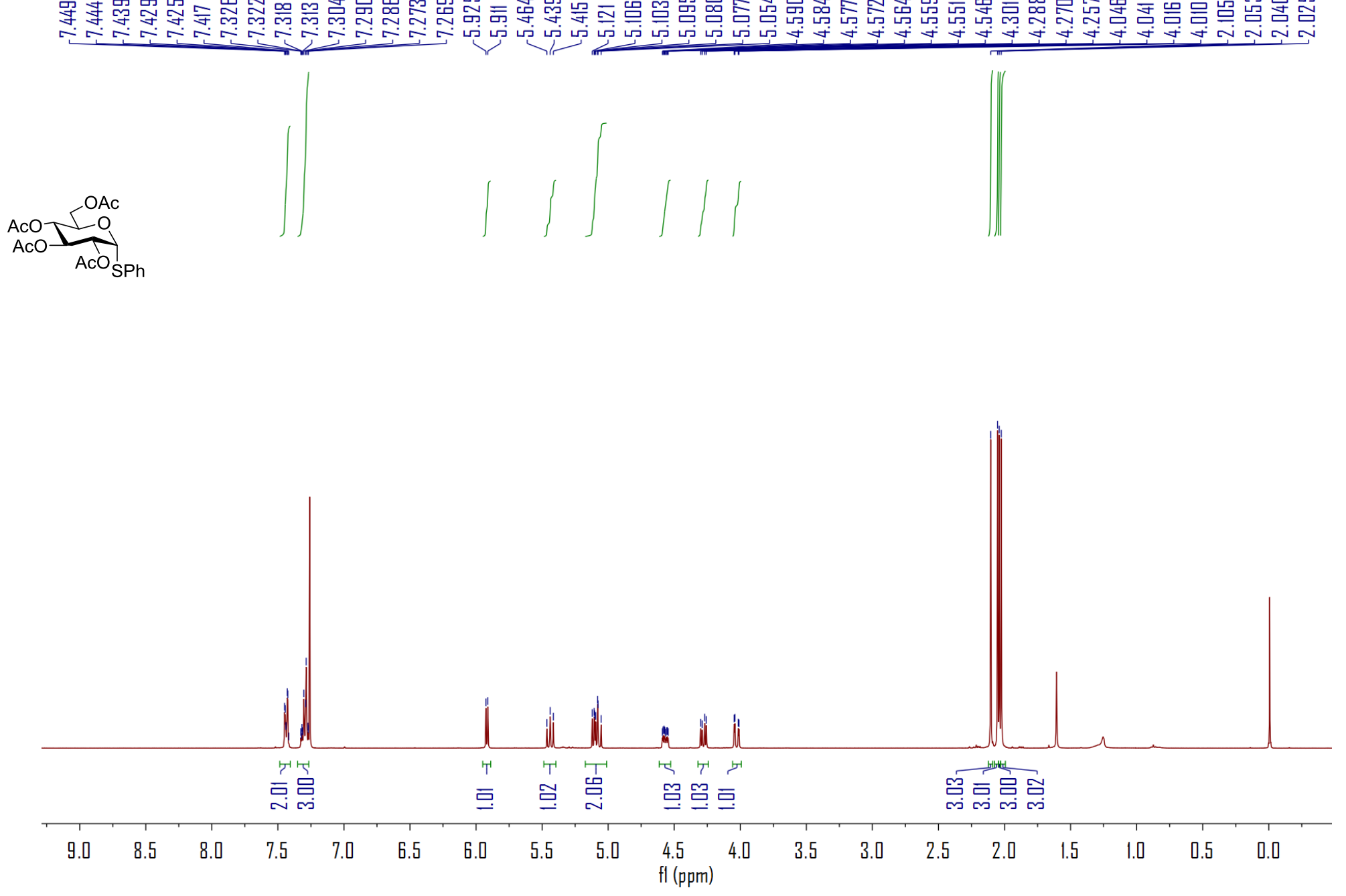

Figure S13. ${ }^{1} \mathrm{H}$ NMR spectrum $(400 \mathrm{MHz})$ of $\mathbf{2} \mathbf{a} \alpha$ in $\mathrm{CDCl}_{3}$ 


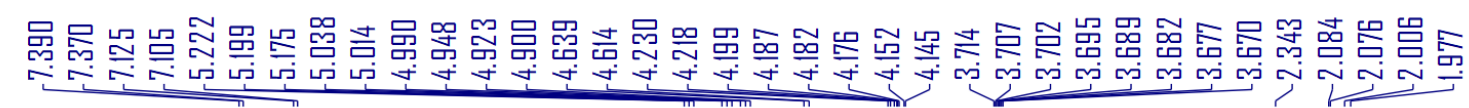
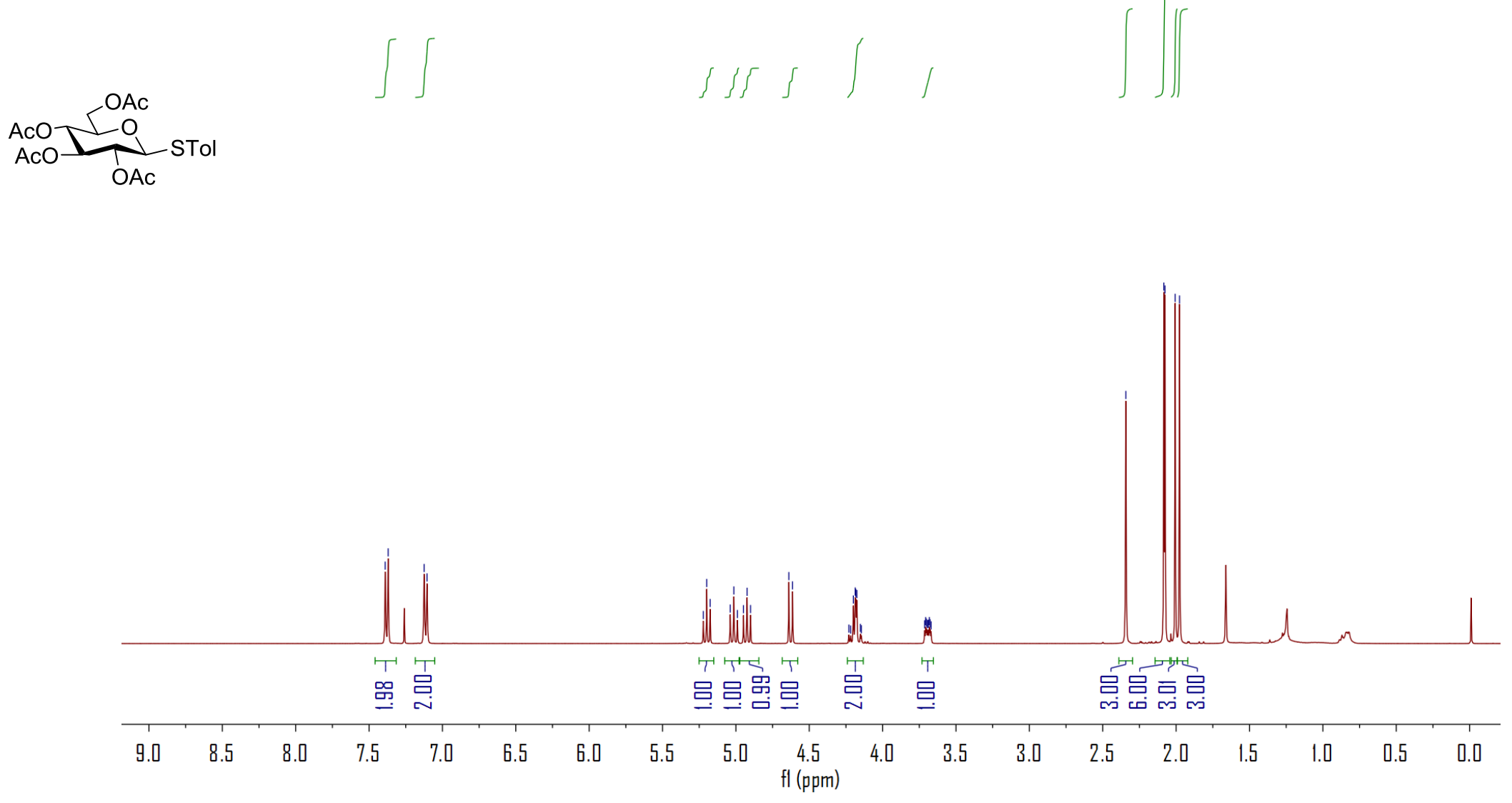

Figure S14. ${ }^{1} \mathrm{H}$ NMR spectrum $(400 \mathrm{MHz})$ of $2 \mathbf{b} \beta$ in $\mathrm{CDCl}_{3}$ 


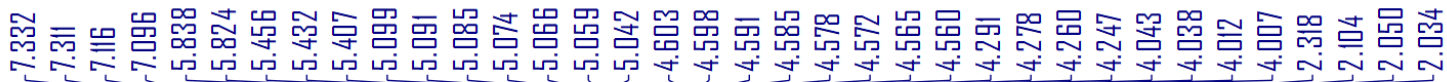
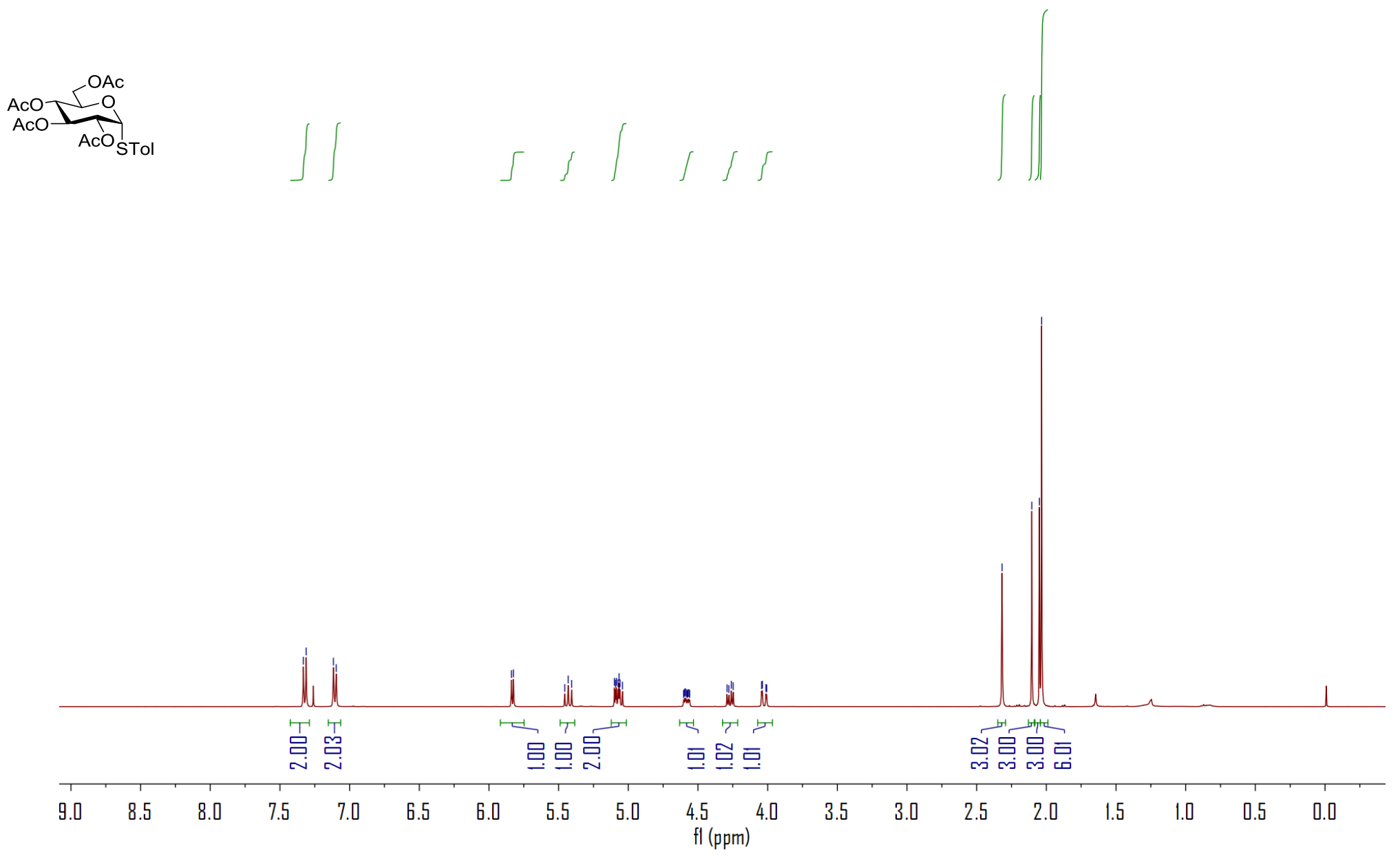

Figure S15. ${ }^{1} \mathrm{H}$ NMR spectrum $(400 \mathrm{MHz})$ of $\mathbf{2} \mathbf{b} \alpha$ in $\mathrm{CDCl}_{3}$ 


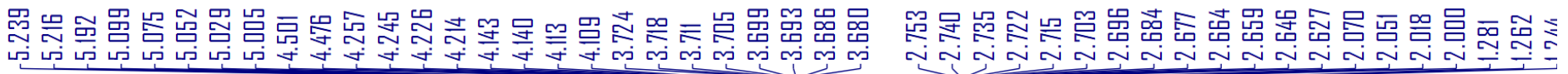
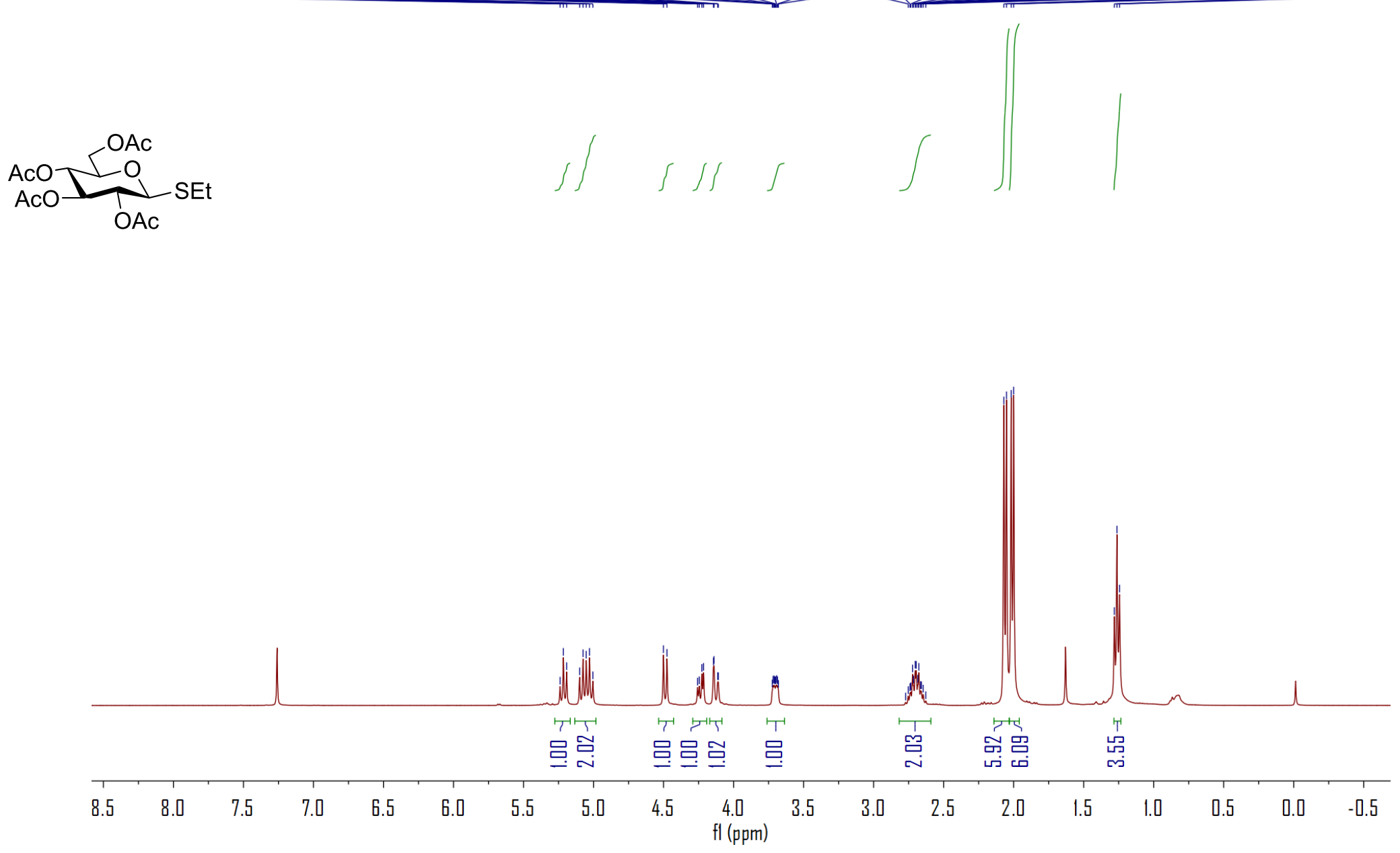

Figure S16. ${ }^{1} \mathrm{H}$ NMR spectrum $(400 \mathrm{MHz})$ of $2 \mathbf{c}$ in $\mathrm{CDCl}_{3}$ 


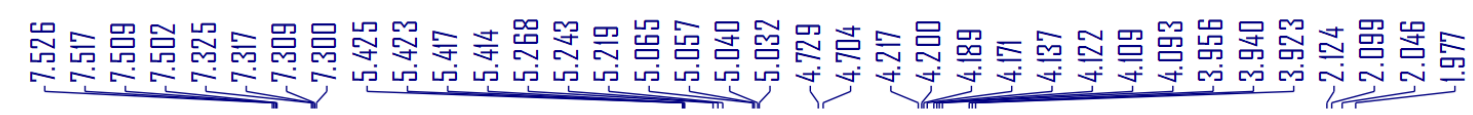
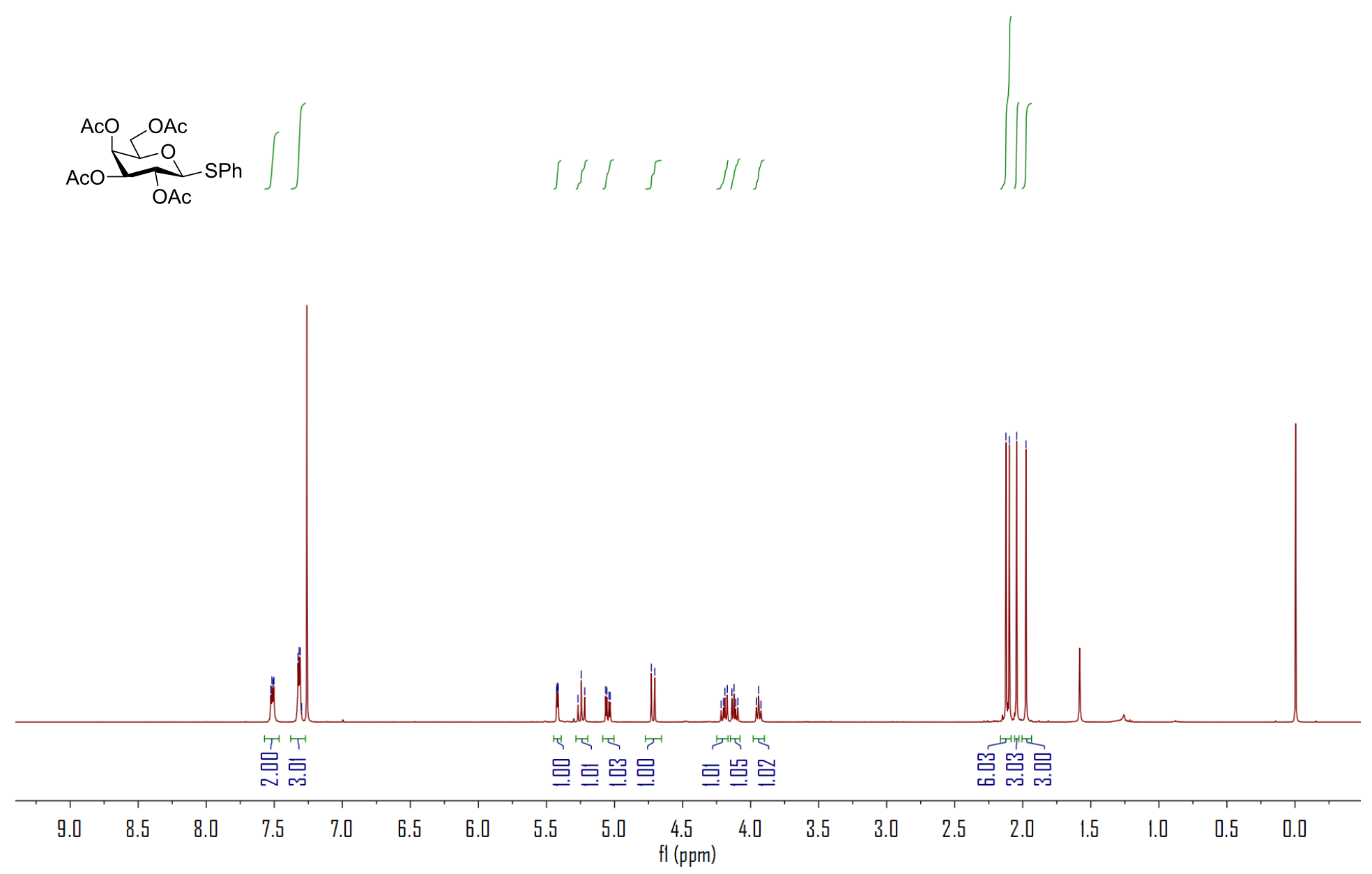

Figure S17. ${ }^{1} \mathrm{H}$ NMR spectrum $(400 \mathrm{MHz})$ of $\mathbf{3 a} \beta$ in $\mathrm{CDCl}_{3}$ 

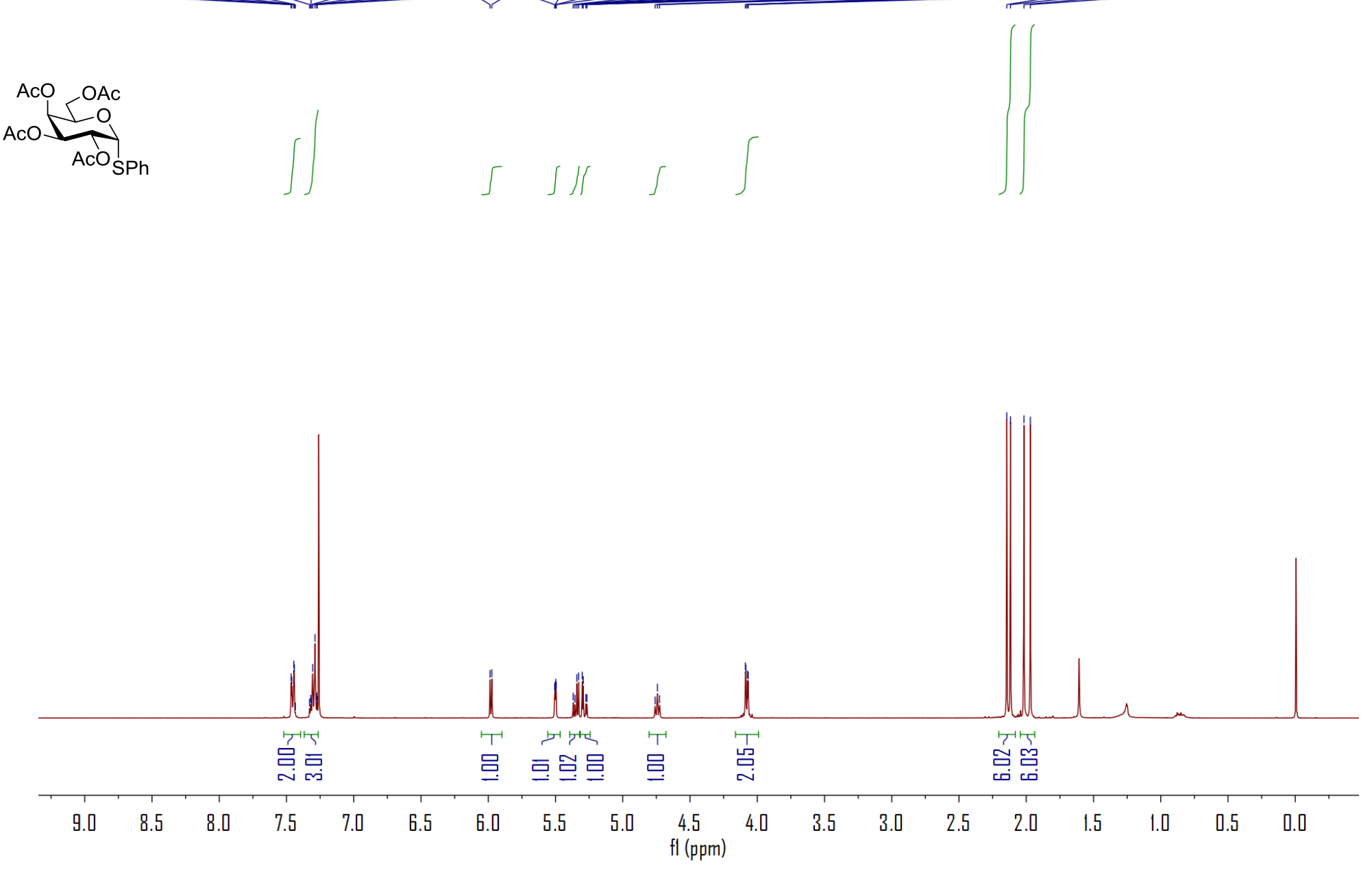

Figure S18. ${ }^{1} \mathrm{H}$ NMR spectrum $(400 \mathrm{MHz})$ of $\mathbf{3 a} \alpha$ in $\mathrm{CDCl}_{3}$ 


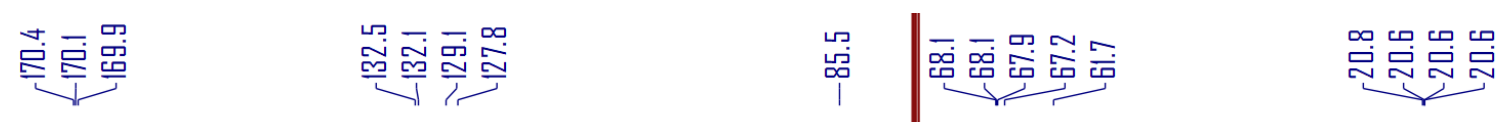

$\underbrace{\mathrm{APh}}_{\mathrm{AcO}}$
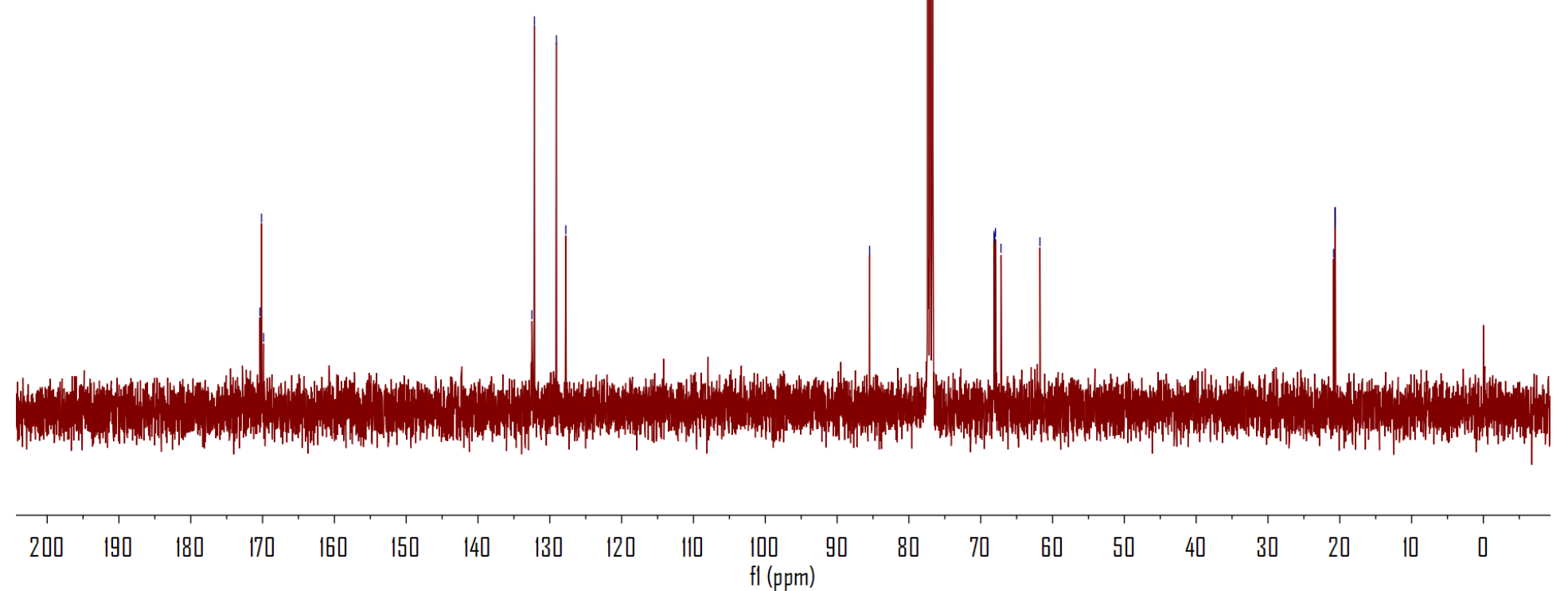

Figure S19. ${ }^{13} \mathrm{C}$ NMR spectrum $(101 \mathrm{MHz})$ of $\mathbf{3 a} \alpha$ in $\mathrm{CDCl}_{3}$ 


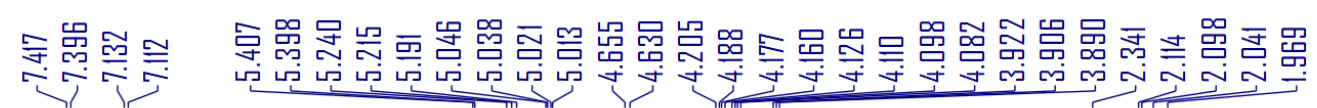
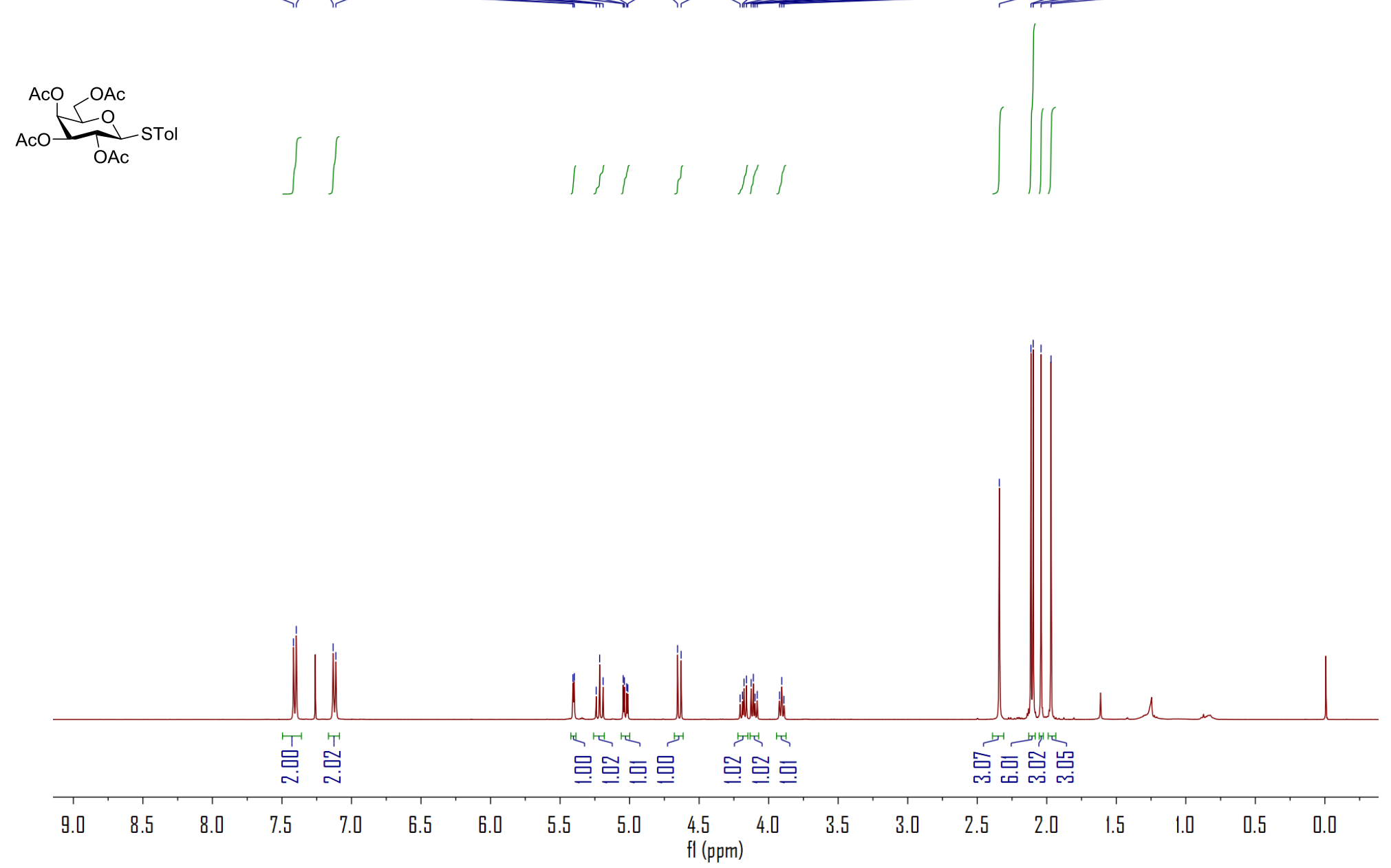

Figure S20. ${ }^{1} \mathrm{H}$ NMR spectrum $(400 \mathrm{MHz})$ of $\mathbf{3 b} \beta$ in $\mathrm{CDCl}_{3}$ 

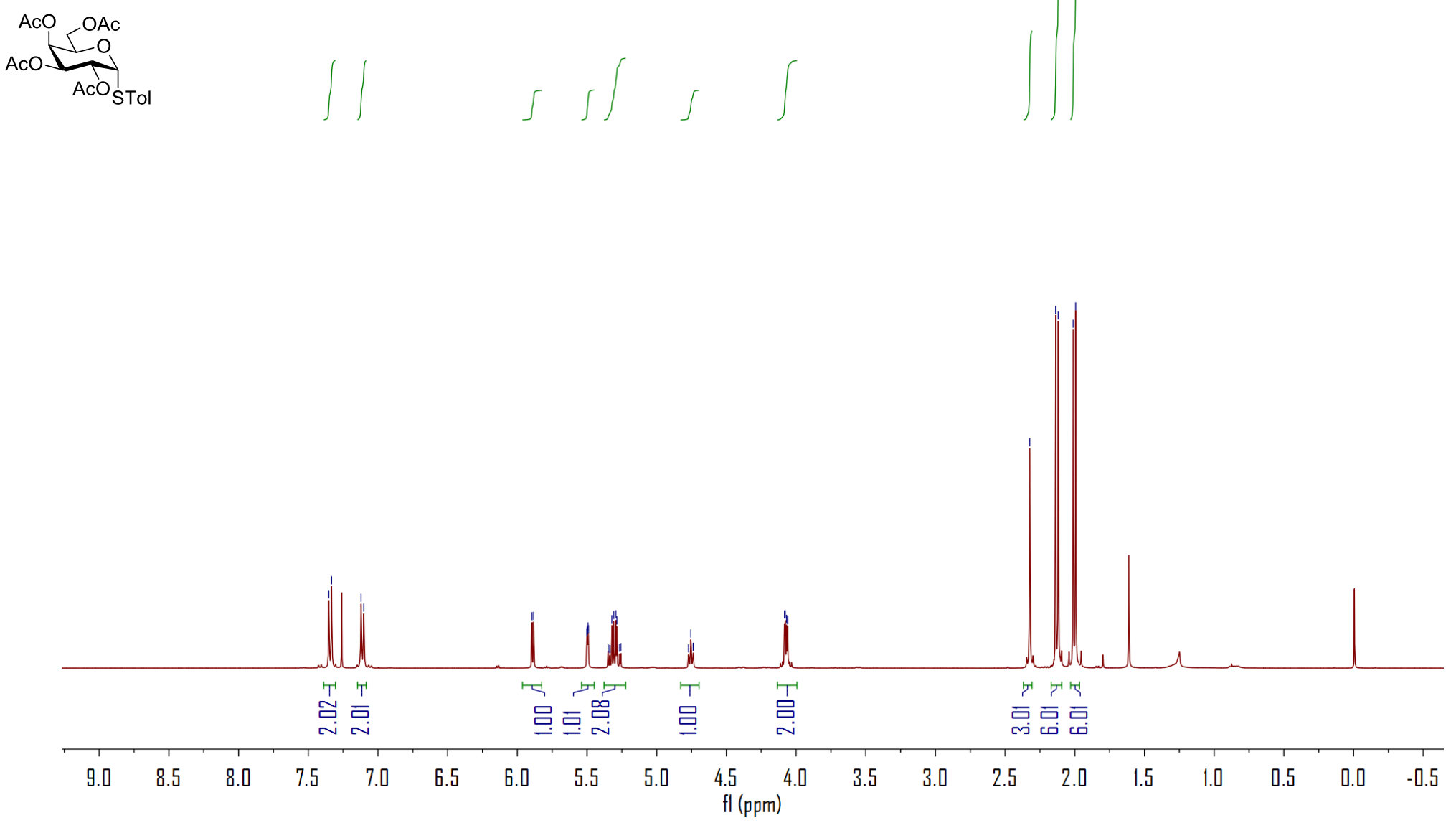

Figure S21. ${ }^{1} \mathrm{H}$ NMR spectrum $(400 \mathrm{MHz})$ of $\mathbf{3 b} \alpha$ in $\mathrm{CDCl}_{3}$ 


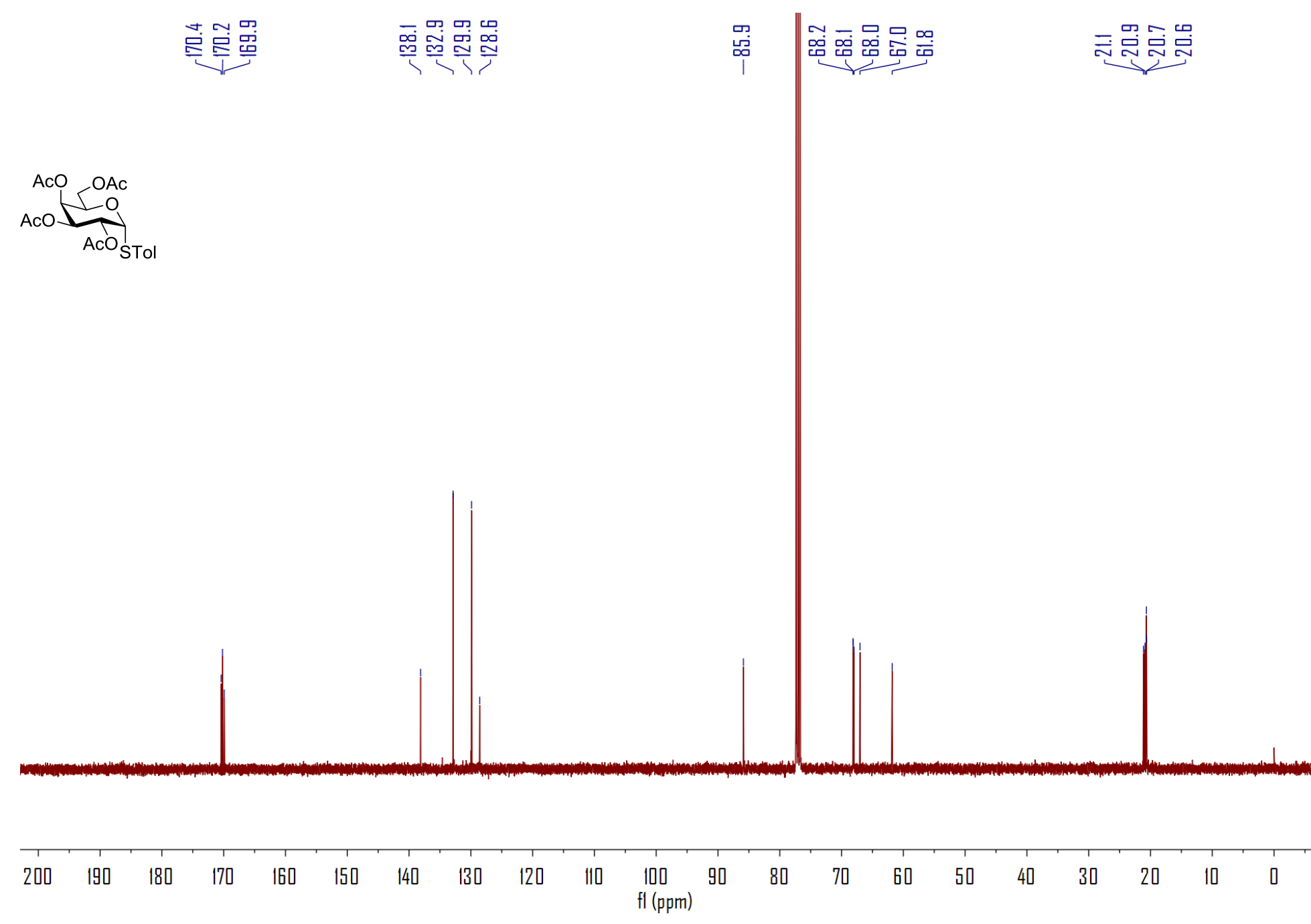

Figure S22. ${ }^{13} \mathrm{C}$ NMR spectrum $(101 \mathrm{MHz})$ of $\mathbf{3 b} \alpha$ in $\mathrm{CDCl}_{3}$ 

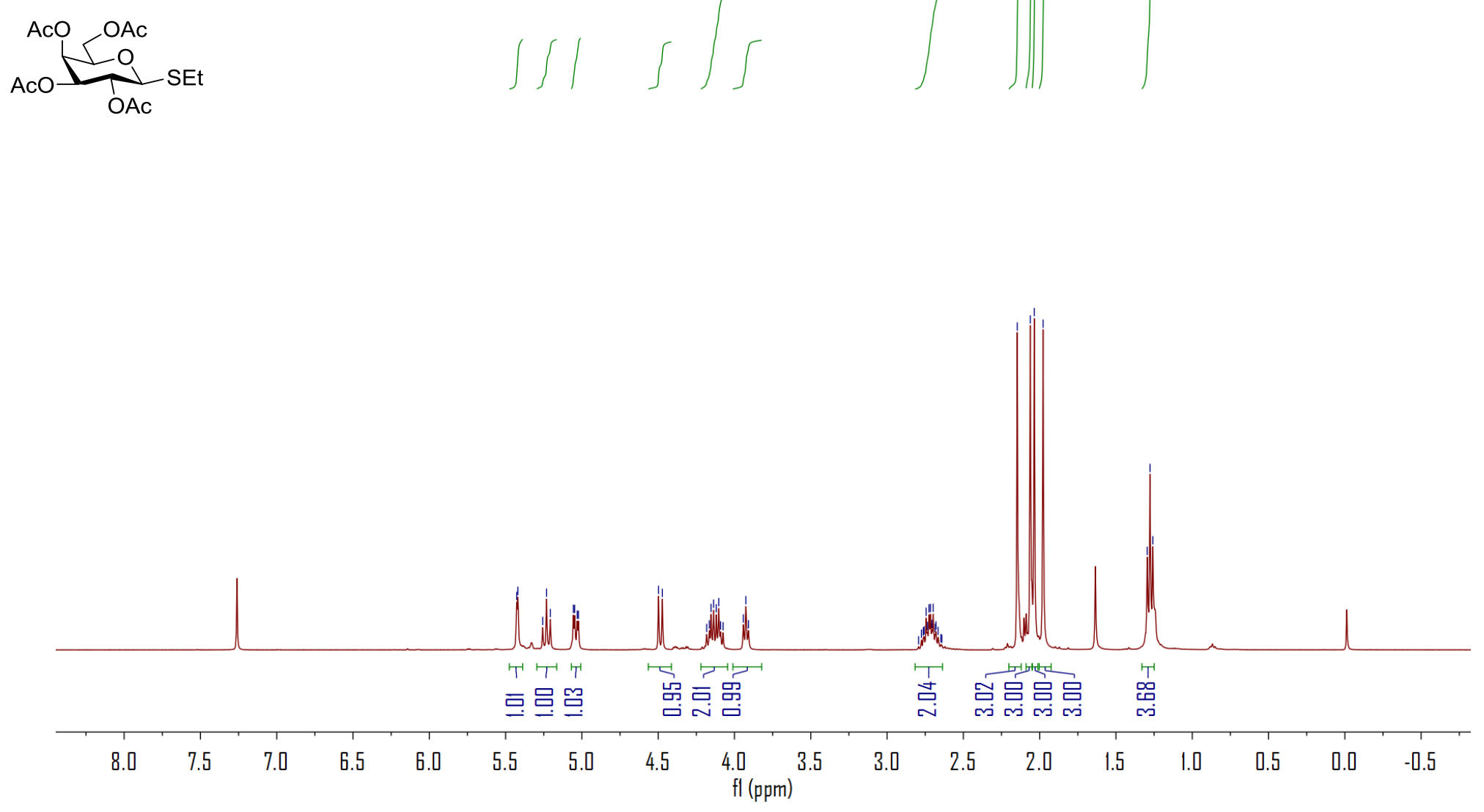

Figure S23. ${ }^{1} \mathrm{H}$ NMR spectrum (400 MHz) of $\mathbf{3 c}$ in $\mathrm{CDCl}_{3}$ 


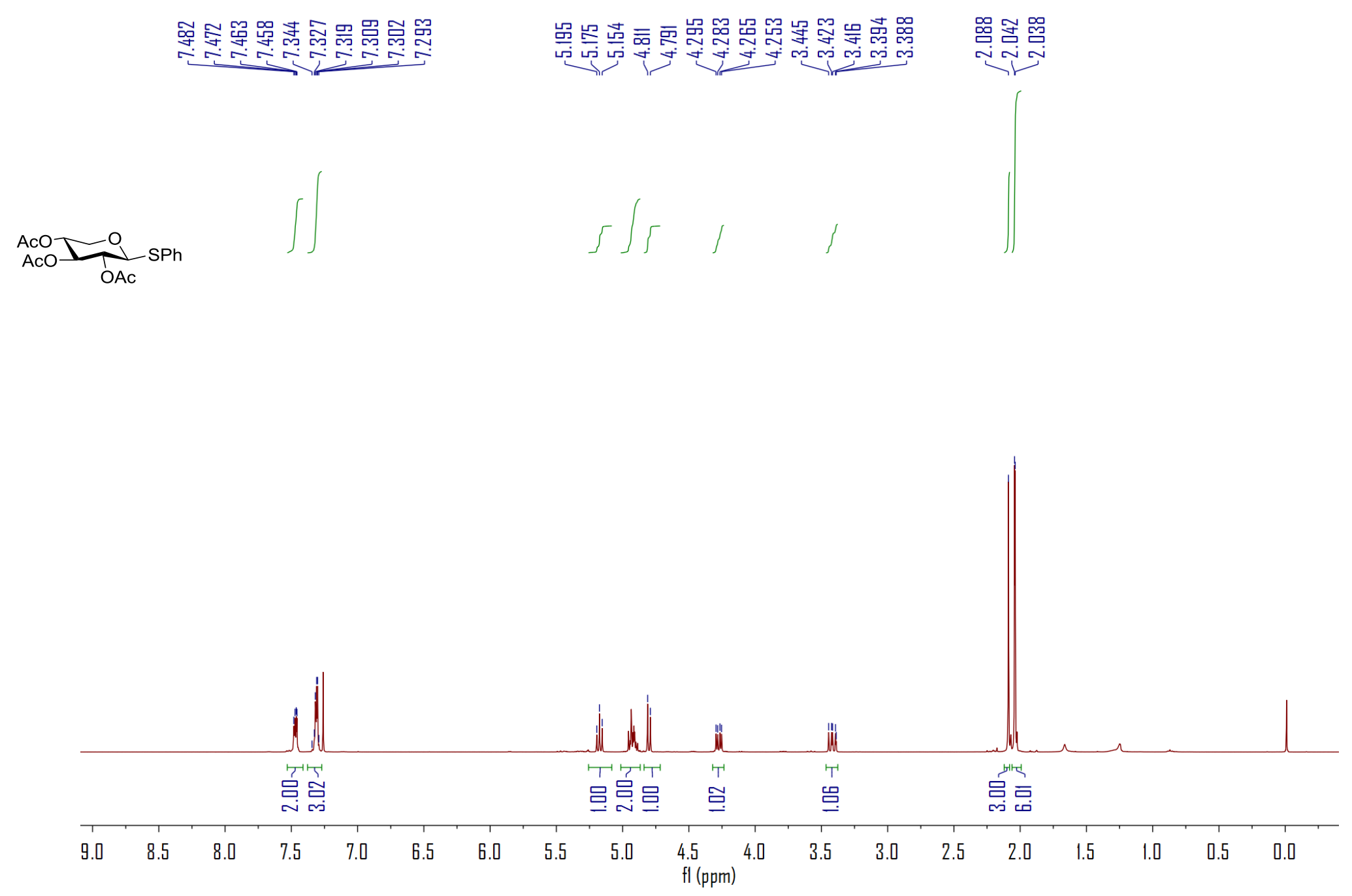

Figure S24. ${ }^{1} \mathrm{H}$ NMR spectrum $(400 \mathrm{MHz})$ of $4 \mathbf{a} \beta$ in $\mathrm{CDCl}_{3}$ 


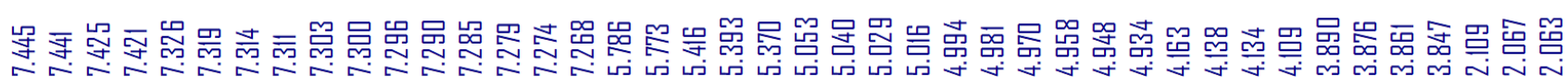

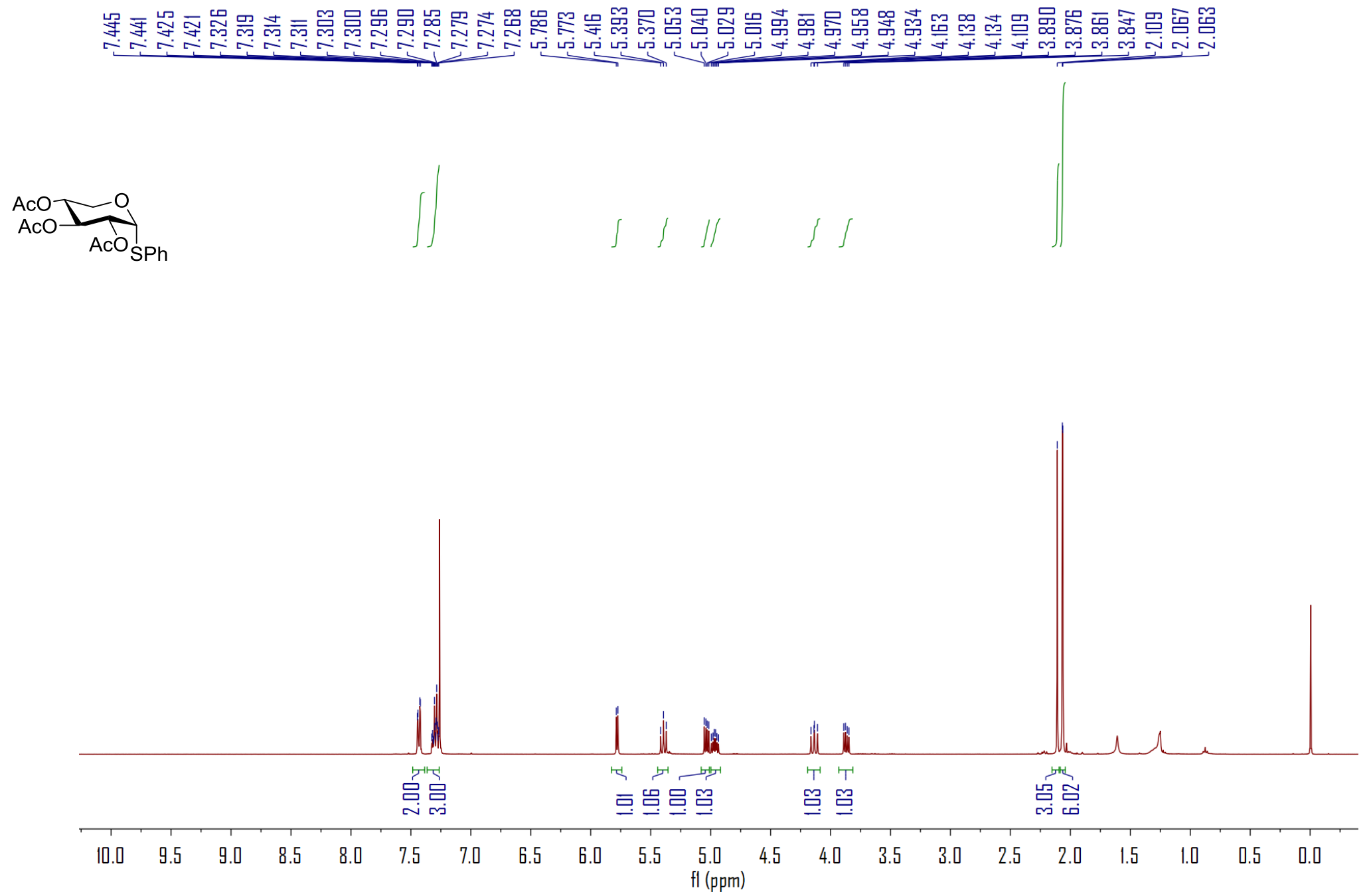

Figure S25. ${ }^{1} \mathrm{H}$ NMR spectrum $(400 \mathrm{MHz})$ of $\mathbf{4 a} \alpha$ in $\mathrm{CDCl}_{3}$ 


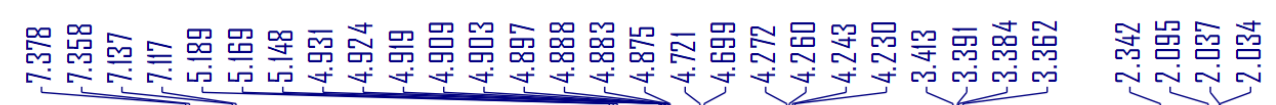

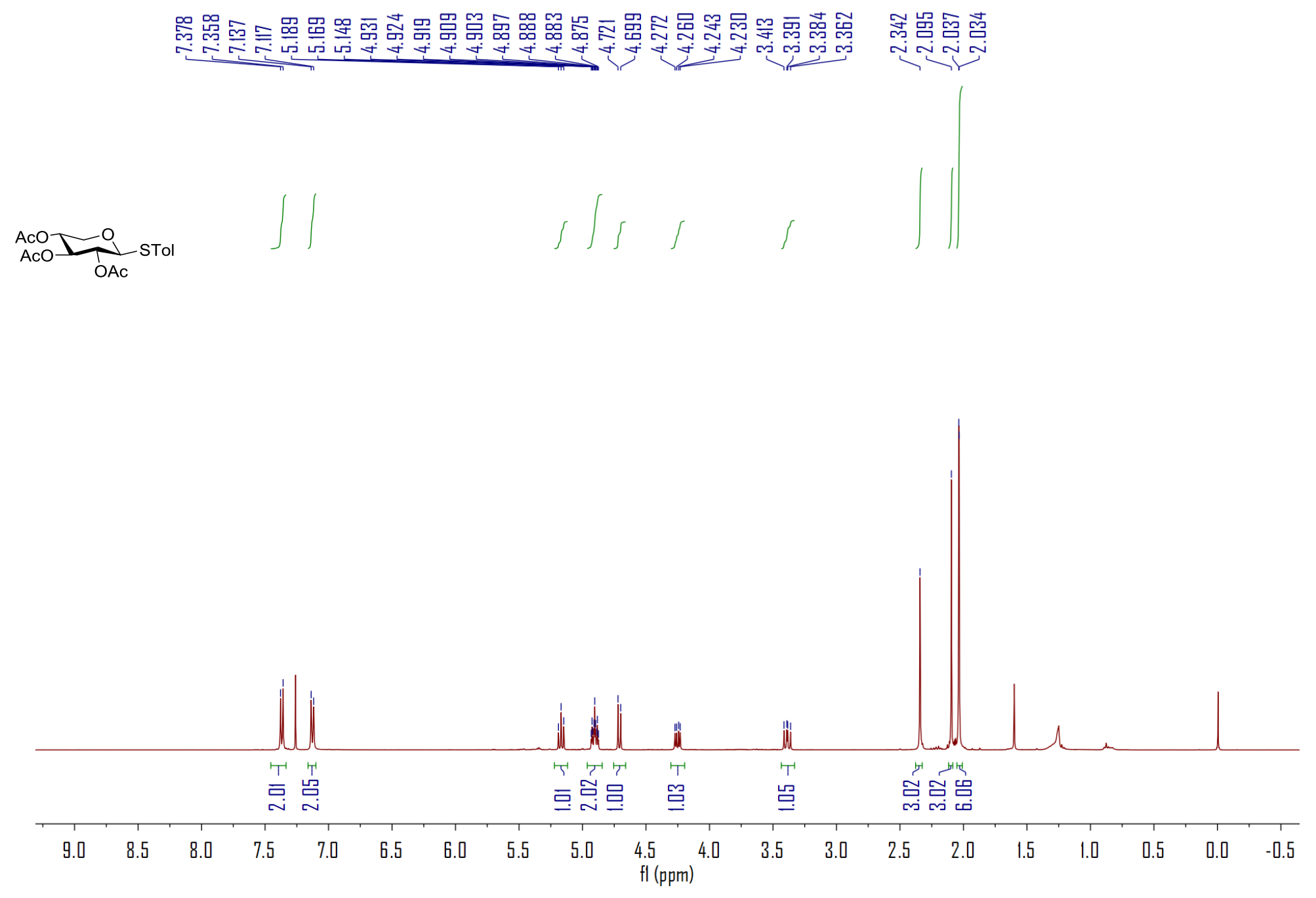

Figure S26. ${ }^{1} \mathrm{H}$ NMR spectrum $(400 \mathrm{MHz})$ of $4 \mathbf{b} \beta$ in $\mathrm{CDCl}_{3}$ 


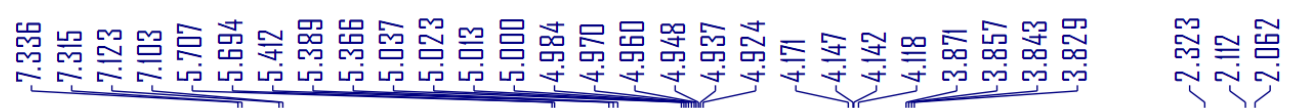

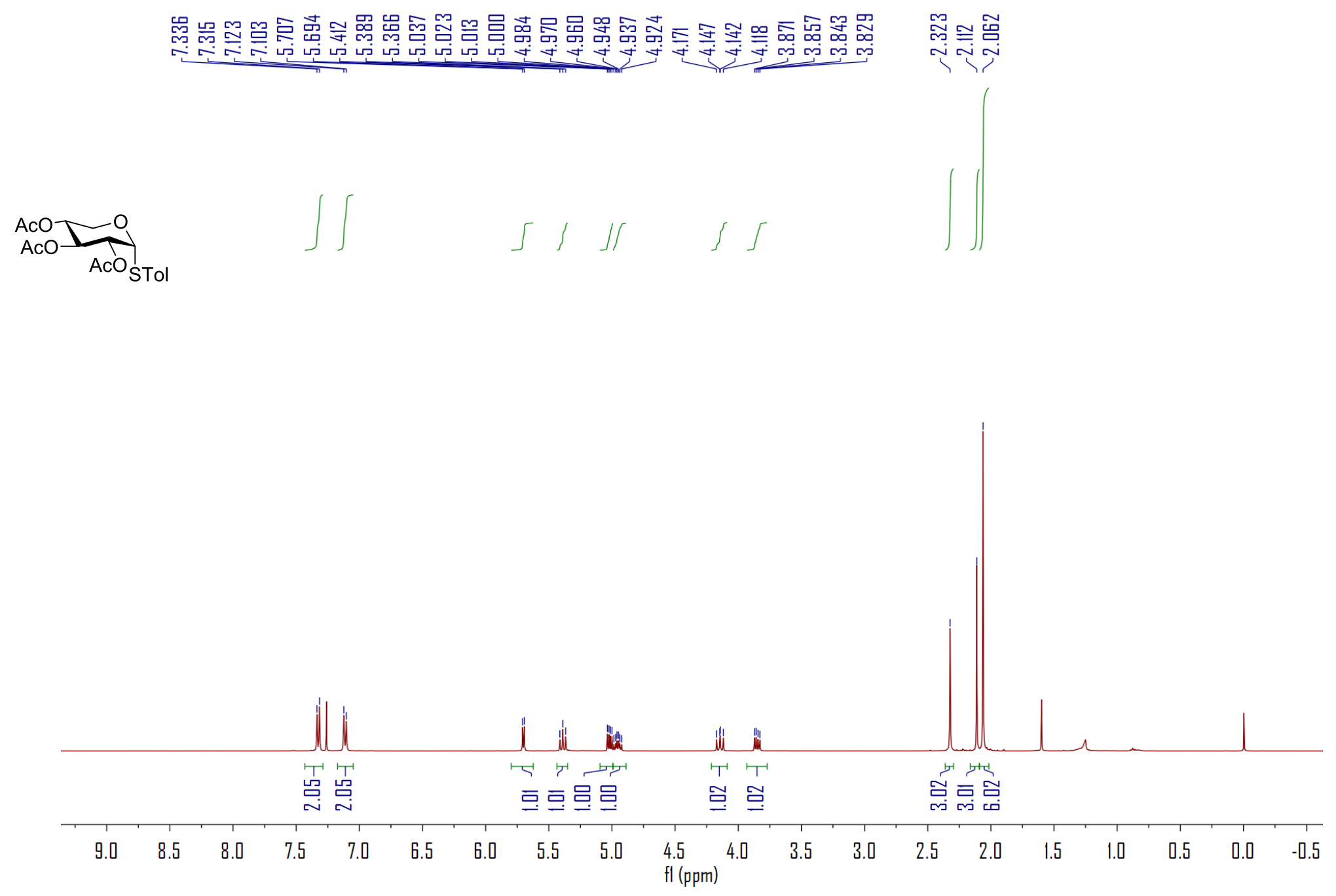

Figure S27. ${ }^{1} \mathrm{H}$ NMR spectrum ( $400 \mathrm{MHz}$ ) of $\mathbf{4 b} \boldsymbol{b}$ in $\mathrm{CDCl}_{3}$ 


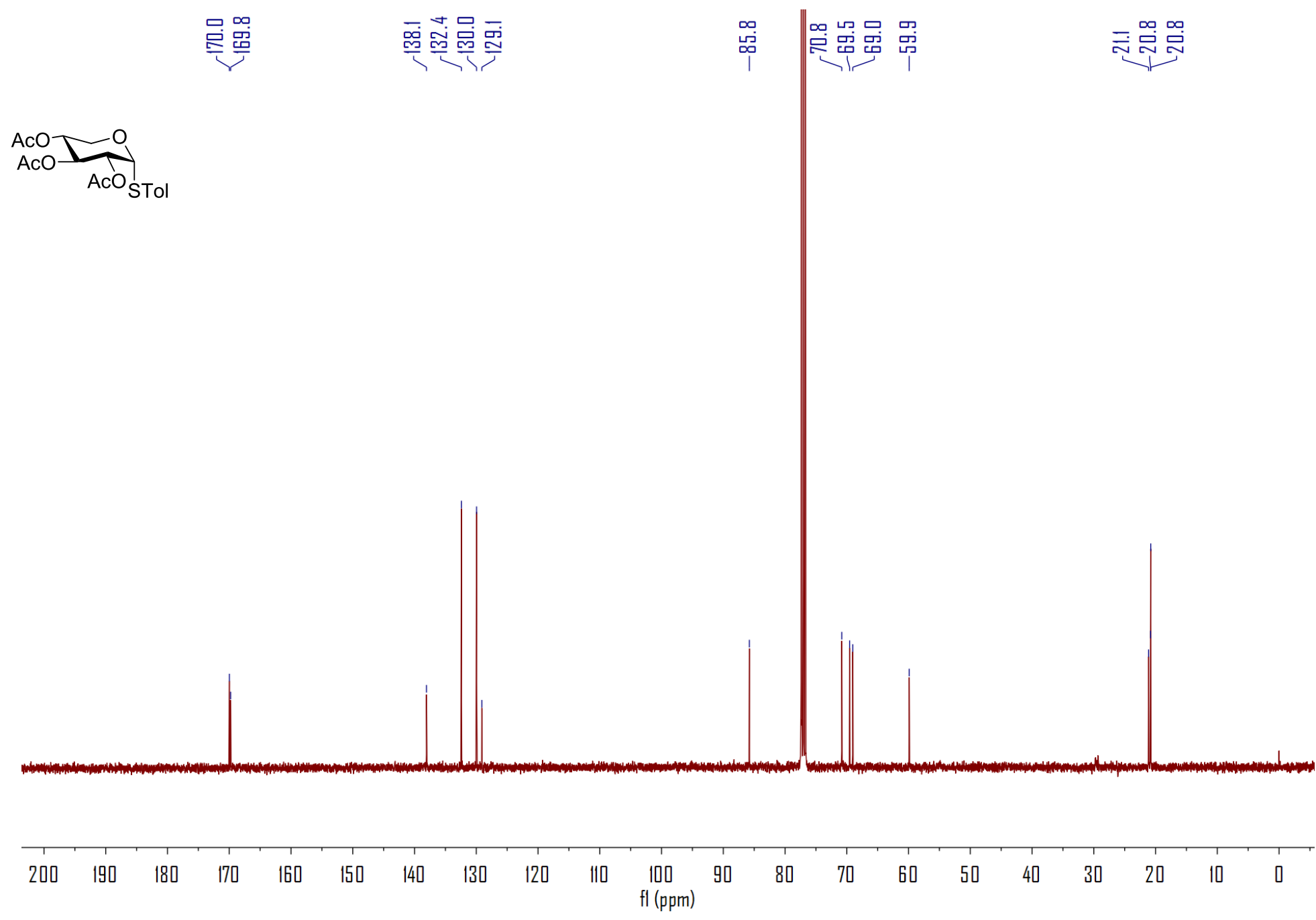

Figure S28. ${ }^{13} \mathrm{C}$ NMR spectrum $(101 \mathrm{MHz})$ of $\mathbf{4 b} \alpha$ in $\mathrm{CDCl}_{3}$ 


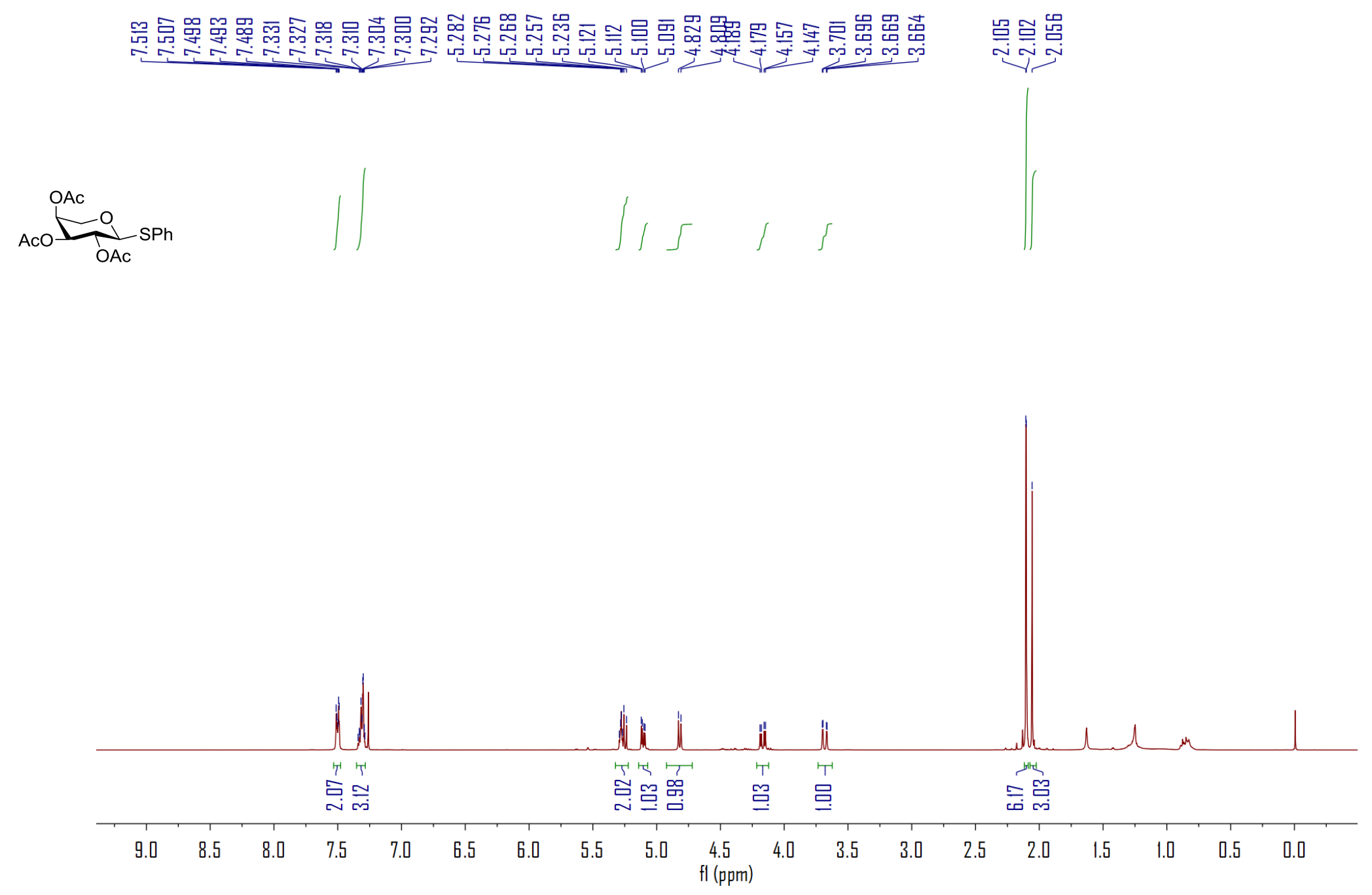

Figure S29. ${ }^{1} \mathrm{H}$ NMR spectrum $(400 \mathrm{MHz})$ of $\mathbf{5 a} \beta$ in $\mathrm{CDCl}_{3}$ 


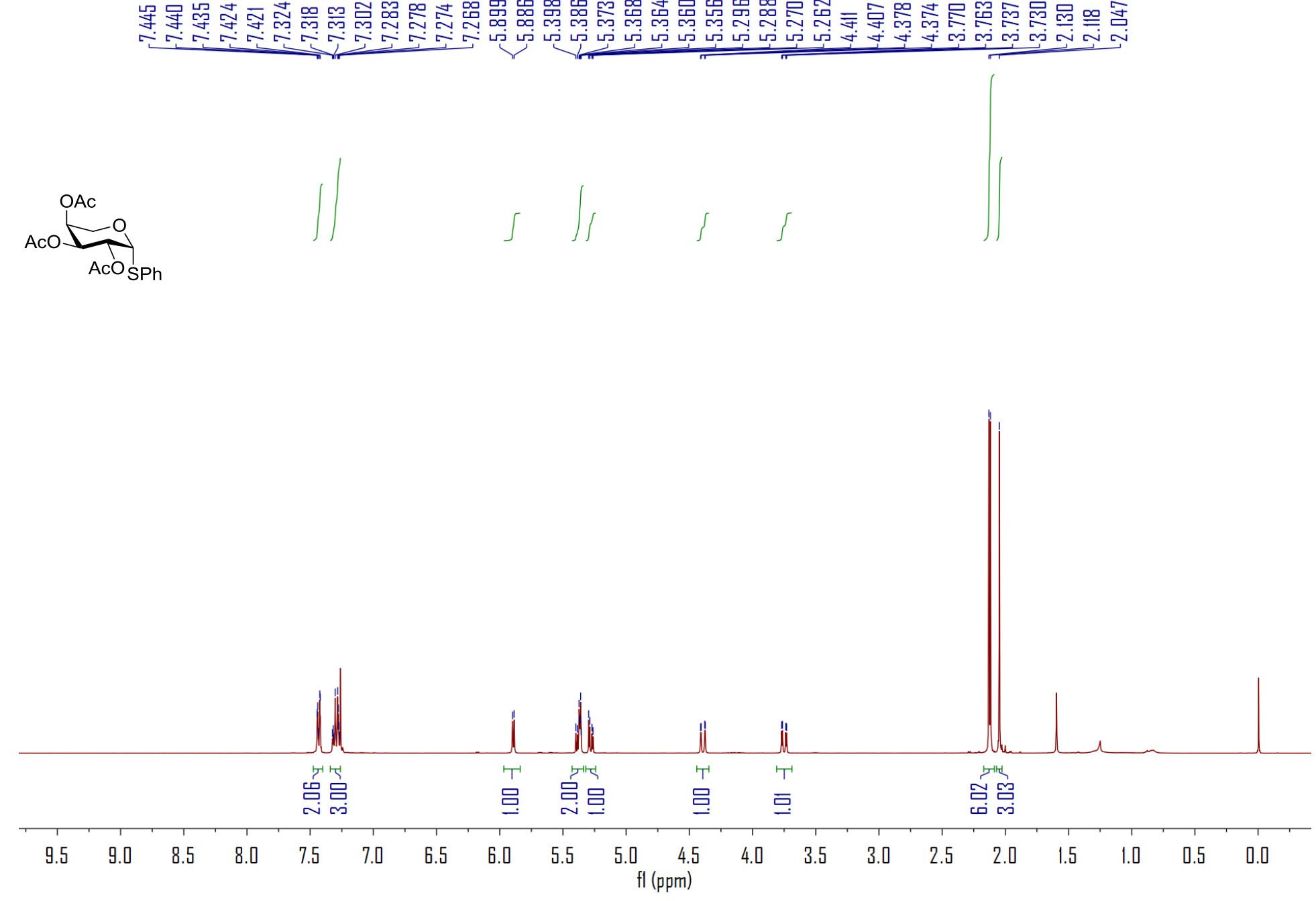

Figure S30. ${ }^{1} \mathrm{H}$ NMR spectrum $(400 \mathrm{MHz})$ of $\mathbf{5 a} \alpha$ in $\mathrm{CDCl}_{3}$ 


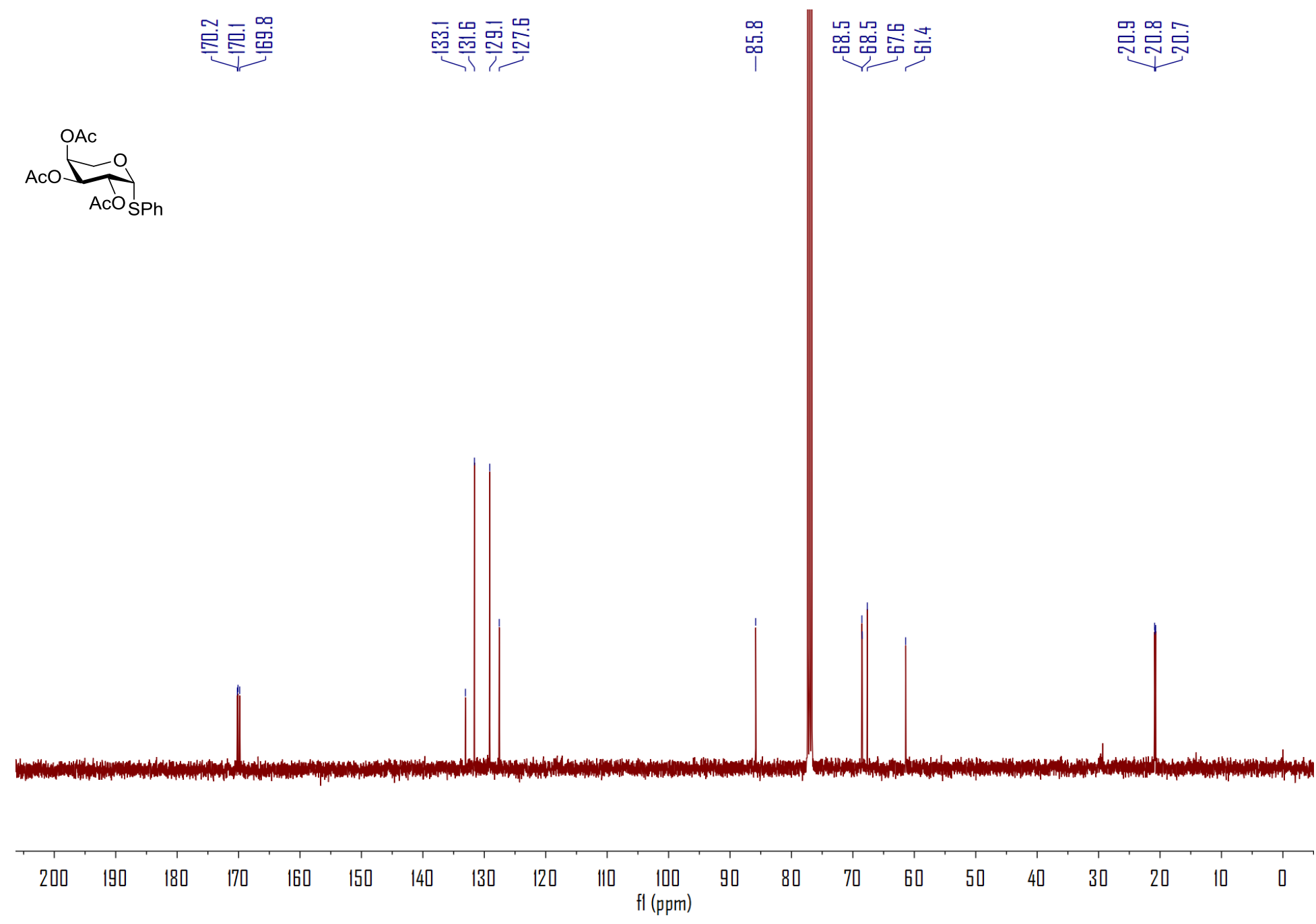

Figure S31. ${ }^{13} \mathrm{C}$ NMR spectrum $(101 \mathrm{MHz})$ of $\mathbf{5 a} \alpha$ in $\mathrm{CDCl}_{3}$ 


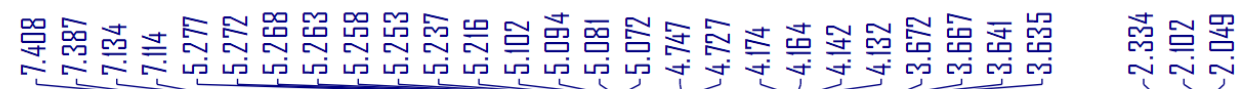

${ }_{\text {OAc }}^{O A C O}$ STol
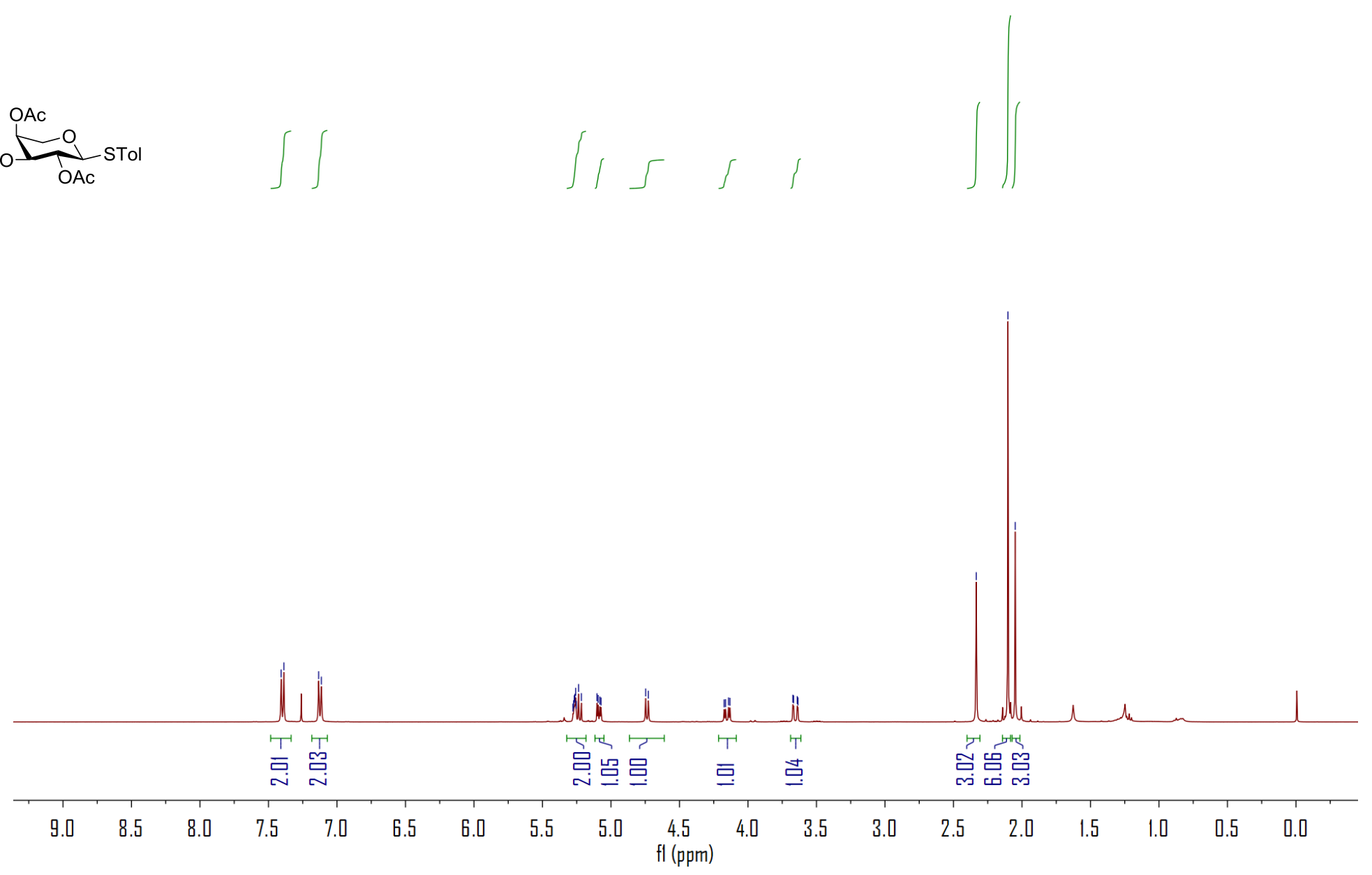

Figure S32. ${ }^{1} \mathrm{H}$ NMR spectrum (400 MHz) of $\mathbf{5 b} \beta \mathrm{Bn} \mathrm{CDCl}_{3}$ 


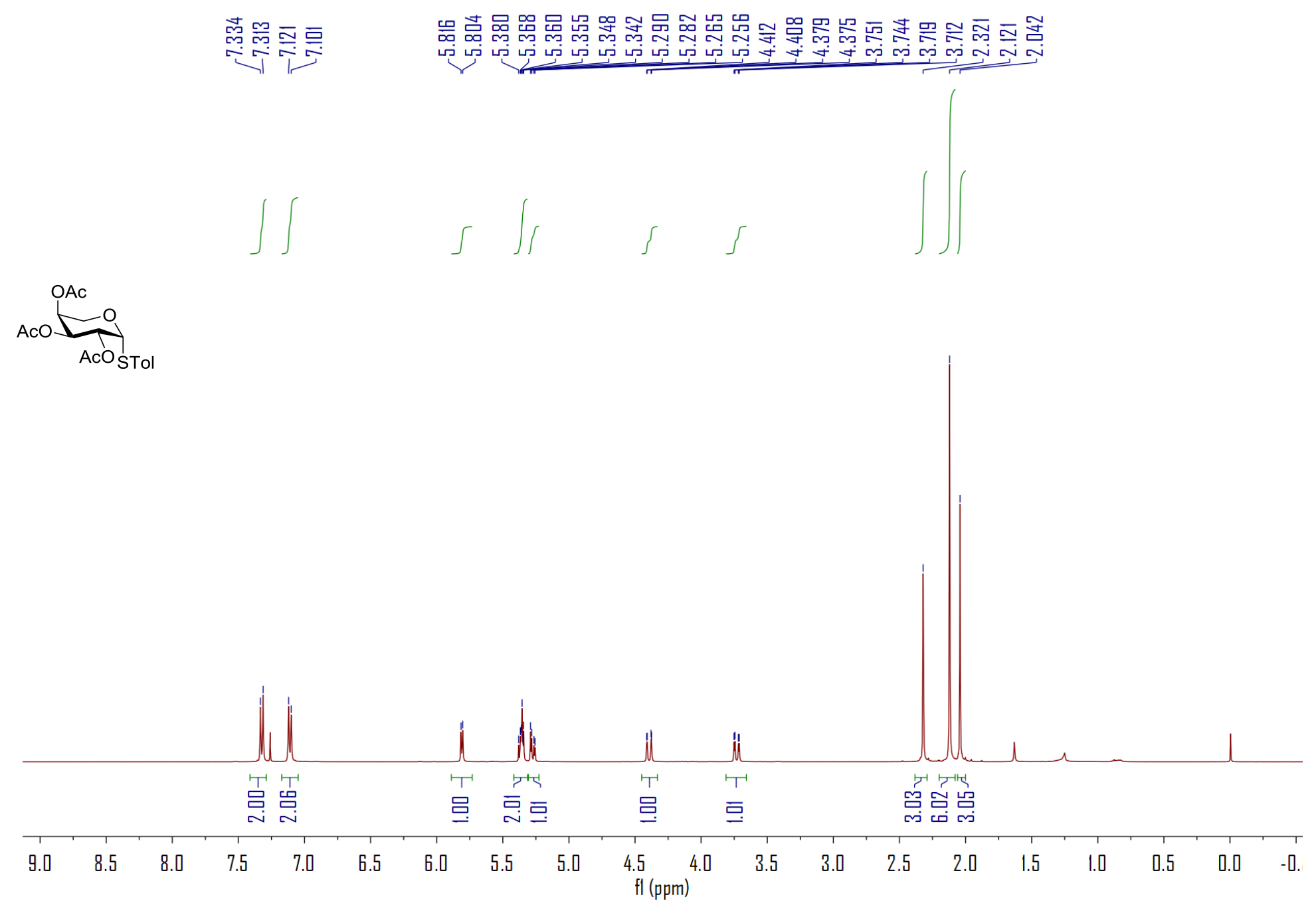

Figure S33. ${ }^{1} \mathrm{H}$ NMR spectrum $(400 \mathrm{MHz})$ of $\mathbf{5 b} \alpha$ in $\mathrm{CDCl}_{3}$ 


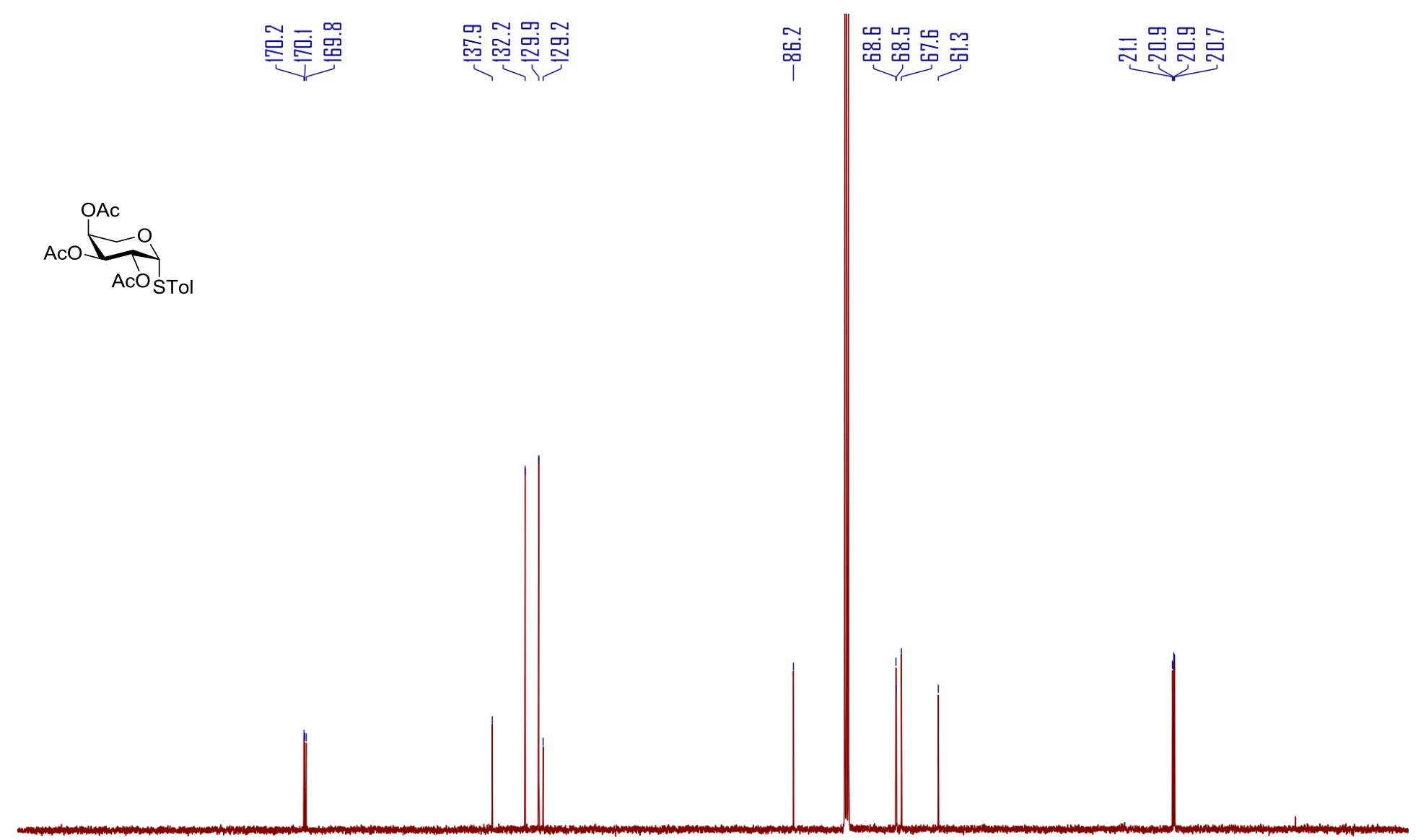

$\begin{array}{llllllllllllllllllllllllllll}210 & 200 & 190 & 180 & 170 & 160 & 150 & 140 & 130 & 120 & 110 & 100 & 90 & 80 & 70 & 60 & 50 & 40 & 30 & 20 & 10 & 0 & -10 & \end{array}$

Figure S34. ${ }^{13} \mathrm{C}$ NMR spectrum (101 MHz) of $5 \mathbf{b} \alpha$ in $\mathrm{CDCl}_{3}$ 


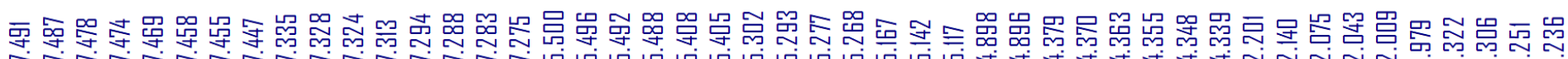

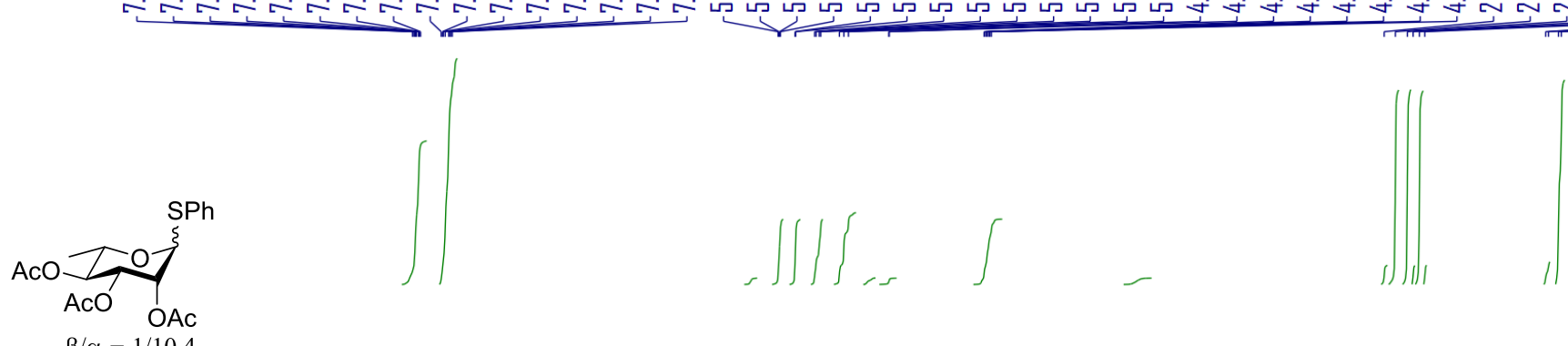

$\beta / \alpha=1 / 10.4$

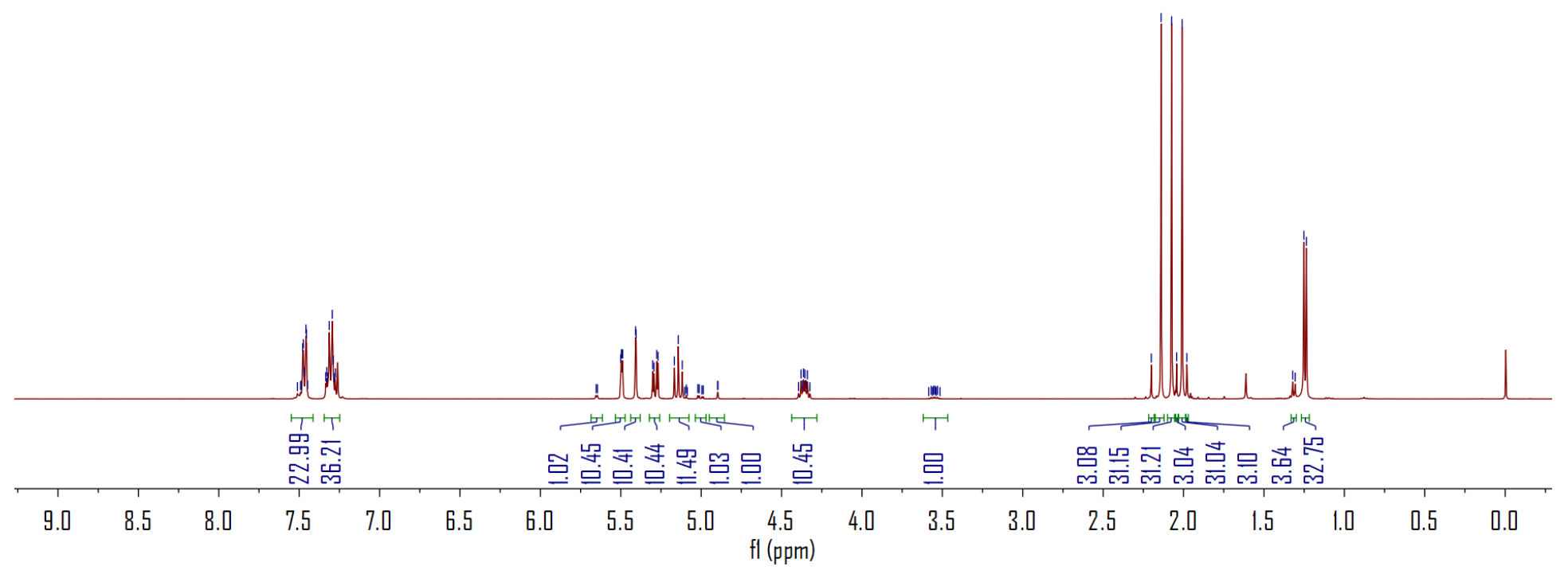

Figure S35. ${ }^{1} \mathrm{H}$ NMR spectrum $(400 \mathrm{MHz})$ of $\mathbf{6 a}$ in $\mathrm{CDCl}_{3}$ 


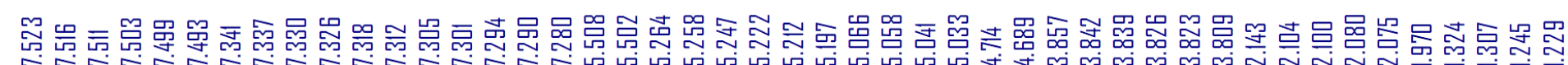

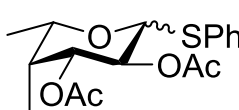

OAC

$\beta / \alpha=7.5 / 1$
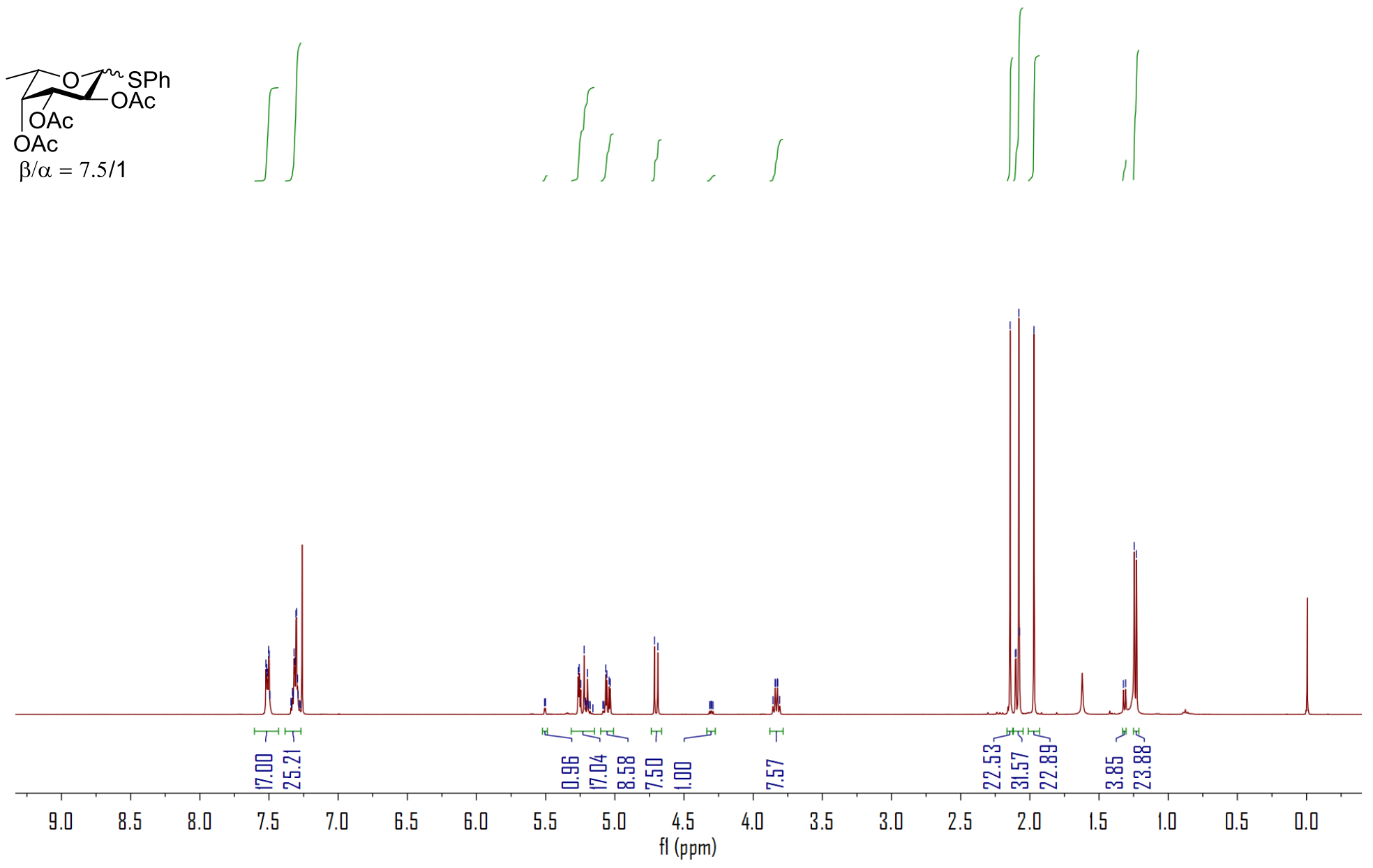

Figure S36. ${ }^{1} \mathrm{H}$ NMR spectrum $(400 \mathrm{MHz})$ of $\mathbf{7 a}$ in $\mathrm{CDCl}_{3}$ 


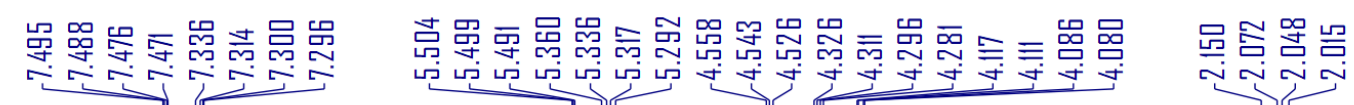

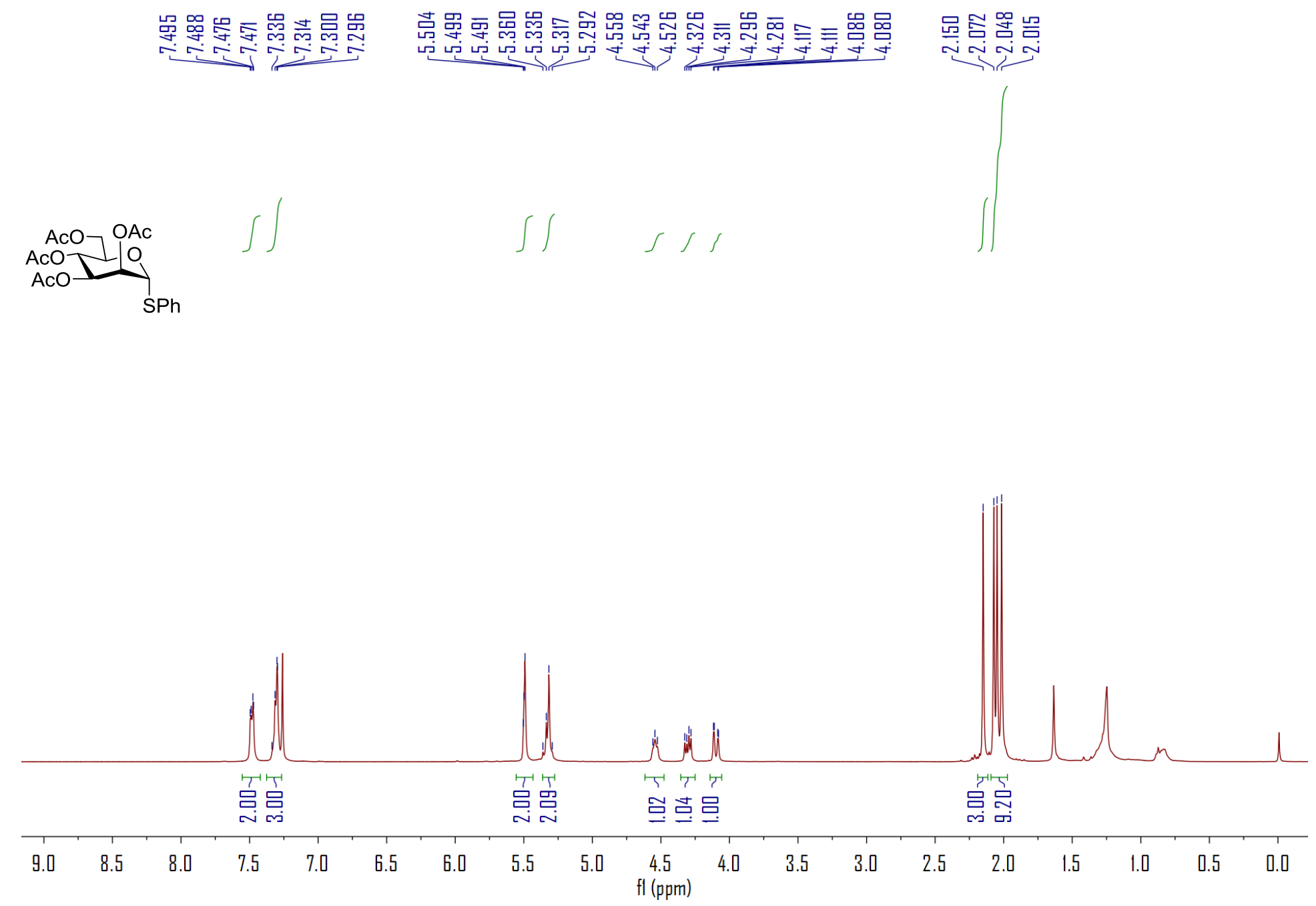

Figure S37. ${ }^{1} \mathrm{H}$ NMR spectrum $(400 \mathrm{MHz})$ of $\mathbf{9 a}$ in $\mathrm{CDCl}_{3}$ 

$\mathrm{AcO}] \mathrm{OAc}$ AcO

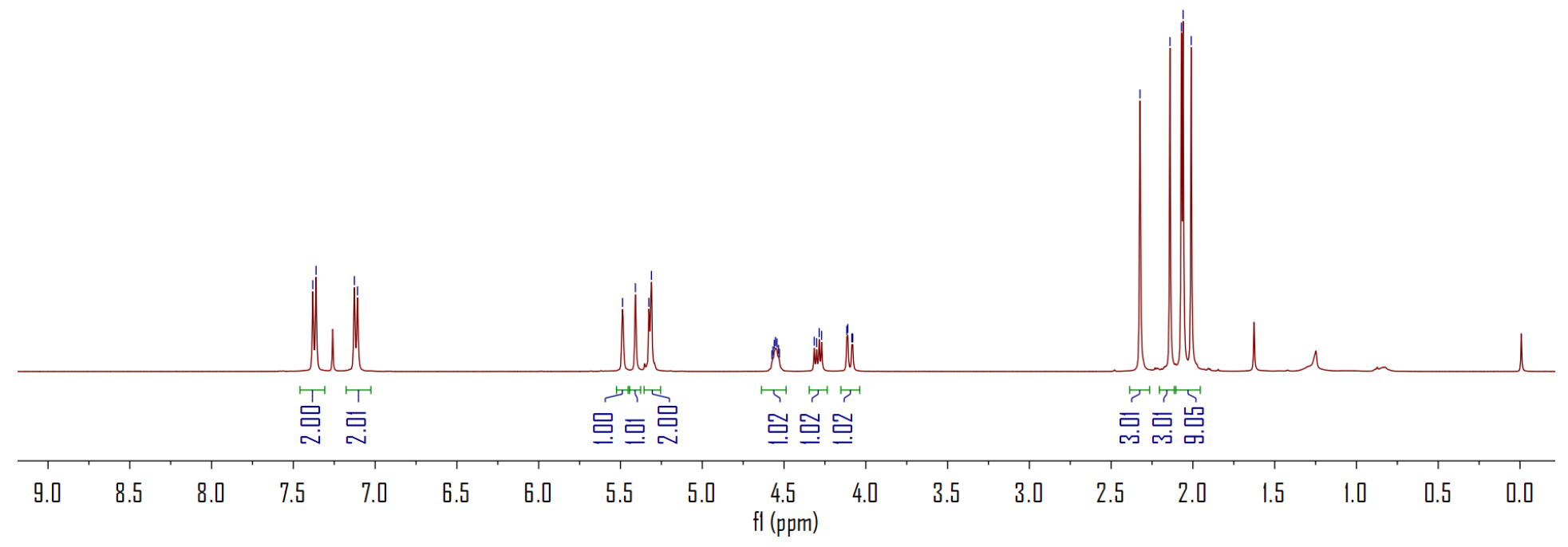

Figure S38. ${ }^{1} \mathrm{H}$ NMR spectrum (400 MHz) of $\mathbf{9 b}$ in $\mathrm{CDCl}_{3}$ 


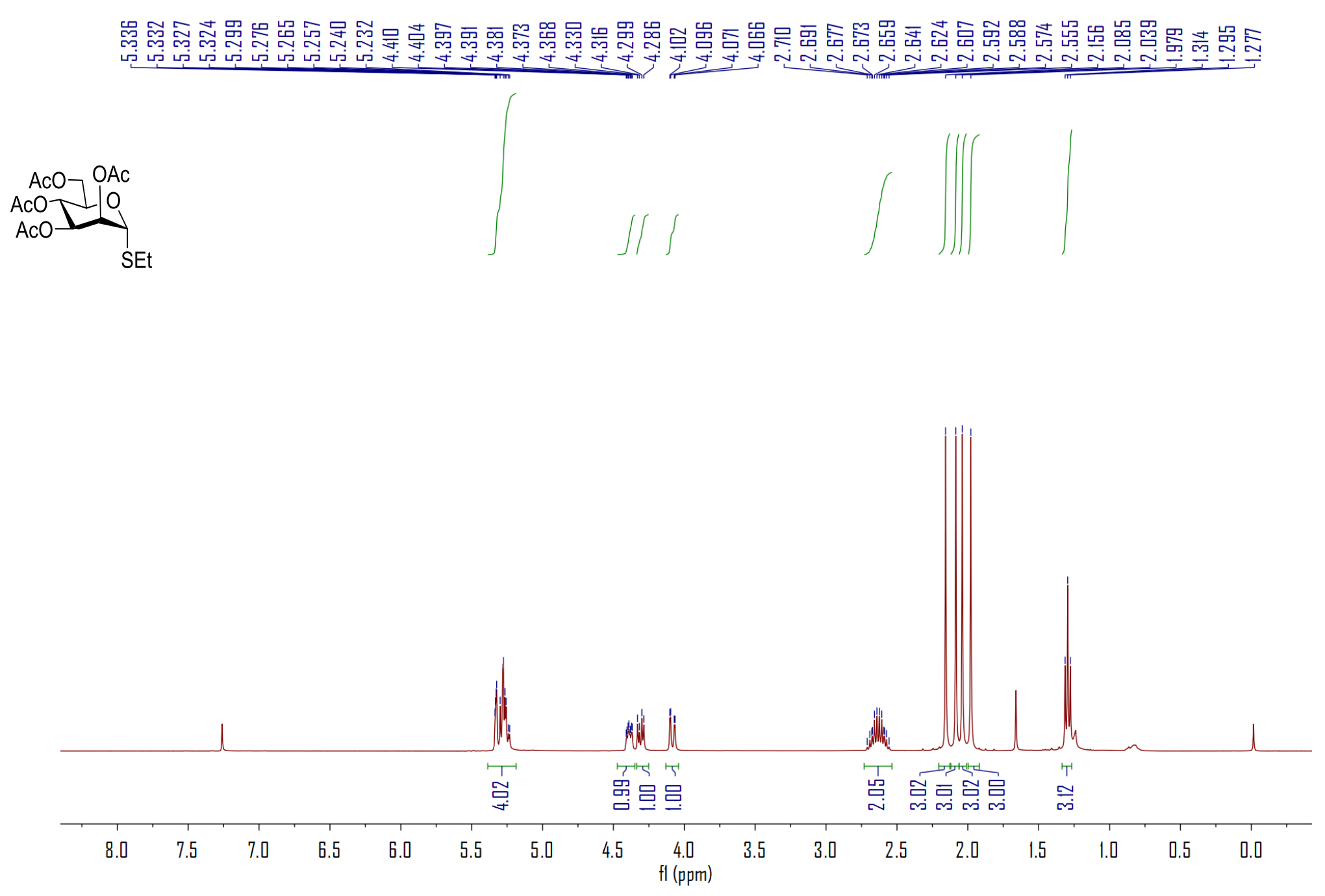

Figure S39. ${ }^{1} \mathrm{H}$ NMR spectrum $(400 \mathrm{MHz})$ of $\mathbf{9 c}$ in $\mathrm{CDCl}_{3}$ 


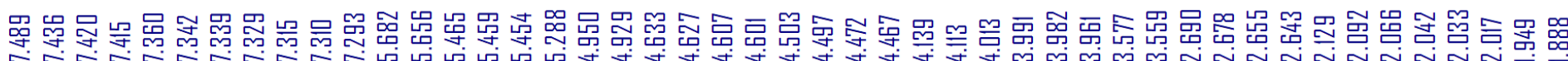

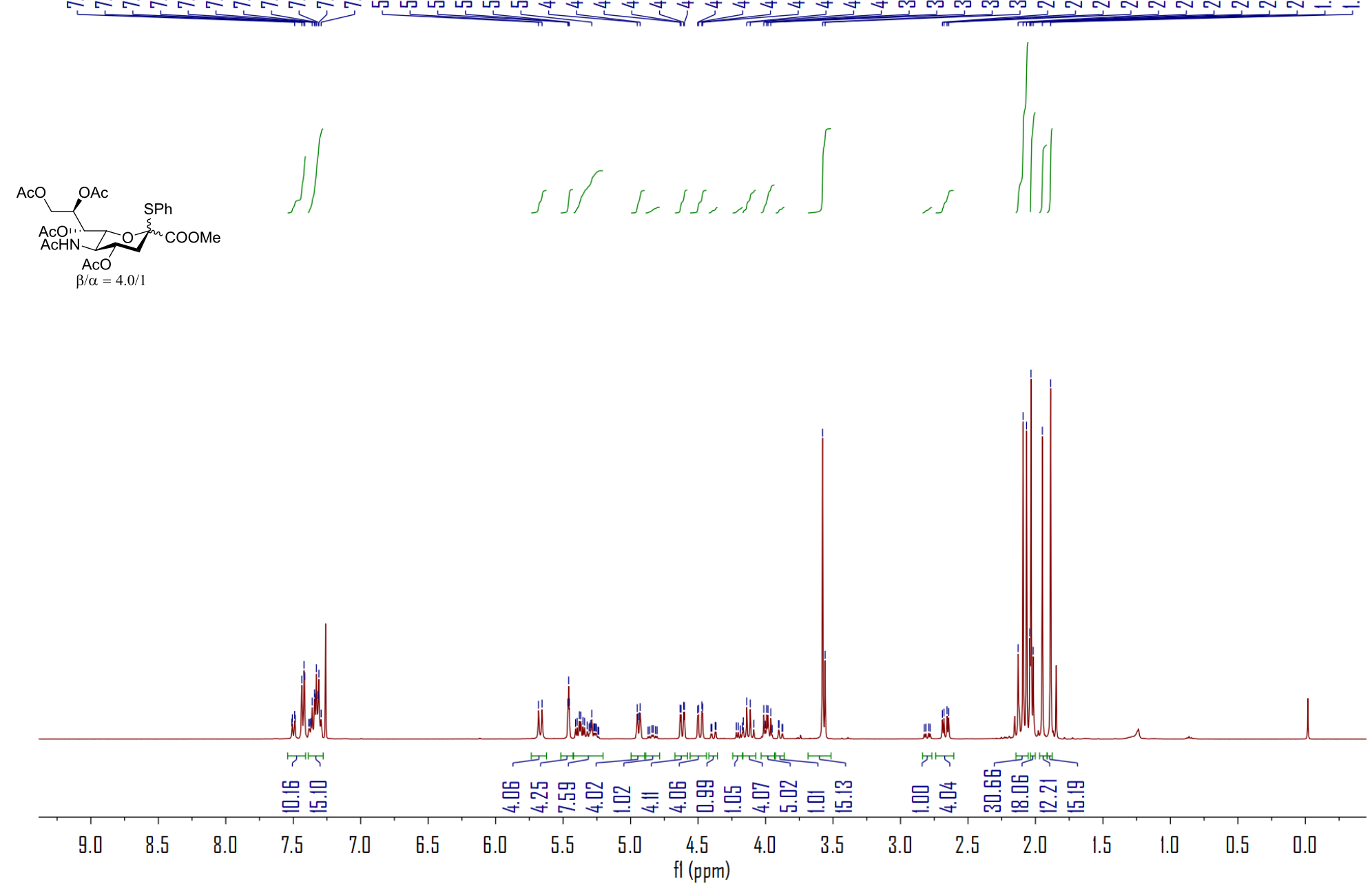

Figure S40. ${ }^{1} \mathrm{H}$ NMR spectrum $(400 \mathrm{MHz})$ of $\mathbf{1 0 a}$ in $\mathrm{CDCl}_{3}$ 


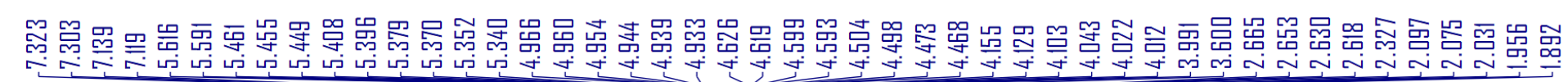
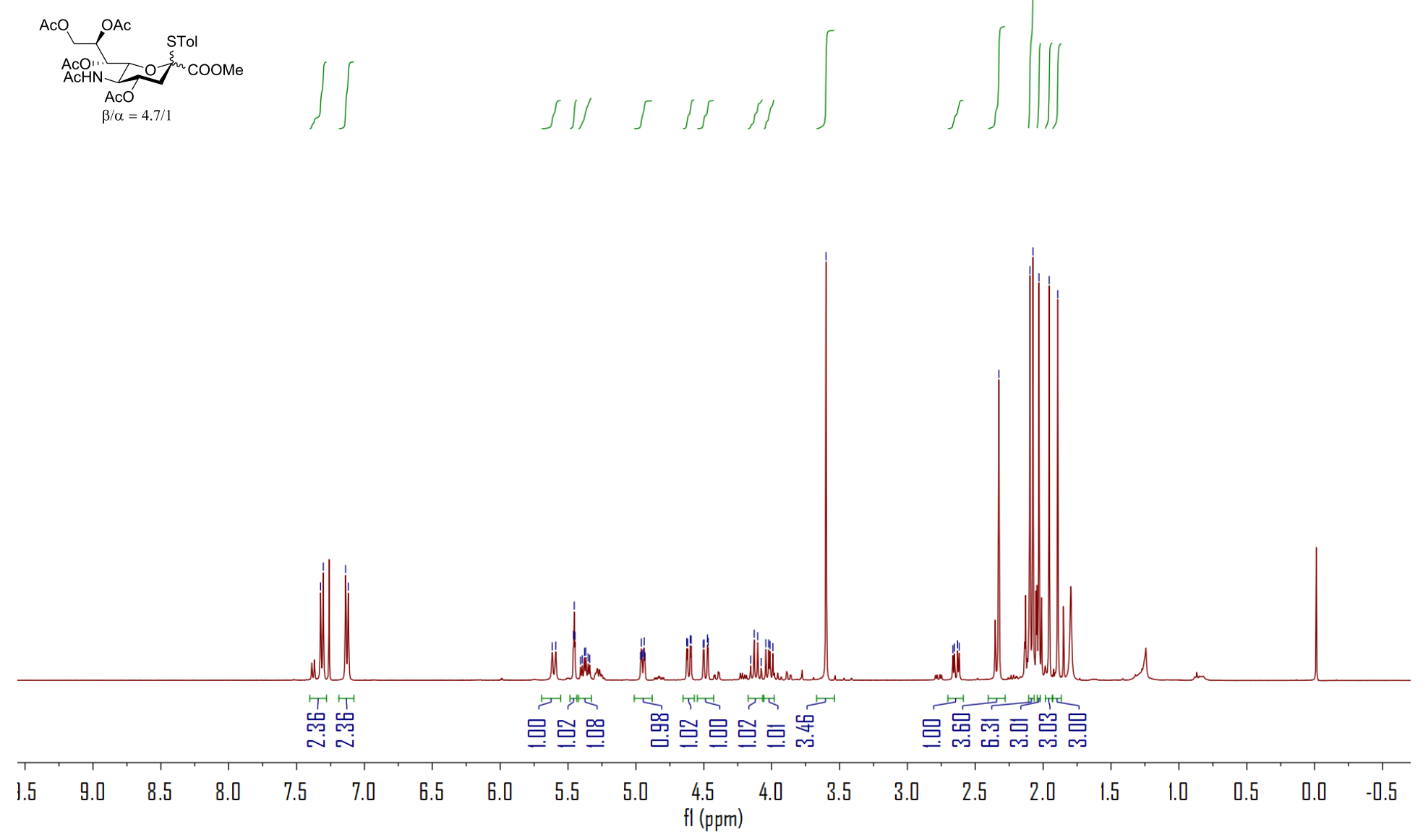

Figure S41. ${ }^{1} \mathrm{H}$ NMR spectrum $(400 \mathrm{MHz})$ of $\mathbf{1 0 b}$ in $\mathrm{CDCl}_{3}$ 


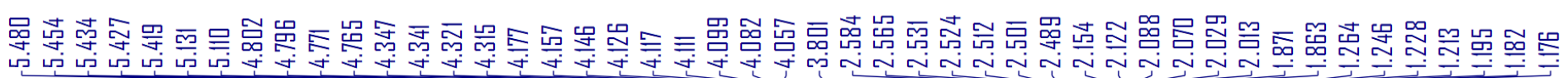

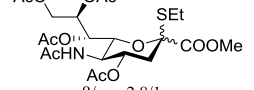
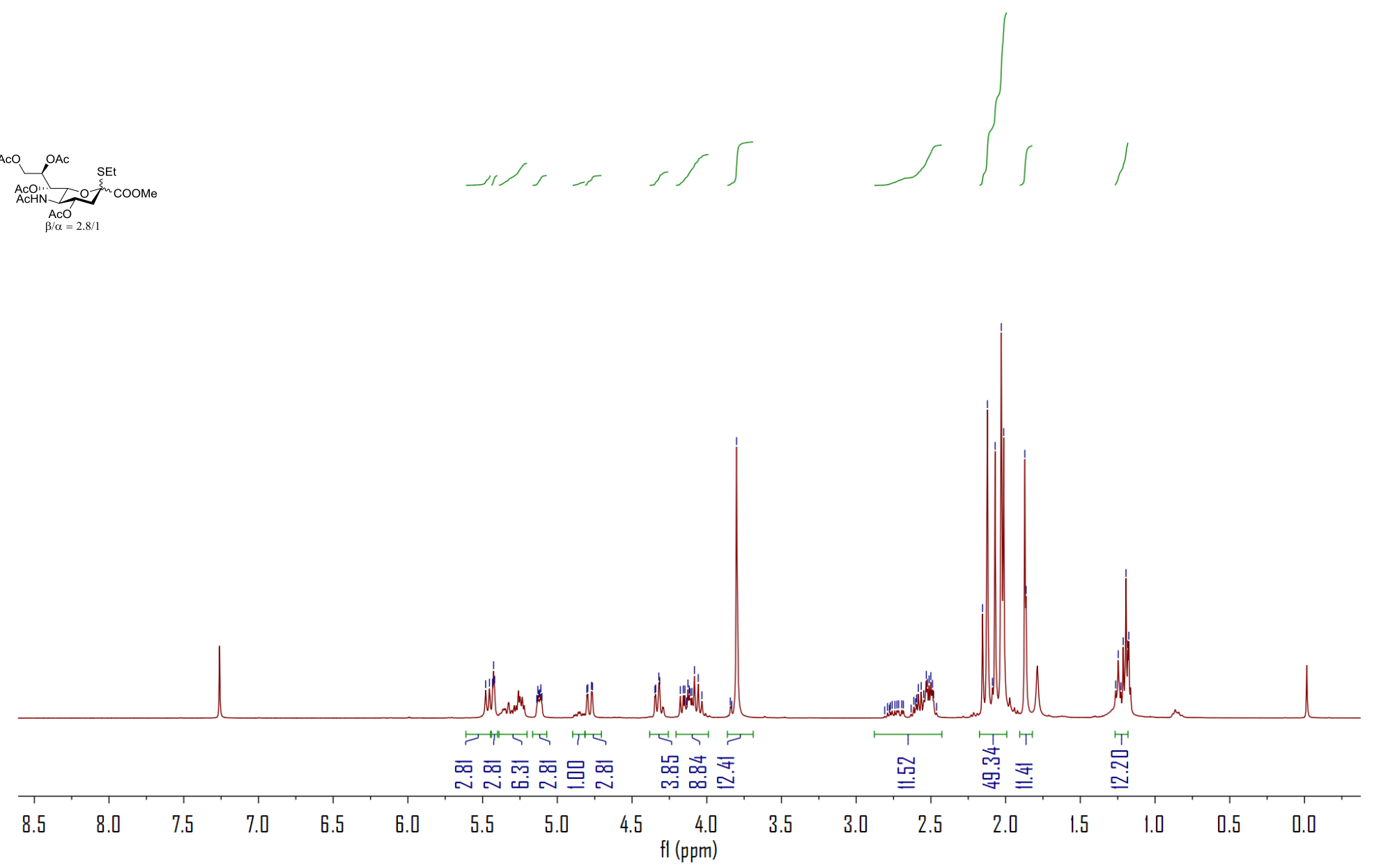

Figure S42. ${ }^{1} \mathrm{H}$ NMR spectrum $(400 \mathrm{MHz})$ of $\mathbf{1 0 c}$ in $\mathrm{CDCl}_{3}$ 

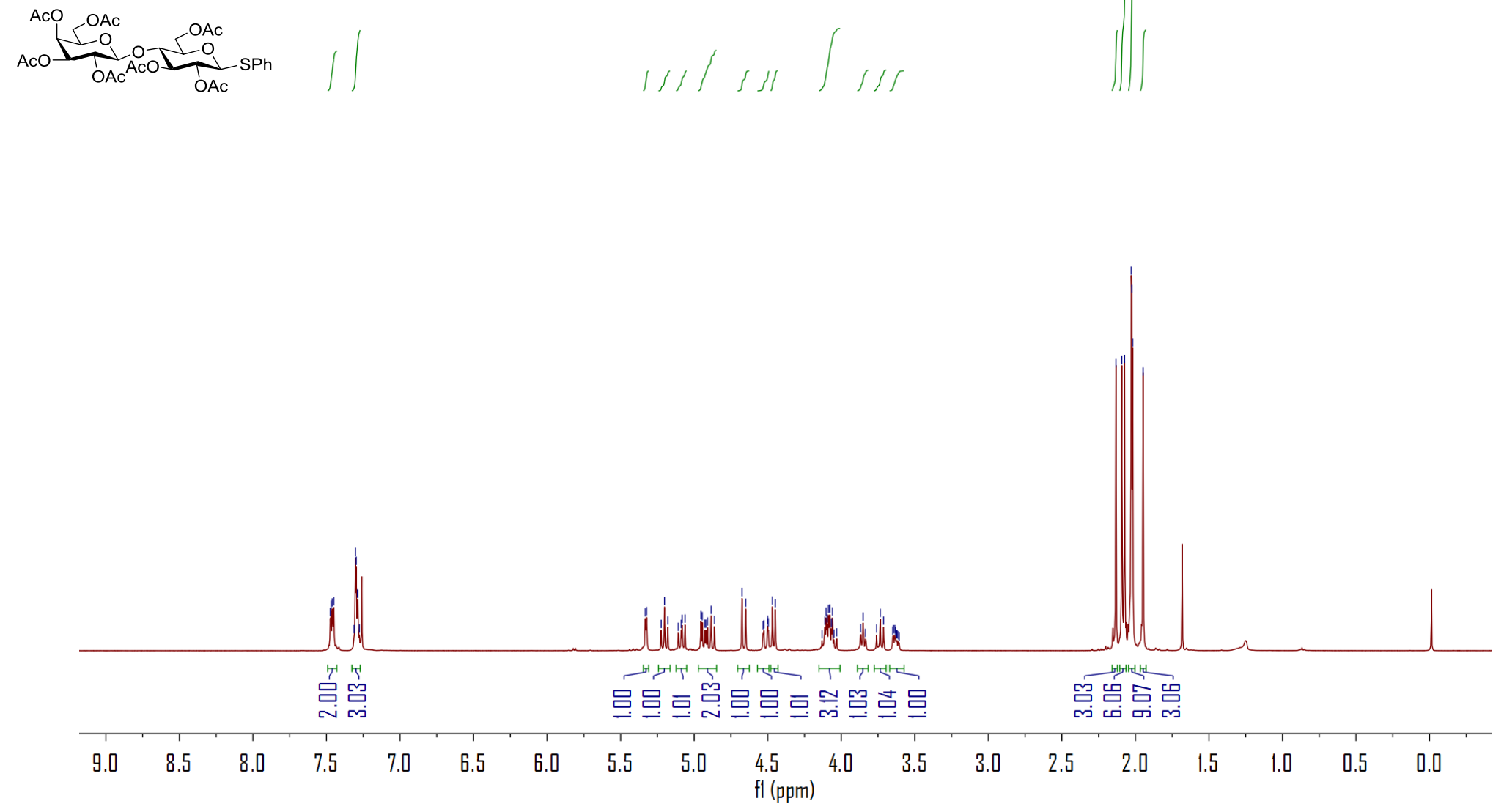

Figure S43. ${ }^{1} \mathrm{H}$ NMR spectrum $(400 \mathrm{MHz})$ of $\mathbf{1 1 a}$ in $\mathrm{CDCl}_{3}$ 


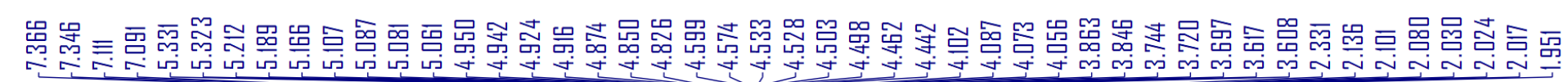
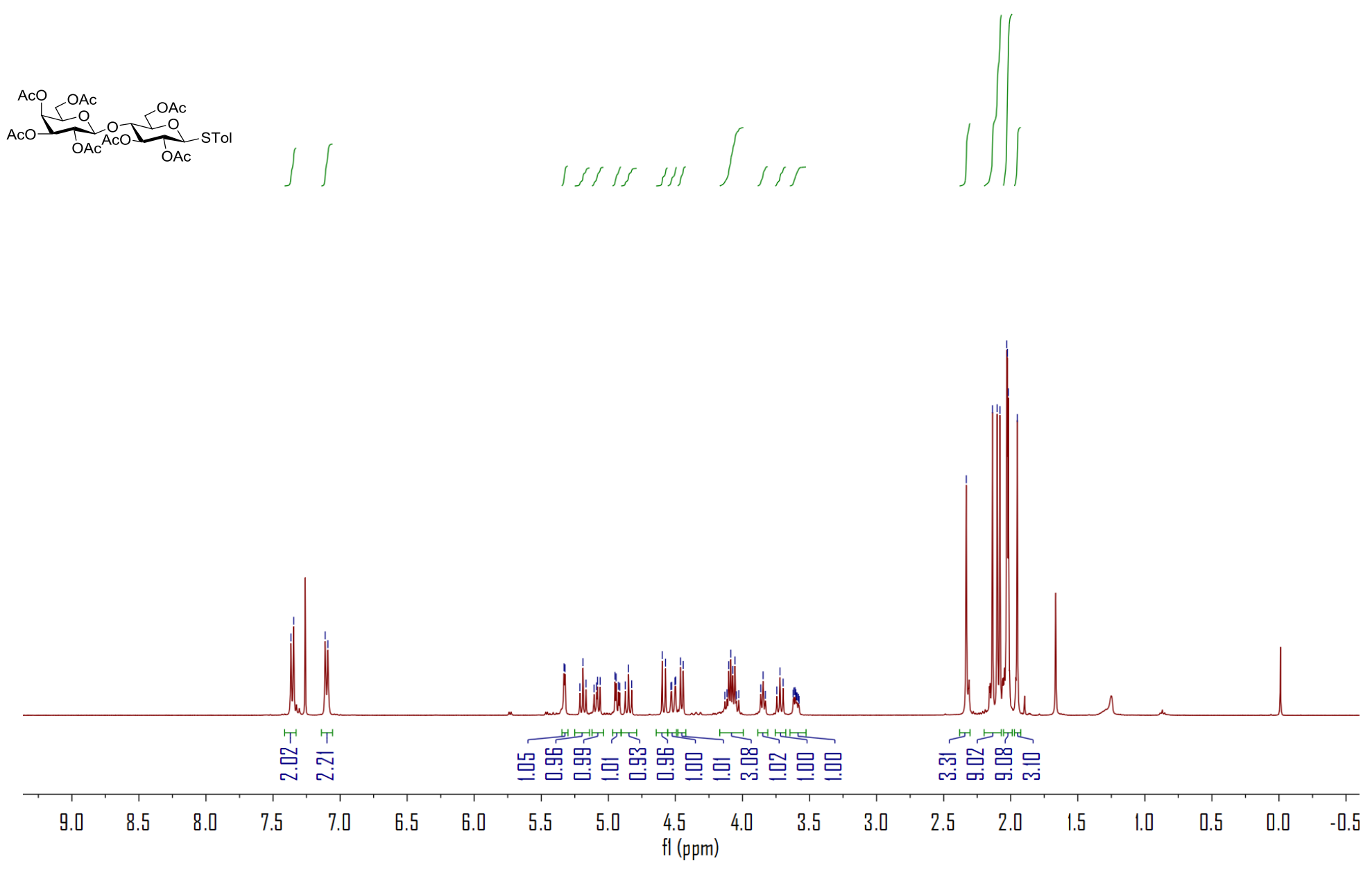

Figure S44. ${ }^{1} \mathrm{H}$ NMR spectrum $\left(400 \mathrm{MHz}\right.$ ) of $\mathbf{1 1 b}$ in $\mathrm{CDCl}_{3}$ 


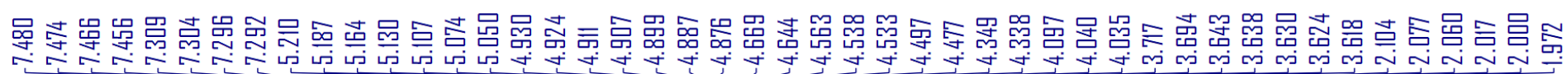
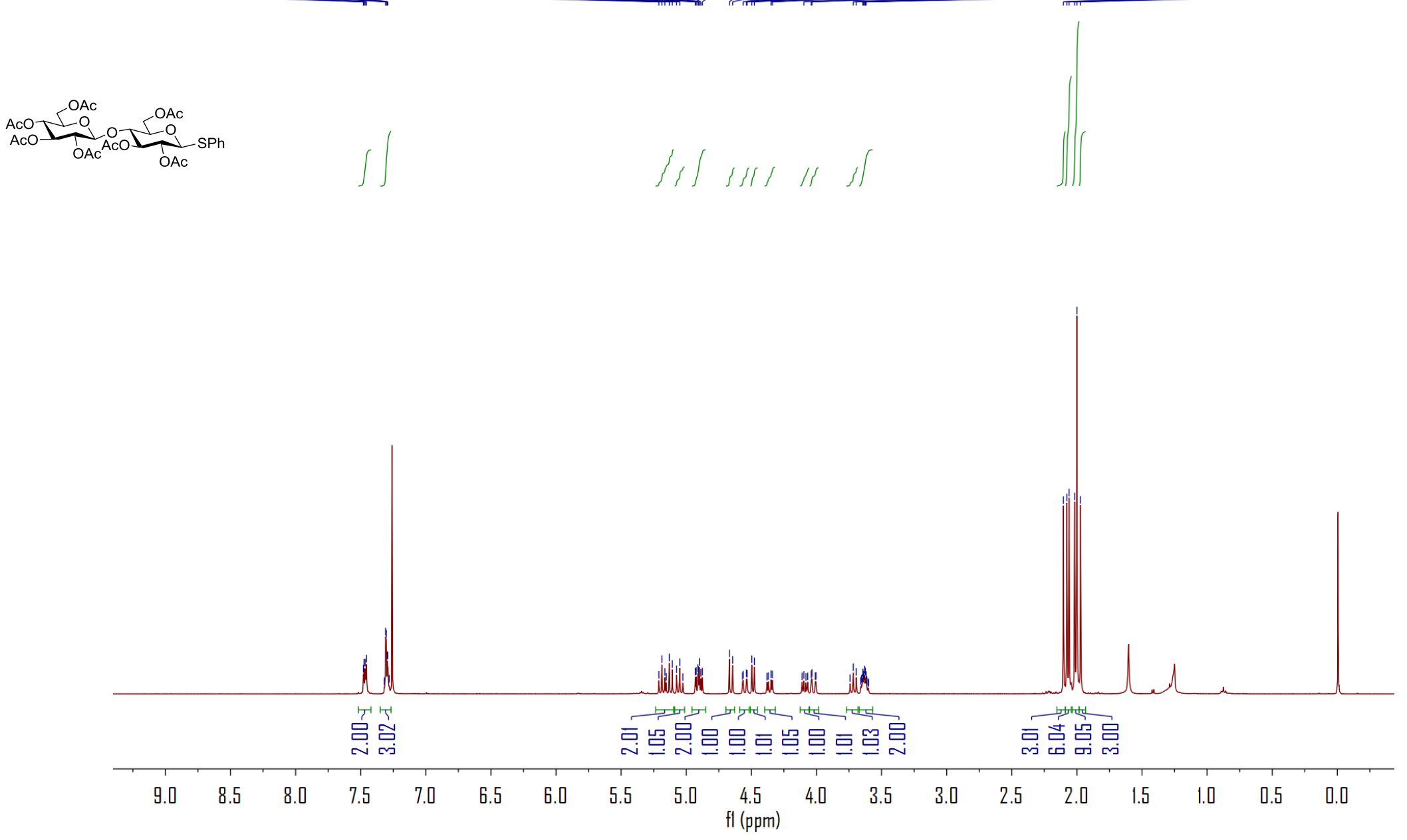

Figure S45. ${ }^{1} \mathrm{H}$ NMR spectrum $(400 \mathrm{MHz})$ of $\mathbf{1 2 a}$ in $\mathrm{CDCl}_{3}$ 